NBSIR $87-3560$

\title{
An Engineering Analysis of the Early Stages of Fire Development - The Fire at the Dupont Plaza Hotel and Casino - December 31, 1986
}

Harold E. Nelson

U.S. DEPARTMENT OF COMMERCE

National Bureau of Standards

National Engineering Laboratory

Center for Fire Research

Gaithersburg, MD 20899

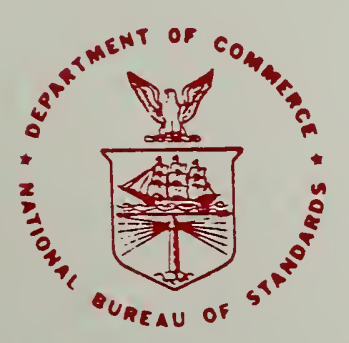

U.S. DEPARTMENT OF COMMERCE NATIONAL BUREAU OF STANDARDS 

AN ENGINEERING ANALYSIS OF THE

EARLY STAGES OF FIRE DEVELOPMENT

- THE FIRE AT THE DUPONT PLAZA

HOTEL AND CASINO

- DECEMBER 31, 1986

Harold E. Nelson

U.S. DEPARTMENT OF COMMERCE

National Bureau of Standards

National Engineering Laboratory

Center for Fire Research

Gaithersburg, MD 20899

April 1987

U.S. DEPARTMENT OF COMMERCE, Malcolm Baldrige, Secretary NATIONAL BUREAU OF STANDARDS, Ernest Ambler, Director 
LIST OF TABLES

LIST OF FIGURES.

Abstract . . . . . . . . . . . . . . . . . 1

Chapter 1. Overview. . . . . . . . . . . . . . . . . . . . . 1

1.1. Scope . . . . . . . . . . . . . . . . . . . . . 1

1.2. Background. . . . . . . . . . . . . . . . . . . . 2

1.3. Purpose . . . . . . . . . . . . . . . . . . . . 2

1.4. Physical Description of Pertinent Aspects of the Facility ... . 3

1.5. Brief Description of Method of Analysis . . . . . . . . . . 6

1.6. Brief Description of Fire Development . . . . . . . . . . . 6

Chapter 2. Details of Analysis . . . . . . . . . . . . . . . . 10

2.1 General. . . . . . . . . . . . . . . . . . 10

2.2 Mass Burning Rate. . . . . . . . . . . . . . . . . . . . 11

a. Pre-Flashover (free) Burning of Initially

Ignited Fuel Package.. . . . . . . . . . . . . . . . . . . . 11

b. Post Flashover Burning of Materials in the South

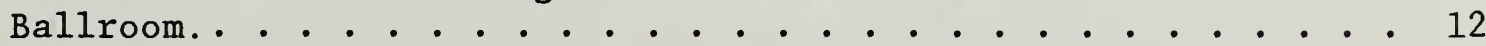

c. Burning of Foyer Ceiling After Flashover of South

Ballroom but Prior to Entry of Fire into Casino. . . . . . . 13

2.3 Rate of Heat Release.

a. Pre-Flashover (Free) Burning of Initially

Ignited Fuel Package.. . . . . . . . . . . . . . . . 13

b. Rate of Energy Flow from South Ballroom to North

Ballroom Prior to Flashover in South Ballroom. . . . . . . . 16

c. Rate of Energy Flow from North Ballroom to

Foyer Prior to Flashover in South Ballroom.. . . . . . . . . . . 17

d. Post Flashover Energy Flow from South Ballroom. . . . . . . . 17

e. Energy Release from the Foyer Ceiling After

Flashover of South Ballroom but Prior to Entry . . . . . . . . 18

into Casino. . . . . . . . . . . . . . . . . . 18

2.4 Smoke Layer Temperatures. . . . . . . . . . . . . . . . . 19

a. Smoke Temperatures in the South Ballroom. . . . . . . . . 19

b. Smoke Temperatures in the North Ballroom. . . . . . . . . . 23

c. Smoke Temperatures in the Foyer Prior to

Flashover in the South Ballroom.

d. Smoke Temperatures in the Foyer Following

Flashover in the South Ballroom. . . . . . . . . . . . . . 24

2.5 Smoke Layer Depth.. . . . . . . . . . . . . . . . 27

2.6 Velocity of Smoke/Flame Front.. . . . . . . . . . . . . . . 28

2.7 Mass Product in Smoke Layer.. . . . . . . . . . . . . . . . 29

2.8 Oxygen Concentration in Smoke Layer.. . . . . . . . . . . . . . . 29

2.9 Visibility in Smoke Layer. . . . . . . . . . . . . . . 30

2.10 Flame Length (Extension.) . . . . . . . . . . . . . . 31

2.11 Flame Spread. . . . . . . . . . . . . . . . . 34

2.12 Potential Response of Sprinklers. . . . . . . . . . . . 35

2.13 Potential Response of Smoke Detectors... . . . . . . . . . 37

2.14 Fire Duration. . . . . . . . . . . . . . . . . 37

Chapter 3 - Summary . . . . . . . . . . . . . . . . . . 40

REFERENCES . . . . . . . . . . . . . . . . . . . . . 42 

Appendix A. Results of Computations Related to the South Ballroom . . . . A-1 Appendix B. Results of Computations Related to the North Ballroom . . . . . B-1 Appendix C. Results of Computations Related to the Foyer . . . . . . . . . . C-1 Appendix D. Results of Computations Related to Sprinklers . . . . . . . . . D-1 Appendix E. Results of Computations Related to Smoke Detectors . . . . . . . E-1 Appendix F. Results of Tests of the Fabric Wall Covering . . . . . . . . . . F-1 Appendix G. A Method for Calculating Ventilation Flow Rate . . . . . . . . . . G-1 Appendix H. Comparison of Results Obtained with Different Procedures . . . . H-1 
Table 1. Estimated Post Flashover Burning Rates

of Materials in South Ballroom. . . . . . . . . . . 45

Table 2. Estimated Pre-Flashover Energy Flow From South

Ballroom to North Ballroom. . . . . . . . . . . 46

Table 3. Estimated Pre-Flashover Energy Flow from North

Ballroom to Foyer. . . . . . . . . . . . . 4 47 


\section{LIST OF FIGURES}

Figure 1. Partial Floor Plan of Ground Floor... . . . . . . . . . . . 48

Figure 2. Second Floor Plan. . . . . . . . . . . . . . . . 49

Figure 3. Situation in Ballroom Complex at $t+60$ Seconds. . . . . . . . 50

Figure 4. Situation in Ballroom Complex at $t+180$ Seconds... . . . . . . 50

Figure 5. Situation in Ballroom Complex at t+420 Seconds..... . . . 51

Figure 6. Situation in Ballroom Complex Just Prior to Flashover

$(t+580 \mathrm{sec}$.$) . . . . . . . . . . . . . . 51$

Figure 7. Situation in Foyer and Lobby From $t+420$ to $t+580$ Seconds.. . . 52

Figure 8. Situation in Foyer Following Flashover of South Ballroom

t+600 Seconds. . . . . . . . . . . . . . . . 52

Figure 9. Situation in Lobby From Flashover of the South Ballroom

(About $t+590$ Seconds) to About $t+630$ Seconds......... 53

Figure 10. Situation in Casino Following Breakage of Glass Partition

Between Casino and Foyer. About $t+720$ to $t+740$ Seconds. . . 53

Figure 11. Estimated Flame Length/Extension in South Ballroom.. • . . . 54

Figure 12. Estimated Flame Length/Extension in North Ballroom.. . . . . 55

Figure 13. Estimated Average Temperature in Smoke Layer (Ballrooms and

Foyer) . . . . . . . . . . . . . . . . 56

Figure 14. Estimated Level of Smoke Layer Interface (Ballrooms and

Foyer) . . . . . . . . . . . . . . . 57

Figure 15. Estimated Vision Distance in Smoke Layer (Ballrooms and

Foyer) . . . . . . . . . . . . . . . 58

Figure 16. Estimate Oxygen Concentration in Smoke (Ballrooms and

Foyer) . . . . . . . . . . . . . . . 59

Figure 17. Section of Building Elevation (Viewed from North) . . . . . 60

Figure 18. T-Squared Fires Rates of Energy Release . . . . . . . . . 61

Figure 19. Relation of T-Squared Fires to Some Test Fires . . . . . . 62 

This report presents the methods and results of an analysis of the fire development through the first and second floors during the December 31 , 1986 fire in the Dupont Plaza Hotel and Casino, San Juan, Puerto Rico. The analysis involved the use of fire growth models, engineering formulae, and technical data. The report details the procedures and data used, the reason for those selected, and the results obtained. The analysis addressed mass burning rate, rate of heat release, smoke temperature, smoke layer depth, velocity of smoke/flame front, mass products in smoke layer, oxygen concentration in smoke layer, visibility in smoke layer, flame length/extension, flame spread, sprinkler response, smoke detector response, and fire duration. The areas of the building analyzed include the ballroom complex where the fire originated, the foyer that connected the ballroom complex to the areas where the fatalities occurred, and the lobby and casino areas where most of the deaths occurred. This report does not address smoke movement above the first floor, the conditions that caused the deaths of three persons caught in an elevator, or the conditions that caused the death of one victim in a guest room on the forth floor.

Key Words: Fire engineering analysis, Fire growth models, Flashover, Fire investigation, Dupont Plaza Hotel

An Engineering Analysis of the Early Stages of Fire Development - The Fire at the Dupont Plaza Hotel and Casino

- December 31, 1986

Chapter 1. Overview.

\subsection{Scope}

The analyses in this report relate to the fire that occurred on the afternoon of December 31, 1986 in the Dupont Plaza Hotel and Casino, San Juan, Puerto Rico. Ninety eight persons died in this fire.

This report addresses the development and growth of the fire and its effects as it progressed through the first floor ballroom complex, the Foyer, the Lobby and entryway, and the Casino. The period of coverage is from the moment of established burning of the initial fuel to emergence of flame from the Casino. The report does not cover the ignition event. The analysis starts when the burning of the initial fuel (furniture in corrugated cardboard cartons) is in the range of 5 
to $10 \mathrm{btu}$ per second (approximately 5 to $10 \mathrm{~kW}$ ). This analysis ends moments after flame extends through the west windows of the Casino. As calculated, this is a period of approximately thirteen minutes. There are, however, assumptions involved in these calculations so that a margin of error, estimated at about 25\%, may exist between the time estimated for any specific event and actual time that event occurred during the fire.

The analysis also does not address movement of smoke or other fire products above the lobby level, the conditions that caused the death of one individual on the fourth floor, nor the conditions that caused the deaths of three persons in an elevator cab. Also, the study does not address fire fighting activities or the physical damage that occurred in the discotheque, bar, and restaurant areas.

\subsection{Background.}

At approximately 3:30 pm on December 31, 1986 a fire originated on cartons of furniture located in the South Ballroom of the Dupont Plaza Hotel and Casino. The fire rapidly broke out of the space of origin and swept through the Hotel Lobby and Casino areas. Ninety eight persons lost their lives. The principle initial investigation team was provided by the National Response Team of the U.S. Department of Treasury Bureau of Alcoholic Tax and Firearms (BATF.) This team was joined by representatives of the Center for Fire Research of the National Bureau of Standards (CFR), the U.S. Fire Administration, the U.S. Fire Academy, and the National Fire Protection Association (NFPA.) Each of the participants contributed to the investigation. The principal resource of the CFR representatives consisted of a knowledge of fire dynamics and predictive methods which was used to develop an engineering estimate of the development of the fire. This contribution along with the evidence gathered at the fire scene and interviews conducted by the BATF team and others in the team led to the development of a consistent picture of the principal events of this fire.

After returning from the fire scene, CFR representatives refined and documented the analysis. This report contains that documentation.

\subsection{Purpose}

The purpose of this report is to document the use of quantitative engineering tools to construct a description of the conditions that occurred during the fire. Also, this study provides information needed to evaluate the impact that fire protection measures, not in place at the time of the fire, would have made on the outcome.

In addition, the occasion of this analysis has provided an opportunity to test and demonstrate the use of quantitative engineering procedures for fire safety analysis purposes. In selecting the calculation methods, an effort was made to use the least sophisticated approach that would give answers that are reasonably consistent with evidence 
from the fire. The intent was to develop a complete and accurate technical description of the fire. The specific approaches, computational methods used, references to source documents describing these methods, and the rationale involved in selecting and using these methods are contained in Chapter 2.

\subsection{Physical Description of Pertinent Aspects of the Facility}

This Section addresses architectural and material descriptions of the spaces involved. The thermophysical and combustion properties used in the individual computations are covered in Chapter 2 as part of the discussions of the computations.

Figures 1 and 2 are floor plans produced the National Fire Protection Association [1]. A few minor changes have been made to clarify details important to the computations in this report. Figure 1 shows the ground floor ballroom area. In this report, the two sections in the ballroom are referred to as the South Ballroom and the North Ballroom.

\section{South Ballroom}

The South Ballroom is approximately $36 \mathrm{ft}$. (1lm) wide by $64 \mathrm{ft}$. (20m) long. The floor to ceiling height is approximately $10 \mathrm{ft}$. (3m.) The two ballroom areas were separated by a removable partition. The partition consisted of a series of panels thought to have been approximately $4 \mathrm{ft} .(1.2 \mathrm{~m})$ wide and $10 \mathrm{ft} .(3 \mathrm{~m})$ high. While almost all of this paneling was consumed during fire, it is believed that the panels were sandwich panels having high-pressure laminate skins, a wood frame, and a foam plastic core. The panels were held in place by pressure against short studs extending down from a structural beam directly over the line of the panel. Witness statements indicated that one of the panel sections near the east end of the partition was not in place at the time the fire started. Since there was no surviving panel, it is assumed that the missing panel was stored somewhere in the general area of the South Ballroom and was consumed.

The south and east walls of the South Ballroom were of reinforced concrete construction finished on the ballroom side with a fabric wall covering. Discussion of the properties related to burning rate and flame spread are covered in paragraphs 2.2 and 2.10 . The results of tests of the wall fabric material are included in Appendix F. Except for a pair of wood doors, the west wall of the South Ballroom consisted of large glass panels separating the South Ballroom from the lower level of the Foyer. From the glass fragments, it appears that the majority of the glass was 1/4-inch $(6 \mathrm{~mm})$ plate glass. A pair of doors located in the south wall near the southeast corner of the South Ballroom connected the South Ballroom to a service corridor. One of these doors swung into the ballroom and the other swung into the service corridor. Each of these doors was $34 \mathrm{in.}(2.83 \mathrm{~m})$ wide by $7 \mathrm{ft}$. (2.1m) high. The floor of the ballroom was hardwood over a softwood sub-floor. The ceiling, we believe, consisted of mineral boards in a grid framework. 
At the time of the fire, about fifty stacked chairs were located along the south wall of this ballroom towards the west end and cartons containing replacement furniture for guest rooms were located at the east end. The furniture consisted primarily of typical hotel dressers, constructed of wood and particle board contained in corrugated shipping cartons. In addition, about $20 \%$ of the storage area consisted of similar corrugated cardboard cartons containing sofa beds with foam mattresses. The evidence available after the fire indicated that the storage pile was neatly stacked, boxes reasonably close together, producing a storage pile approximately $6 \mathrm{ft} .3 \mathrm{in.}(1.9 \mathrm{~m})$ high by 15 ft. $(4.6 \mathrm{~m})$ wide in the east to west direction and $30 \mathrm{ft} .(9.1 \mathrm{~m})$ in the north to south direction, the north end of the pile being very close to the line of the removable partition. The missing panel was described as immediately adjacent to the furniture storage.

\section{North Ballroom.}

The North Ballroom is $23 \mathrm{ft}$. ( $7 \mathrm{~m}$ ) tall having a balcony at the same level as the second floor of the building. The level of the balcony is $13 \mathrm{ft}$. (3.9m) above the floor of the ballroom. The walls of the ballroom consisted of concrete, plaster, and gypsum board materials. Most of the walls were covered with the same fabric wall covering as the South Ballroom. Major portions of the west wall were glass. The North Ballroom contains four doorways, each has a set of double doors. There also were two wood doors leading to the pantry area. The fire damage on these two doors was limited to the ballroom side of the doors, indicating that they remained closed during the course of the fire. At the south end of the west wall there was a set of $10 \mathrm{ft}$. (3m) tall by $3 \mathrm{ft} .(.9 \mathrm{~m})$ wide doors. These were of decorative wooden construction and opened from the North Ballroom into the Foyer. The other three doors are of metal construction, each leaf of which is 3 ft. $(.9 \mathrm{~m})$ wide by $7 \mathrm{ft} .(2.1 \mathrm{~m})$ high. These doors open directly to the outside. On the east wall of the North Ballroom, there is a shipping door entrance of similar size that opens to a service corridor and an archway to the outside. According to witness accounts, one panel of the $10 \mathrm{ft} .(3 \mathrm{~m})$ high door was opened and all of the leaves of the other doors in the west wall of the North Ballroom were opened early in the fire and blocked in that position. In addition it is understood that the shipping door entrance was open before and through the course of the fire. The computations in this report assume this arrangement of doors.

The north end of this ballroom is a stage elevated about 30 in. (.8m). The stage has a ceiling level approximately $3 \mathrm{ft}$. higher than the rest of the ballroom. Frames for stage lighting are located in this area. 


\section{Foyer}

A two-story high Foyer (see Figure 2) housing a 10-ft. ( $3 \mathrm{~m}$ ) wide open stairway provided the connecting link from the ground floor entrances to the ballroom complex and the Lobby. In addition to the glass partition separating the South Ballroom from the Foyer, approximately $12 \mathrm{ft}$. of the west wall of the North Ballroom was also common to the Foyer. The center portion of this section consisted of the $10 \mathrm{ft}$. ( $3 \mathrm{~m})$ high door and a decorative wood panel extending from the top of the door to the ceiling. Side panels of glass completed this section of wall.

The separation of the balcony portion of the North Ballroom and the function room at the second floor level from the Foyer also consisted of glass partitions. A major portion of the separation between the west wall of the Foyer and the Casino was also glass. On the first floor, there is a glass window near the north end of the Foyer separating the Foyer from a restaurant area. This window survived the fire.

The north (external) wall of the Foyer was of glass construction. Also the Foyer was separated from the Lobby by a glass partition at the second floor level. The partition ran from floor to ceiling but had an opening at the head of the stairs approximately $14 \mathrm{ft} .(2.3 \mathrm{~m})$ wide extending from the slab to the ceiling. On the second floor, the floor to ceiling distance is $10 \mathrm{ft}$. $(3 \mathrm{~m})$. On the first floor level, the south end of the Foyer extends under the stairs and was separated from the service corridors by a closed door.

\section{Lobby}

The main Lobby area is open connecting to an entrance arcade. At the south end of the entrance arcade is the main entrance to the hotel. This entrance was an open arch approximately $10 \mathrm{ft}$. (3m) high by $27 \mathrm{ft}$. $(8.2 \mathrm{~m})$ wide. At the west end of the main Lobby an open archway approximately $3 \mathrm{ft} .(.9 \mathrm{~m})$ wide by $7 \mathrm{ft} .(2.1 \mathrm{~m})$ high opened onto a spiral staircase leading to the swimming pool. North of the Lobby is the central core of the high-rise building containing elevators, stairs, shafts, rest rooms, and similar spaces.

\section{Casino}

The Casino wrapped around the central core area. The main entrance to the Casino was at the east end. This door consisted of two tempered glass leafs each approximately $3 \mathrm{ft} .(.9 \mathrm{~m})$ wide by $7 \mathrm{ft} .(2.1 \mathrm{~m})$ high. At the start of the fire, these doors were standing open. At the east end of the Casino, there was a second wood frame door consisting of a single leaf. This door is reported as having been standing in the open position at the start of the fire. 


\subsection{Brief Description of Method of Analysis}

All pertinent data and information available to the author were used in conducting the fire analysis contained in this report. These included information provided by witnesses, evidence left by the fire, and the computational efforts described in Chapter 2. The rationale for the choice of data and the selection of assumptions are part of the discussion of the computations contained in Chapter 2. Throughout the evaluation, cross checks were made between the witness statements and physical evidence and the development of the computations.

In general, values used for both the thermophysical and combustion properties of materials are based on generic values for the types of materials involved. Except as mentioned in Chapter 2, there were no tests of the materials from this building.

For each stage of fire development, appropriate models and equations were assembled to describe the development of fire and its impact on the building environment. The output of each stage became the input of the next, until a consistent set of calculations was developed to describe the full course of events in the fire. The mechanisms and methods are described in Chapter 2.

The degree of expected variation in the predicted times is discussed in Chapter 2. The computations yield exact numbers, but the reader is cautioned that a tolerance in the range of about $25 \%$ on indicated times and somewhat smaller tolerances on indicated temperatures and concentrations must be expected. Corroboration with witness accounts give confidence to the accuracy of the computations. But without a rigorous re-creation of the events of this fire, the computations must be viewed as engineering estimates.

\subsection{Brief Description of Fire Development}

Figures 3 through 10 schematically trace the development of the fire at different times and places as determined by this analysis. Each of these figures is annotated with the calculated results for the variables at that time. The results are presented in terms of flame height measured from the floor, smoke layer height, smoke temperature, visibility through the smoke, oxygen concentration, and other variables where necessary.

Figures 11 through 16 summarize the results of major calculations used to develop the values presented in the forgoing figures.

Figure 11 shows a graph of the estimated flame height and flame extension under the ceiling against time in the South Ballroom.

Figure 12 displays the calculated flame height and flame extension under the ceiling in the North Ballroom. This flame is an extension of 
the flame from the objects burning in the South Ballroom and emanates from the opening in the partition between the two ballrooms.

Figure 13 shows predicted smoke layer temperature in the North and South Ballrooms and in the Foyer. The computed temperatures in the North Ballroom appear consistent with the limited extent of fire growth and damage in that space. Much of the wall covering, chairs, and the stage were visibly intact after the fire. However, most of the balcony area and major portions of the ceiling reveal these areas experienced much higher temperatures, probably later in the fire. This damage is believed to be indicative of a reentry of fire into the upper portions of the North Ballroom at time beyond that shown in figure 13 (i.e., later than 600 seconds), probably after the breakage of the glass partitions at the Lobby level of the foyer. In this analysis that breakage is estimated to have occurred at about 720 seconds after established burning ( $t+720$ seconds.)

Figure 14 shows the calculated descent of the smoke level in these same spaces.

Figure 15 tracks predicted oxygen concentration in the smoke. The plots in this figure stop at 600 seconds (the approximate time of flashover in the South Ballroom) because the procedure used to generate this data is not valid beyond that time. As discussed in Chapter 2, some broad judgement estimates of further decrease in oxygen content are made. The estimates more than 600 seconds after established burning are not considered sufficiently quantitative to include them in the plot.

Figure 16 follows the estimated visibility through smoke against time. This value is an indicator of the opaqueness of the smoke. Again the procedure used to estimate this value is not valid for the conditions believed to have occurred after 600 seconds following established burning.

In all of these presentations, the time indicated is the time following established burning as discussed in paragraph 2.3a. This is not the moment of ignition but rather the moment when fire becomes established on the corrugated cartons of the furniture pile. This report does not address the means or manner of ignition.

Figure 17 is a simplified elevation of the building viewed from the north. Based on the results of the analysis and on the evidence of fire damage, the following quantitative narration is our best estimate of the fire progress.

The fire is believed to have originated on a large pile of cartons of new furniture in the northeast corner of the South Ballroom near the arrow labeled number 1 in Figure 17.

Smoke began to fill both the $10 \mathrm{ft}$. (3m) high South Ballroom and flowed into the main $23 \mathrm{ft}$. ( $7 \mathrm{~m})$ high North Ballroom through the missing panel 
in the partition as the fire progressed in the cartons. This flow is indicated by arrow 1 in Figure 17.

Witness accounts indicate that one of the doors leading from the North Ballroom to the Foyer which contained the main staircase to the Lobby was open during this period.

As smoke filled the ballrooms, it is estimated to have emerged into the Foyer at approximately seven minutes. This was the first time smoke entered the view of the general public. The smoke flow into the Foyer, however, was cool, thin smoke at this time.

At about ten minutes after initial involvement of the fuel package, flashover is thought to have occurred in the South Ballroom. The flashover involved large portions of combustible wall materials, any unignited portion of the partition between the two locations, significant portions of the wood flooring, and the stacked chairs.

Flashover caused heat and stress to break the window partition between the Foyer and the South Ballroom and a massive quantity of smoke and flames was released into the Foyer (arrow 2). Our calculations indicate that in approximately forty seconds, from the time of flashover of the South Ballroom, a deep, hot, toxic (depleted in oxygen and likely containing high concentrations of carbon monoxide) smoke front traversed the Lobby forcing the occupants to flee and blocking both of the doors exiting the Casino into the Lobby area. (See both arrows numbered 3) The main door being blocked almost instantly after flashover of the South Ballroom, the rear door remaining passable for about forty seconds.

It is believed that the occupants of the Lobby and the Casino first became aware of the serious threat to their lives with the crash involved in the breakage of the windows between the South Ballroom and Foyer at the time of flashover of the South Ballroom and the subsequent flow of dense smoke into the Lobby.

Our computations indicate that with flashover of the South Ballroom, a wall of flame lapped out of the ballroom up to the wooden ceiling of the Foyer and across a major portion of that ceiling. Very quickly, this added the fuel from the ceiling to the fire. At about two minutes after flashover of the South Ballroom, the temperature rise in the Foyer caused failure of the remaining glazed areas surrounding the Foyer (except for the first floor window between the Foyer and the restaurant area which was probably cooled by the air flow that occurred from the outside.) A sudden flow of hot gases and unburned fuel traversed from the Foyer into the Casino quickly changing to a flame front that swept the length of the Casino in about twenty seconds (arrow 4.)

A large body of flame broke through the glass windows of the west wall of the Casino. It is presumed that an eddy of flame caused the deaths 
of two of the victims found in the pool side bar area one floor below the Casino windows. 
Chapter 2. Details of Analysis

\subsection{General.}

This chapter covers the procedures used to estimate conditions that occurred in the ballroom complex, Foyer, Lobby, Casino, and adjacent areas during the development of the fire.

An attempt was made to accomplish the evaluation using methods that can be quickly executed on personal computers or hand held calculators. This objective was nearly accomplished. It was necessary, however, to resort to a more comprehensive model (FIRST, see paragraph 2.3, below) to develop a credible estimate of the development of the smoke layer in the South Ballroom prior to flashover in that room. FIRST was also needed to compute the amount and unburned fuel content of the preflashover flow of smoke from the South Ballroom to the North Ballroom.

This chapter addresses the analysis of the fire from the standpoint of the specific calculations undertaken. The organization of the subsequent paragraph is listed below. Appendices A, B, and C present tables, graphs, and computer printouts covering the results of computations related to the South Ballroom, North Ballroom and Foyer, respectively. Figures 3 through 10 depict the situation as a series of selected times in the fire development. The titles of the remaining paragraphs in this chapter are given below as a preview of this discussion.

Many of the subparagraph headings in paragraphs 2.2,2.3 and 2.4 of this chapter include an indication of the time span of fire development discussed in that subparagraph (eg: $t+0$ to about $t+590$ seconds.) These are provided to assist the reader in following the course of fire development. In some cases the actual determination of the indicated time interval is developed in a different paragraph. Also all indicated times are estimated times following established burning. See Chapter 1, paragraph 1.5 for discussion of the general range of expected variation between predicted time and actual time.

2.2. Mass Burning Rate

a. Pre-Flashover (free) Burning of Initially Ignited Fuel Package.

b. Post Flashover Burning of Materials in the South Ballroom.

c. Burning of Foyer Ceiling After Flashover of South

Ballroom but Prior to Entry of Fire into Casino.

2.3. Rate of Heat Release.

a. Pre-Flashover (Free) Burning of Initially Ignited Fuel

Package.

b. Rate of Energy Flow from South Ballroom to North

Ballroom Prior to Flashover in South Ballroom. 
c. Rate of Energy Flow from North Ballroom to Foyer Prior

to Flashover in South Ballroom.

d. Post Flashover Energy Flow from South Ballroom.

e. Energy Release from the Foyer Ceiling After Flashover of South Ballroom but Prior to Entry into Casino.

2.4. Smoke Temperatures.

a. Smoke Temperatures in the South Ballroom.

b. Smoke Temperatures in the North Ballroom.

c. Smoke Temperatures in the Foyer Prior to Flashover in the South Ballroom.

d. Smoke Temperatures in the Foyer Following Flashover in the South Ballroom.

2.5. Smoke Layer Depth.

2.6. Velocity of Smoke/Fire Front.

2.7. Mass Product in Smoke Layer.

2.8. Oxygen Concentration in Smoke Layer.

2.9. Visibility in Smoke Layer.

2.10. Flame Length (Extension.)

2.11. Flame Spread.

2.12. Potential Response of Sprinklers.

2.13. Potential Response of Smoke Detectors.

2.14. Fire Duration.

\subsection{Mass Burning Rate.}

a. Pre-Flashover (Free) Burning of Initially Ignited Fuel Package, $t+0$ to about $t+590$ Seconds.

The mass burning rate of the initial fuel package was derived by dividing the rate of energy release (see paragraph 2.3 , below) by the average heat of combustion. The average heat of combustion is estimated at $12000 \mathrm{btu} / \mathrm{lb} .(27,885 \mathrm{~kJ} / \mathrm{kg})$ of consumed material. This estimate is based on an assumption of an approximately 50/50 mixture of cellulosic (paper and wood) and hydrocarbon (plastics and similar resins.) A mean value of $8000 \mathrm{btu} / \mathrm{lb}(18,590 \mathrm{~kJ} / \mathrm{kg})$ is assigned for the cellulosic materials and $16000 \mathrm{btu} / \mathrm{lb}(37,180 \mathrm{Kj} / \mathrm{kg})$ for the hydrocarbon portion. This estimate includes that portion of the wall covering and panel material involved prior to flashover of the South Ballroom. For a further discussion of the extent of involvement of 
the wall covering material and the paneling see paragraph 2.10 , below.

\section{b. Post Flashover Burning of Materials in the South Ballroom, After} about $t+590$ Seconds.

The method used is adapted from chapter 5 of Drysdale [2].

The basic equation is:

$$
\mathrm{m}^{\prime \prime}=\quad \frac{\dot{\mathrm{q}}}{\mathrm{L}}_{\mathrm{v}}^{\prime \prime}
$$

Where:

$$
\begin{aligned}
& \dot{\mathrm{m}}=\text { Mass Burning Rate per unit area } \\
& \dot{\mathrm{q}}_{f}=\text { Total Heat Flux on Material per unit area } \\
& \mathrm{L}_{\mathrm{v}}=\text { Heat of Gasification }
\end{aligned}
$$

Since the prime interest is the first minutes after flashover, the impact of charring of wood elements is not considered.

\section{Post Flashover Flux}

The post flashover total heat flux is estimated to be $7 \mathrm{btu} / \mathrm{ft} .^{2}$ ( 80 $\mathrm{kW} / \mathrm{m}^{2}$ ) on the exposed surfaces of the initial fuel package, the walls, and the partition. These materials burned above the post flashover hot gas interface in the South Ballroom. This value is typical of the range of total heat flux found in full scale room experiments.

The wood floor of the South Ballroom lies below the estimated level of the post flashover hot gas interface. For this reason the post flashover heat flux on the floor is estimated at $1.75 \mathrm{btu} / \mathrm{ft} .^{2}$ $\left(20 \mathrm{~kW} / \mathrm{m}^{2}\right.$.) This estimate is based on the fact that only about 50 per cent of the floor surface showed signs of significant burning. In the calculations in this report the involved surface area of the South Ballroom floor is set at 508 of the floor area (1015 $\mathrm{ft}^{2}$ or $108 \mathrm{~m}^{2}$.)

\section{Heat of Gasification.}

The heat of gasification is taken as $860 \mathrm{btu} / \mathrm{lb}(2 \mathrm{~kJ} / \mathrm{g})$ for all of the exposed combustible materials except the fabric wall covering material. This is a typical value representative of the values given for materials similar to those in the South Ballroom in Table 5.6 of Drysdale's textbook [2]. The fabric wall covering material was tested as bonded to concrete using the Cone Calorimeter [3.] The report of this test indicated a heat of gasification about $3400 \mathrm{btu} / 1 \mathrm{~b}(8 \mathrm{~kJ} / \mathrm{g}$. $)$ The test results are contained in Appendix $\mathrm{F}$. 


\section{Pyrolysis Rates.}

For calculation purposes it is assumed that the surface areas of the exposed materials did not appreciably change prior to flashover. Equation (1) and the data listed above were used to estimate the post flashover pyrolysis rates of materials in the South Ballroom. The results are shown in Table 1 .

\section{Wall Covering.}

The wall covering material is a fabric material having a weight of approximately $1 / 7 \mathrm{lb} . / \mathrm{ft} .{ }^{2}\left(700 \mathrm{~g} / \mathrm{m}^{2}\right.$.) At a post flashover burning rate of $0.125 \mathrm{lb} . / \mathrm{min} / \mathrm{ft} .^{2}\left(10 \mathrm{~g} / \mathrm{s} / \mathrm{m}^{2}\right)$ the fabric is consumed in 1 to 2 minutes following post flashover involvement. There were sufficient quantities of all of the other materials to continue burning for at least 10 to $15 \mathrm{~min}$. after flashover. Some burned for a much longer time. See paragraph 2.15 for a discussion of fire duration.

\section{c. Burning of Foyer Celling After Flashover of South Ballroom but} Prior to Entry of Fire Into Casino. About $t+590$ to about $t+720$ Seconds.

As discussed in more detail in paragraph 2.10, Flame Length, a significant body of flame covered portions of the heavy timber ceiling of the Foyer. This occurred immediately after flashover of the South Ballroom.

The total heat flux from this flame to the ceiling is estimated at $3.5 \mathrm{btu} / \mathrm{sec} / \mathrm{ft} .^{2}\left(40 \mathrm{~kW} / \mathrm{m}^{2}\right)$. This level was chosen as typical of the flux levels observed in flame spread and wall burning experiments. At this level of heat flux, the timber ceiling surfaces can be expected to ignite in about one minute. Based on a heat of gasification of 680 $\mathrm{btu} / 1 \mathrm{~b}(2 \mathrm{~kJ} / \mathrm{g})$ the rate of mass loss from the ignited portion of the ceiling was about $0.005 \mathrm{lb} / \mathrm{sec} . / \mathrm{ft} .^{2}\left(20 \mathrm{~g} / \mathrm{s} / \mathrm{m}^{2}\right)$ of wood surface. Because of the deep beams, the wood surface of the ceiling is approximately 1.9 times the projected floor area beneath it.

\subsection{Rate of Heat Release}

\section{a. Pre-flashover (Free) Burn of Initially Ignited Fuel Package, $t+0$ to about $t+590$ Seconds.}

\section{Initial Fuel Package}

The initial fuel package consisted of guest room furniture packed in corrugated cardboard shipping cartons. Much of the furniture was dressers made of wood and particle board. The cartons containing dressers were stacked two high. About $20 \%$ of the total volume contained urethane foam upholstered sofa beds.

The fuel array stood approximately $6.25 \mathrm{ft} .(1.9 \mathrm{~m}) \mathrm{high}$ and covered approximately $450 \mathrm{ft}^{2}\left(42 \mathrm{~m}^{2}\right)$ of floor area. The point of ignition is 
assumed to have involved cartons containing dressers and to have been about 3 feet $(0.9 \mathrm{~m})$ above floor level. It is assumed that failure of corrugated board and other factors widened the fire and involved sufficient downward extension so that it is reasonable to assume a virtual source at floor level. All of the calculations of fire development and appraisals of the potential response of fire protection devices, other than smoke detectors in the South Ballroom, are based on this assumption. In view of the early response of smoke detectors, the calculation of smoke detector response assumes a virtual source at the level of ignition (i.e., 3 feet $(0.9 \mathrm{~m})$ ) above floor level.

\section{Source Data}

The rate of heat release during the burning of this package was estimated by comparing it to experimental burns of similar arrays.

Many large scale tests of material in corrugated cartons have been conducted at the Factory Mutual Research Corporation. The results of these tests have been tabulated by Alpert and Ward [4]. A different presentation of the same material is contained in NFPA 204M, Smoke and Heat Venting (1985) [5]. A report of a test of a sofa, reasonably similar to the sofa beds in the fuel array is reported by Gross [6] in his compilation of data for predictive modeling. A similar compilation including the above and others (but with less detail) has been presented by Nelson [7].

In the past several years, persons interested in developing generic rate of heat release rates have classed open flaming fires into four basic catagories. The catagories are labeled Ultra-Fast, Fast, Medium, and Slow. These are well described by Fleming [8.]

Figure 18 is adapted from Fleming's article. Of interest is the dashed curve labeled "6-ft storage." The fuel array for the test that gives this result is used as a standard in numerous tests of fire protection systems. The test cartons for the "6-ft storage" array contain foam plastic pails. This is expected to burn slightly faster than wooden furniture in similar cartons. The ignition source for the test array is a cotton wick soaked in a gasoline class liquid, placed between two boxes.

The second set of dashed lines in Figure 18 shows that shown for "furniture" and "6-ft storage", relocated to the origin of the graph. This is a more appropriate comparison with the generic curves. The time difference, roughly 100 to 120 seconds in the cases shown in Figure 18, represents an incubation period. Such a delay in active burning always occurs with solid fuels. The length of this delay depends on the ease of ignition of the solid fuel and the position and intensity of the ignition source. All of the times evaluated in this report start at the end of the incubation period. The transition from incubation to a predictable rate of heat release rate is often referred to as the point of established burning. Typically from the point of established burning, free burning fires follow a relatively 
consistent initial growth rate. This usually continues until either the fire reaches the limits of the fuel array or a physical change, such as the burning through of an outer layer or the collapse of the array occurs. In this analysis the point of established burning is the initial time of all estimates made. This point is indicated by the letter " $t$ " in time indications. That is, 300 seconds after the point of established burning is shown as $t+300 \mathrm{sec}$.

Figure 19 is similar to Figure 18. In this case, however, the figure has be annotated to show the relationship of the generic curves to the rates of heat release for various fuel arrays. The shaded area defines the range considered to describe pre-flashover burning in the South Ballroom. The rate of heat release curves following the edges of the shaded area were considered and used for sensitivity analyses. A curve approximately the same as the curve marked FAST was selected for the evaluations conducted. The curve used is defined as one that grows in rate of energy release as the square of time and has a growth rate that would reach $1000 \mathrm{btu} / \mathrm{sec}$ in 150 seconds. The left hand edge of the shaded area describes a similar curve that reaches $1000 \mathrm{btu} / \mathrm{sec}$ in 100 seconds. The right hand curve in 200 seconds.

The general equation is:

$$
\dot{q}=\alpha t^{2}
$$

Where: $\dot{q}=$ Rate of Heat Release

$$
\begin{aligned}
& \alpha=\text { A constant } \\
& t=\text { Time (sec.) }
\end{aligned}
$$

From equation (2) the values for $\alpha$ for the fire growth curves

\section{FOR}

TIME TO REACH

$1000 \mathrm{btu} / \mathrm{sec}$.

$t$ (sec.)

100

150

200

\begin{tabular}{ll}
$\begin{array}{l}\text { RATE OF HEAT RELEASE } \\
\text { IN } \\
\text { btu/sec }\end{array}$ & $\mathrm{KW}$ \\
$\alpha$ & $\alpha$ \\
\hdashline$\ldots .1$ & -10.1055 \\
0.0444 & 0.047 \\
0.025 & 0.0264
\end{tabular}




\section{Basis for Choice of Initial Fire Source.}

The choice of the fire following the curve that reaches $1000 \mathrm{btu} / \mathrm{sec}$ in 150 seconds was based on both fire test histories and sensitivity analysis. Reported large scale test results [5] indicate that the rate of heat release curve chosen reasonably describes a fire involving ordinary combustibles in corrugated cartons. The sensitivity analysis consisted of using all three curves shown above and comparing the results to reported events in the course of the fire. The fastest curve (1000 btu/sec in 100 seconds) condensed the time intervals to a point inconsistent with witness accounts of the fire. Both of the other curves produced results generally within the range of reasonable consistency with reported events. The faster of the two was chosen by the author based on his subjective judgement that it is nearer the true situation. The difference in this choice makes virtually no difference in the ultimate fire conditions. It does, however, involve a 20 to 25 percent difference in times to reach any given condition up to flashover of the South Ballroom. Fire events subsequent to flashover of the South Ballroom are independent of the pre-flashover growth rate.

\section{b. Rate of Energy Flow from South to North Ballrooms Prior to} Flashover in South Ballroom, $t+0$ to about $t+590$ Seconds.

The rate of energy flow from the South Ballroom to the North Ballroom was derived from a computation of the mass flow rate. Mass flow between the ballrooms was obtained as an output from the execution of a version of the Harvard model designated as FIRST [9]. The selection of this model is discussed in paragraph 2.5, below. FIRST reports vent flow (i.e., flow through the opening) in terms of temperature, total mass, and fraction of the mass that consists of unburned fuel. As the fire developed, the flow contained increasingly larger portions of unburned fuel gases. The fuel burned as it entrained air in the North Ballroom. This constituted the major energy input into the North Ballroom. In addition the elevated temperature of the flowing mass also transferred energy to the North Ballroom.

An assumption was made that, up to flashover of the South Ballroom, all of the unburned fuel that flowed into the North Ballroom found sufficient oxygen to burn. The reliability of this assumption is a function of the oxygen content in the smoke layer in the North Ballroom. Oxygen content was calculated assuming burning of all of the fuel (see paragraph 2.8, below.) After $t+480$ seconds the calculated oxygen concentration in the smoke layer in the North Ballroom was below $10 \%$. It is therefore likely that the actual smoke temperatures in the North Ballroom were less than those calculated. In which case the energy flow from the North Ballroom to the Foyer might have been less than that estimated in paragraph $2.3 \mathrm{c}$, below. The rate of energy produced by the combustion of the transferred fuel equals the rate of mass flow times the fraction of that flow that is unburned fuel (both from FIRST) times the average heat of combustion 
(i.e. $12000 \mathrm{btu} / \mathrm{lb}$. - $27,885 \mathrm{~kJ} / \mathrm{kg}$.), plus the additional energy provided by the vented hot gases given by the equation:

$$
\dot{\mathrm{q}}=\dot{\mathrm{m}} \mathrm{C}_{\mathrm{p}} \Delta \mathrm{T}
$$

WHERE: $\dot{\mathrm{q}}=$ Rate of Heat Release

$\dot{\mathrm{m}}=$ Mass Flow of Hot Gases

$\mathrm{C}_{\mathrm{p}}=$ Specific Heat (of Air)

$\Delta \mathrm{T}=$ Temperature of Hot Gases Above Ambient

See Table 2. for the rates of energy release developed.

c. Rate of Energy Flow from North Ballroom to Foyer Prior to Flashover in South Ballroom. From about $t+420$ to about $t+590$ Seconds.

The first smoke to become evident in the Foyer area is believed to be smoke that vented through an open 10 foot high door leading from the Foyer into the North Ballroom. Based on the previous assumption that prior to flashover in the South Ballroom, all of the fuel discharged from the South Ballroom burned in the North Ballroom, the estimate of energy flow is based solely on the temperature and mass of the hot gases flowing from the door way. The details of method used to estimate the temperature and mass flow are discussed in paragraph 2.4, below. The rates of energy release are shown in Table 3 .

\section{d. Post Flashover Energy Flow from the South Ballroom, After about $t+590$ Seconds.}

\section{Flow of Mass Generated}

The mass generation (burning) rates are listed in Table 1. Even though the doors to the South Ballroom probably stayed in place briefly after the surrounding glass shattered, estimates are based on all of the partition between the South Ballroom and the Foyer failing.

It is also assumed that all of the partition between the North and South Ballrooms was down by the time the South Ballroom had fully flashed over. Both openings then became 10 feet $(3.05 \mathrm{~m})$ high. That to the Foyer being approximately 36 feet $(11 \mathrm{~m})$ long. The opening between the ballrooms was 64 feet $(19.5 \mathrm{~m}$.) wide. If this assumption is incorrect and portions of the partition actually stayed in place for some period after flashover of the South Ballroom, a proportionally greater mass flow into the Foyer would result. This is because the rate of mass generation (see paragraph 2.2b above) would remain the same while the ratio of opening to the Foyer versus opening to the North Ballroom would increase. In view of the ventilation 
restrictions in the Foyer, the impact would be limited to an increased concentration of unburned fuel in the Foyer and in the products flowing into the Lobby.

\section{Distribution of Mass Flow}

Following flashover the walls of the South Ballroom absorbed little energy. It is reasonable to estimate energy flow as equal to the combustion of the mass generated. The mass flow being proportional to the relative magnitude of the ventilation factors of the openings. Ventilation factor is defined and discussed in chapter 10 of Drysdale [10.] For the South Ballroom the relative portions of total ventilation factor indicate a mass flow of 638 to the North Ballroom, 35.48 to the Foyer and $1.6 \%$ through the open door to the Service Corridor.

From paragraph 2.2, the total mass pyrolysis rate following flashover is $1,029 \mathrm{lb} . / \mathrm{min}(7,790 \mathrm{~g} / \mathrm{s}$.$) The heat of combustion is 12000 \mathrm{btu} / \mathrm{lb}$ $(27,885 \mathrm{~kJ} / \mathrm{kg}$.$) This amount of fuel has the capability of generating$ about 205,800 btu/second (217 MW.) As discussed in paragraph 2.8, Oxygen Concentrations in Smoke Layers, it is unlikely that all mass flowing into the North Ballroom could find sufficient oxygen to burn. The 35.48 product flow into the Foyer produces a calculated initial rate of energy release of $88,830 \mathrm{btu} / \mathrm{sec}$ (94MW.) Similarly that entering the Service Corridor has a calculated initial rate of 3293 $\mathrm{btu} / \mathrm{sec}(3474 \mathrm{~kW})$.

After the wall covering material is consumed (an estimated 2 minutes after flashover) these rates drop to $64,400 \mathrm{btu} / \mathrm{sec}$. (68 MW) entering the Foyer and about $3000 \mathrm{btu} / \mathrm{sec}$ ( $3.2 \mathrm{MW}$ ) entering the Service Corridor.

\section{e. Energy Release from the Foyer Celling After Flashover of South} Ballroom but Prior to Entry of Fire into Casino From about $t+590$ to $t+720$ Seconds.

As discussed in paragraph $2.2 \mathrm{c}$, the total heat flux to that portion of the heavy timber wooden ceiling of the Foyer covered by flame is about $3.5 \mathrm{btu} / \mathrm{sec} . / \mathrm{ft} .^{2}\left(40 \mathrm{~kW} / \mathrm{m}^{2}\right.$.) The heat of gasification is about 860 btu/lb $(2 \mathrm{~kJ} / \mathrm{g}$.

The rate of energy release from the wood surface bathed by thick flame is equal to the mass burning rate divided by the heat of gasification times the area covered by flame. That is $0.0041 \mathrm{~b} / \mathrm{ft} .{ }^{2} / \mathrm{sec}\left(20 \mathrm{~kW} / \mathrm{m}^{2}\right.$.)

The exposed timber Foyer ceiling between the glass exterior wall and the glass partition separating the Foyer from the Lobby areas covers an area of approximately $2000 \mathrm{ft}^{2}\left(185 \mathrm{~m}^{2}\right.$.) The construction consists of several inch thick planks supported on 4 foot ( $1.2 \mathrm{~m}$ )

centers on 20 inch $(0.5 \mathrm{~m})$ deep glue-laminated wood beams. The beams run east to west (perpendicular to the long walls of the Foyer.) The 
total exposed surface of wood is approximately 1.9 times the project area of the ceiling.

The ceiling members have an inherent resistance to immediate ignition because of their thermal inertia. At the level of energy involved in the flame from the South Ballroom, this delay is estimated at 30 to 60 seconds. For calculation purposes it is assumed that the initial entry of energy from the Foyer ceiling occurs at nearly the same time as the consumption of the South Ballroom wall covering.

Since the ceiling contains only wood the heat of combustion is set at $8000 \mathrm{btu} / 1 \mathrm{~b}(15,500 \mathrm{~kJ} / \mathrm{kg}$. $)$

From these factors it is estimated that the rate of energy release from the Foyer ceiling is $52 \mathrm{btu} / \mathrm{sec} / \mathrm{projected} \mathrm{ft} .^{2}$ (590 kW/projected $\mathrm{m}^{2}$ ) of flame covered ceiling. The rate of heat release available from total flame involvement of the entire exposed ceiling is approximately $104,000 \mathrm{btu} / \mathrm{sec}$ ( $110 \mathrm{MW}$.$) As discussed in paragraph 2.4 \mathrm{~d}$, this energy potential is believed to have been released starting shortly after the flashover of the South Ballroom. As oxygen is depleted, in the Foyer, that portion of the excess fuel that flows from the room will find new paces to burn as it encounters air.

\subsection{Smoke Layer Temperatures.}

Figure 13 is a plot of the estimated average smoke temperatures in the South Ballroom, North Ballroom, and Foyer.

All times are the time from established burning. This follows the incubation period from the moment of the presence of an ignition source until a firm flame several inches high involving the cartons of the initial fuel package is established.

\section{a. Smoke Temperatures in the South Ballroom,}

\section{(1) Prior to Flashover. $t+0$ to about $t+590$ Seconds.}

The method used to predict smoke temperatures in the South Ballroom from $t+0$ to flashover of that space (i.e., about $t+590$ ) is that proposed by Quintiere [11.] A programed version of this procedure is contained in FIREFORM [12.] A further adjustment of the program developed during this appraisal handles up to 5 different lining materials and calculates a series of results through the progression of time and temperature exposure. The results of applying this procedure to the South Ballroom are contained in Appendix A. While the printout lists the results in a manner similar to those produced by model, each line of results represents a separate independent calculation. In this report the specific computer program involved is assigned the title UTEMP[13].

The results of this calculation are a function of the rate of energy input at any time, the length of time that the lining material is 
exposed to elevated temperatures, and the ventilation factor of the openings.

The description of the energy release rate of the fire is a continuation of the $t$-squared fire started at $t+0$. The time of exposure of the room linings also starts a $t+0$.

\section{Room Lining Materials}

The procedure evaluates the effective conductance of the room linings. To accomplish this the program requires the thermal inertia and the thermal conductivity of each segment of wall lining. Thermal inertia as used in these calculations is the product of specific heat, density, and thermal conductivity of the material involved. Thermal inertia is in terms of $(\mathrm{MJ})^{2} / \mathrm{s} / \mathrm{m}^{4} / \mathrm{K}^{4}$. Thermal conductivity is in terms of $\mathrm{MJ} / \mathrm{kg} / \mathrm{K}$.

The South Ballroom calculation involves five different lining materials. They are:

(1) Wood floor. Area $2304 \mathrm{ft.}^{2}\left(214 \mathrm{~m}^{2}\right.$.) The thermal properties are based on those of wood. The values used are 0.16 for thermal inertia and 0.00012 for thermal conductivity.

(2) Mineral ceiling. Area $2304 \mathrm{ft} .{ }^{2}\left(214 \mathrm{~m}^{2}.\right)$ All of the ceiling was dislodged during the fire events. It appeared to have been a mineral tile about 1 inch $(0.025 \mathrm{~m})$ thick. The thermal properties are based on data on gypsum. The values used are 0.18 for thermal inertia and .00017 for thermal conductivity.

(3) Partition Panels. Area $600 \mathrm{ft} .{ }^{2}\left(56 \mathrm{~m}^{2}.\right)$ The partition consisted of separate panels each believed to be 4 feet $(1.2 \mathrm{~m})$ wide and 10 feet $(3.05 \mathrm{~m})$ high. It is estimated that each individual panel weighed less than 25 1b. (11.3 kg.) All but a few square feet of the outer skin of the partition panels were consumed in the fire. It appears that the panel was of sandwich construction. The sandwich appears to have consisted of thin (0.06 inch $0.0015 \mathrm{~m}$ thick) high pressure laminate skins over a thermoplastic foam core. The thickness of the core is unknown. The sandwich frame is believed to have been common wood. For initial heat transfer purposes the core and unexposed side of the panel were ignored. The available data base does not have values for high pressure laminate materials. As an approximation, the values for hardboard were used. The values used are 0.24 for thermal inertia and 0.0002 for thermal conductivity.

(4) Glass. Area $360 \mathrm{ft}^{2}\left(33.4 \mathrm{~m}^{2}\right.$.) The values used for the glass separation between the South Ballroom and the 
Foyer are 22.5 for thermal inertia and .0012 for thermal conductivity.

(5) Fabric Covered Concrete. Area $1000 \mathrm{ft} .^{2}\left(93 \mathrm{~m}^{2}\right.$.) For purposes of heat conduction during the developmental stages of the fire these walls were treated as having properties similar to concrete. This is felt reasonable, in the absence of test data, because of the lightness of the wall covering. This approximation breaks down if the covering delaminated from the wall. A small section of covering surviving in the south end of the east wall of the North Ballroom showed minor blistering. This area was close to the South Ballroom but partially protected by the alcove for the stairs to the balcony. Other surviving wall covering located near the north end of the North Ballroom did not blister. The values used are 2.9 for thermal inertia and 0.0012 for thermal conductivity.

\section{Determining Ventilation Factors}

The majority of the air for combustion of the fire in the South Ballroom entered through the opening in the partition between it and the North Ballroom. The air drawn into the fire was replaced in the North Ballroom by air from four open doors to the outside and the open leaf of the door between the North Ballroom and the Foyer. These same openings also served as the exit route for smoke and other gases expelled by the fire. In view of the importance of both combustion air and the venting of fire product, the impact of both the openings between the ballroom sections and the openings out of the ballrooms was evaluated. The impact of an opening on fire development is a function of the opening dimension called ventilation factor. When there is more than one opening the impact of ventilation is proportional to the sum of the ventilation factors of the individual openings. The ventilation factor of an opening is equal to the area of the opening times the square root of the height of that opening.

At $t+0$, one panel in the partition separating the South Ballroom from the North Ballroom was missing. This left an opening adjacent to the area of ignition. The estimated size of this opening is 10 feet high by 4 feet wide. Also within the first minute of fire development a door 7 feet high by 2.83 wide leading to the service corridor was opened. This door stayed open for the duration of the fire.

The partition panels appeared to have been held in place by pressure against an over head member and a thermal plastic tongue and grove like fitting between individual panels. It is estimated that each of the individual panels fell from its position within 30 to 60 seconds of major flame impingement on it. The approach used to estimate flame impingement is detailed in paragraph 2.10 , below.

On this basis it is estimated that the panels adjacent to the 
initially ignited fuel package all failed within 3 to 4 minutes from established ignition.

Also at about the time the panels close to the initial fuel package failed, one three-foot $(0.91 \mathrm{~m})$ leaf of the 10 -foot $(3.05 \mathrm{~m})$ high door from the North Ballroom to the Foyer was opened. The UTEMP[13] computations are based on ventilation provided by one 16 -foot $(4.9 \mathrm{~m})$ wide by 10 -foot $(3.05 \mathrm{~m})$ high opening towards the North Ballroom and one 2.83-foot $(1.2 \mathrm{~m})$ wide by 7 -foot $(2.13 \mathrm{~m})$ high open door to the Service Corridor being established by $t+180$ seconds.

The vented (fuel controlled burning) phase of the fire in the South Ballroom ends when the calculations indicate an average upper layer temperature of about $1100 \mathrm{~F}$ (600 C.) This temperature was taken in these calculations to indicate flashover. As shown in Appendix A these calculations predict flashover of the South Ballroom in about $t+590$ seconds.

\section{(2) Post Flashover Phase. From $t+590$ seconds}

At the time of flashover additional ventilation occurred due to the failure of the glass partition wall between the South Ballroom and the Foyer. Following this the burning rate is regulated by the amount of air that can enter the South Ballroom and the rate of heat transfer into the ballroom walls. A equation for estimating post flashover smoke temperature is presented by Quintiere [11.] The equation is:

$$
\Delta T=896\left\{A_{0} \sqrt{H} /\left(h_{k} A\right)\right\}^{1 / 3}
$$

WHERE: $\quad \Delta \mathrm{T}=$ Post Flashover Temperature Rise (C)

$$
\begin{aligned}
& A_{0}=\text { Area of Opening }\left(\mathrm{m}^{2}\right) \\
& H_{0}=\text { Height of Opening }(\mathrm{m}) \\
& h_{k}=\text { Effective Enclosure Conductance }\left(\mathrm{kW} / \mathrm{K} / \mathrm{m}^{2}\right) \\
& A=\text { Surface Area of Room Lining }\left(\mathrm{m}^{2}\right)
\end{aligned}
$$

UTEMP stops when temperatures indicate flashover allowing the user to adjust the size of openings to account for breakage due to flashover. The program saves the information on thermal properties of the lining 
material and the duration of energy impact on the lining materials. It then executes equation 4. The results are shown the UTEMP printout in Appendix A. The procedure is unable to account fully for the venting of post flashover hot gases following the failure of the partition, the probable partial depression of burning due to the mass excess of fuel in the fire gases, and the actual venting efficiency of the air supply routes. For these reasons it is likely that the actual temperature may have been several hundred degrees $F$ less than that indicated.

\section{b. Smoke temperatures in North Ballroom.} Seconds.

(1) Up to flashover of South Ballroom. $t+0$ to about $t+590$

The Available Safe Egress Time Model (ASET) developed by Cooper and Stroup [14] is the principle calculation tool for this phase. The basic form (ASETB) as developed by Walton [15] and modified by Nelson in FIREFORM [12] was used. In addition the specific form of ASETB used includes a significant number of modifications to adjust the input and output form to the meet author's needs and to undertake a series of related calculations. These are discussed in subsequent paragraphs of this report. The form of ASET used, however, remains exactly true to the computations developed by Cooper [14] and the numerics contained in ASETB [15.] This adjusted version combining ASETB with other procedures has been assigned the name ROOMFIR[16] for this report.

Since the upper part of the North Ballroom constitutes a closed space ROOMFIR was used to estimate smoke temperatures in that space. In view of the ratio of height to width of the space involved an overall energy loss factor of 0.8 was selected. The radiant energy loss factor was set at 0.35 . The base level of the fire was set at 6 feet $(1.8 \mathrm{~m})$ above floor level to reflect the smoke level of the fire in the South Ballroom. (See paragraph 2.5, below.)

\section{$t+590$ Seconds.}

\section{(2) Following flashover of the South Ballroom. After about}

At the time of flashover of the South Ballroom the estimated oxygen concentration in the smoke in the North Ballroom is approaching zero. Little, if any, burning can occur in this reduced oxygen atmosphere. With flashover and the subsequent mass burning rate (see paragraph 2.2 , above), a initial fuel flow rate of in excess of $875 \mathrm{lbs} . / \mathrm{min}$. $(6732 \mathrm{~g} / \mathrm{s})$ entered the North Ballroom. For the most part this fuel collected in the upper portions of the North Ballroom until the subsequent failure of the window wall between the North Ballroom balcony and the Foyer. The development of these subsequent events is discussed in paragraph 2.4d, below. When this occurred fuel flowed from the $\mathrm{Ball}$ room into the Foyer and air flowed into the upper portion of the North Ballroom. As evidenced by the burn patterns in the North 
Ballroom, a localized flashover occurred in the balcony and adjacent areas.

\section{c. Smoke temperatures in Foyer Prior to Flashover in the South}

Ballroom, From about $t+420$ to $t+590$ Seconds.

The flow of smoke into the North Ballroom progressively filled the upper portions of the North Ballroom. As shown in Appendix B, the smoke level is calculated to have reached the 10 -foot level at about $t+420$ seconds. At this point the first flow of smoke from the ballroom complex to the Foyer started. The flow passed under the soffit of the 10 -foot $(3.05 \mathrm{~m})$ tall open door between the North Ballroom and the Foyer. While the smoke was relatively cool compared to that in the South Ballroom, it still contained energy and started. to flow to the roof of the Foyer and into the ceiling spaces of the Lobby. If any unburned fuel was present, the flow was too cool to ignite it.

The energy flow to the Foyer was determined using equation (3) as described in paragraph 2.2b., above. Equation (3) requires determination of the mass flow of hot gases. The procedure used to estimate smoke flow through an opening is contained in FIREFORM [12.] In making these calculations it is assumed that the venting through the single 3 -foot $(0.91 \mathrm{~m})$ wide door has no significant effect on the rate of descent of smoke predicted by ROOMFIR for the North Ballroom. Once the smoke drops below the tops of the 7 -foot $(2.13 \mathrm{~m})$ high open door ways, it is assumed that the venting will limit the further descent of smoke to 6 -foot $(1.8 \mathrm{~m})$ above the floor.

Application of the perfect gas law determined the density of the discharged gases. In this application it is assumed that the density of the discharged gases is approximately the same as that of air at the same temperature. Equation 3 was then used to estimate the energy flow rate. The calculated values are presented in Table 3 .

The Foyer area connected directly to the Lobby area through a ceiling high opening approximately 14 feet $(4.3 \mathrm{~m})$ wide. At the low levels of energy flowing into the foyer at this stage, the opening presented little restriction to smoke flow. This resulted in a common ceiling area of about $8500 \mathrm{ft}^{2}\left(790 \mathrm{~m}^{2}.\right)$ In view of the large area involved an overall energy loss factor of 0.6 is used. Since the ceiling layer gases that enter the Foyer at this time are relatively cool, the radiant heat loss is low, assumed zero. The height of the fire is 7 feet $(2.13 \mathrm{~m}$.$) The computer program printout detailing these results$ is contained in Appendix $C$.

\section{d. Smoke Temperatures in the Foyer Following Flashover in the South} Ballroom, From about $t+590$ to about $t+720$ Seconds.

This portion of the analysis covered the period from the flashover of the South Ballroom ( $t+590$ seconds) to the subsequent flashover-like occurrence in the Foyer area. 
When the South Ballroom flashed over, it is expected that the 36 -foot $(10.9 \mathrm{~m})$ long by 10 -foot $(3.05 \mathrm{~m})$ high window wall between the South Ballroom and the Foyer failed. It is likely that the two 3 -foot $(0.9 \mathrm{~m})$ wide glass panels in the short section of wall between the North Ballroom and the Foyer also failed at this time or soon after. It is believed, however, that the window wall between the Foyer and the outside, the glass partition adjacent to the top of the Foyer stairs and the windows between the Foyer and the second floor function rooms, the Casino, and the restaurant beneath the Casino did not break at this stage. While the physical evidence and witness statements cannot fully confirm this assumption, it is felt that it best fits the reported course of the fire.

As discussed in paragraph 2.3c, above, the rate of flow of mass from the flashed over South Ballroom into the Foyer starts at approximately $364 \mathrm{lbs} / \mathrm{min}(2757 \mathrm{~g} / \mathrm{s}$.) Approximately 2 minutes later, this drops to a level of about $322 \mathrm{lbs} / \mathrm{min}(2435 \mathrm{~g} / \mathrm{s})$ as the wall covering is consumed. During this same period, however, the Foyer ceiling starts to burn releasing additional energy at a rate of about 0.4 $\mathrm{lbs} / \mathrm{min} / \mathrm{ft} .^{2}\left(9.5 \mathrm{~g} / \mathrm{s} / \mathrm{m}^{2}\right)$ of involvement. The area of involvement being quoted on projected area rather than actual surface area. Discussion of flame impingement and extension along the Foyer ceiling is provided in paragraph 2.10 , below.

Had there been sufficient air for combustion such rates of mass flow could have produced an initial energy level of about $88,000 \mathrm{btu} / \mathrm{sec}$ (94MW.) The major source of combustion air for the fire in the Foyer was, however, the 10 -foot $(3.05 \mathrm{~m})$ high by 14 feet $(4.3 \mathrm{~m})$ wide opening between the Foyer and the Lobby. The ultimate source of this air being the open 10 -foot $(3.05 \mathrm{~m})$ high by 25 -foot $(7.6 \mathrm{~m})$ wide main entrance to the building.

The smoke temperature in the Foyer was estimated using UTEMP[13]. One of the features incorporated in UTEMP is a test for ventilation limit. The maximum rate of heat release is that which can obtain air to burn within the space (Foyer.) The maximum rate of heat release being equal to a constant ( $k$ ) times the ventilation factor of the opening. If the opening dimensions are in feet, a value of 1100 for $k$ gives the maximum rate of energy release in btu/sec. If the opening dimensions are in meters, a value of 55 for $k$ gives the maximum rate of energy release in $\mathrm{kW}$.

Since the computation program used has an internal capability of adjusting actual heat release in ventilation limited conditions, the input was based on the estimated potential combustion energy available. Potential energy, in this case, is that energy which would be released if all of the available fuel actually burned within the Foyer.

For this calculation, time zero equals the time of flashover in the South Ballroom ( $t+590 \mathrm{sec})$ The imputed rates of heat release are: 
(1) At flashover. $400 \mathrm{btu} / \mathrm{sec}(422 \mathrm{~kW}$.) This reflects the maximum preflashover flow of energy through the open door between the North Ballroom and the Foyer.

(2) Flashover +5 seconds. $88,000 \mathrm{btu} / \mathrm{sec}$ (94 MW.) This reflects the initial post flashover flow of fire products into the Foyer from the South Ballroom. (See paragraph 2.3d, above.)

(3) Flashover +30 seconds. $88,000 \mathrm{btu} / \mathrm{sec}$ ( $94 \mathrm{MW}$.) At this point it is expected that timber in the Foyer ceiling will start to pyrolyze. Progressive involvement of the flame impacted portion of the timber ceiling is expected in the next 30 seconds. The initial area of flame involvement is estimated as extending the width of the opening to the South Ballroom resulting from the failure of the partition between that room and the Foyer and the 19-foot $(6 \mathrm{~m})$ initial extension of flame across the ceiling. (See paragraph 2.10, below for discussion of flame extension.

(4) Flashover + 60 seconds. $145,000 \mathrm{btu} / \mathrm{sec}$ (152 MW.) This to reflect the addition of fuel from pyrolysis of about 750 project ft. ${ }^{2}\left(22 \mathrm{~m}^{2}\right)$ of Foyer ceiling. Since the ceiling is totally of wood construction the rate of energy release per unit mass burned of ceiling timber burned is estimated at $8000 \mathrm{btu} / \mathrm{lb}$ $(18.6 \mathrm{~kJ} / \mathrm{g}$.

(5) Flashover + 120 seconds. 200,000 btu/sec (211 MW.) This to reflect the addition of fuel from pyrolysis of all of the Foyer ceiling and the burnout of the fabric wall covering.

Appendix $C$ contains the computer print out of the results. As can be seen the burning rate is limited by the ventilation capacity of the opening at the top of the Foyer stairs. The calculated rate of energy release is about $25,000 \mathrm{btu} / \mathrm{sec}$ (26MW.) This burning rate uses about 800 of the over $3000 \mathrm{~g} / \mathrm{s}$ of material being released. Some of the remaining material is carried into the Lobby area in the discharged smoke. That which can find air, shows as flame. The rest adds to the blackness of the smoke front. Much of the excess unburned fuel remains in the smoke accumulating in the Foyer.

The calculations also indicate that a second flashover occurs about 135 seconds after flashover in the South Ballroom. Since the fire in the Foyer was already ventilation limited and virtually all available fuel surfaces were pyrolyzing, the traditional concept of radiant ignition of all unignited surfaces increasing the burning rate and forcing a fuel controlled fire into a ventilation limited condition is inappropriate. Rather it is likely that either the expansion forces caused by the heating of one of the large glass surfaces or the thermal shock of flame impacting on the glass resulted in failure of a large section of window. 
The occurrence of such a failure would then allow more of the available fuel to burn in the Foyer, increasing temperatures rapidly causing the failure of the other glass surfaces. In this process, it is believed that the failure of the glass partition between the balcony in the North Ballroom and the Foyer released the large reservoir of fuel gases that collected in the upper portion of the North Ballroom following flashover of the South Ballroom.

The most likely glass surface to have been the initial surface to fail is the glass partition between the Foyer and the Lobby. This section of glass was the closest to the flame expelled from the South Ballroom. Also, due to the turbulence near the smoke venting through the South Ballroom opening, this partition would have received more convective heat transfer.

The estimated time of this second flashover like occurrence is about $t+720$. The time $t+720$ seconds coincides with the rise of smoke temperature to about $1100 \mathrm{~F}$ (600C) in the Foyer. The choice of 720 seconds is, however, an approximation made by the author based primarily on experience and derived from witness accounts. The development of the fire at this stage was so rapid that the maximum potential error, in terms of time, is small.

\subsection{Smoke Layer Depth}

Figure 14 is a plot of the estimated height of the smoke layer above the floor in the South Ballroom, North Ballroom, and Foyer.

The height of the smoke layer above the floor was estimated in each case where ROOMFIR[16] was used to evaluate smoke layer temperature (i.e. the North Ballroom and the Foyer, see paragraph 2.4 above. The prediction of the height of the smoke above the floor is a standard output of the ASETB [15] segment of ROOMFIR. The amount of volume occupied by the smoke is based on the entrainment of air in the rising smoke column and the expansion of the gases due to the rise in temperature.

ROOMFIR was not used for the smoke level prediction in the South Ballroom. In. this space the large vent areas, presented by the openings in the partition between the ballroom sections, in combination with the rapid fire development caused conditions exceeding the capabilities of ASETB[15]. The prediction in this area used a recently developed form of the Harvard model now refereed to as FIRST [9]. FIRST has the capability of tracking the flows in and out of openings, the mass and fuel flows involved, and the impact of this on the rate of heat release and environment in the fire room. FIRST also has the capability of increasing the opening conditions at a designated point in the development of the fire. At the start of the FIRST simulation, the openings consisted of the $2.83 \mathrm{ft} .(0.86 \mathrm{~m})$ wide by 7 -foot $(2.1 \mathrm{~m})$ high door to the service corridor and an opening in the partition 10 foot $(3.05 \mathrm{~m})$ high by 4 -foot $(1.2 \mathrm{~m})$ wide. By instruction, the size of the opening was increased to 16 feet $(4.9 \mathrm{~m})$ wide at 180 seconds into 
the simulation to simulate the estimated time of failure of the panels next to the initial fuel package as discussed in paragraph $2.4 \mathrm{a}$, above.

The post flashover level of the smoke at the interface between the South Ballroom and the Foyer was estimated using a computer program dubbed HOTVENT[17]. This program estimates the level of the neutral plane in an opening venting from an flashed-over space. The equations executed by HOTVENT are discussed in paragraph 2.6 , below.

\subsection{Velocity of Smoke/Flame Front.}

The velocity of the smoke and hot gases vented from the Foyer to the Lobby during the period following flashover in the South Ballroom is of interest. It is believed that these gases blocked first the main (west) entrance to the Casino (causing occupants to shut those doors to inhibit the flow of smoke into the Casino) then the back (east) door, again forcing Casino occupants to close the door to hold back the smoke.

Also of interest is the rate of flow of the flame front through the Casino following flashover of the Foyer area and the failure of the windows between the Foyer and the Casino.

The set of equations developed by Kawagoe and Sekine [18] and reported by Lawson and Quintiere [19] under the title Ventilation Flow Rate in their paper Slide Rule Estimates of Fire Growth was used for both conditions. This set of equations relates the pressure driven flow from the opening to the conservation of mass flow in and out of the vented room. The flow and neutral plane being primarily a function of the temperature difference between the out flowing hot gases and the incoming cooler gases, the ventilation factor of the opening, and the neutral plane where the total mass vented is equal to the total mass drawn into the room. Discussion of this method, by Lawson and Quintiere [19], is included in Appendix G.

Since the calculations were based on conditions where the temperature differences between room temperature and smoke temperatures were large and the neutral plane was near the bottom of the opening the iterative form was required. The computer program, HOTVENT, was developed to handle the iterative calculations. Appendix $C$ contains the printout of HOTVENT giving the rate of mass flow and level of the neutral plane for each case. The mass flow was converted to volume flow at the smoke temperatures of the exposing fire and divided by the cross section of the portion of the receiving space (i.e., Lobby and entrance corridor for the Lobby flow case and Casino for the Casino case) above the level of the neutral plane. This produced a flow rate at that point.

In the case of the flow in the Lobby some cooling and condensing of the volume occupied by the smoke occurred as it traversed the Lobby. It is assumed that this had little effect on the speed of smoke travel but probably resulted in a raising of the level of the smoke somewhat above 
the level of the neutral plane existing at the opening between the Foyer and the Lobby.

By these calculations the smoke front moved through the Lobby at an initial speed of about $2.2 \mathrm{ft} . / \mathrm{sec}(0.67 \mathrm{~m} / \mathrm{s}$.$) At this rate the smoke$ front traversed the Lobby in about 40 seconds.

Similarly HOTVENT was used to estimate the flame front that moved through the Casino. The speed of this flame front was about $6 \mathrm{ft} . / \mathrm{sec}$. $(1.8 \mathrm{~m} / \mathrm{s}$.$) It is believed that the window closest to the main Casino$ entrance failed first. From that point the Casino would become completely engulfed in flame in about 20 seconds.

\subsection{Mass of Products in Smoke Layer.}

The tracking of the concentration of the mass of products contained in the smoke layer was computed as an adjunct calculation in ROOMFIR[16]. The ASETB[15] routine in ROOMFIR is based on an input tracking the rate of heat release of a fire against time. The relationship of rate of heat release to mass burning rate is discussed in paragraph 2.2 , above. For the fuel burned in the South Ballroom, this has been taken as 0.00083 pounds of mass per btu of energy released ( 0.000043 kilograms of mass per kilojoule of energy released). For the burning of the ceiling in the Foyer, a lower number indicative of wood is appropriate. This value is 0.000125 pounds of mass per btu of energy released ( 0.000064 kilograms of mass per kilojoule of energy released).

The concentration of mass of products in the smoke layer at any time is therefore the total mass discharged to that moment divided by the volume of the smoke layer (area of ceiling times depth of smoke under ceiling). This can be expressed as the following equation:

$$
\begin{aligned}
& P_{(n)}=\left\{\Sigma_{0}^{n} q / H_{c}\right\} / N \\
& \text { Where: } P_{(n)}=\text { Mass of products concentration at time } n . \\
& q=\text { rate of heat release } \\
& H_{c}=\text { Heat of combustion. } \\
& V=\text { Volume occupied by smoke at time } n .
\end{aligned}
$$

\subsection{Oxygen Concentration in Smoke Layer}

The calculated oxygen concentrations in the North and South Ballrooms and Foyer are shown in Figure 16.

The method used is based on the oxygen depletion concepts described by Huggett [20]. Huggett showed that for virtually all common combustible 
materials one gram of oxygen is consumed for each thirteen kilojoules of energy produced ( 1 pound of oxygen for each $5866 \mathrm{btu}$ ).

The amount of oxygen consumed in the process was derived from the data developed on mass concentration, see paragraph 2.6 above. The perfect gas law, assuming no significant influence due to the relatively minor differences in atmospheric pressure between the ambient air and fire gases was used to determine the density of the gases in the smoke layer.

The amount of oxygen that would have normally been contained had the upper layer consisted entirely of air, was determined on the basis of the density of air multiplied by the normal 0.23 value for the mass fraction of oxygen and air. The amount of oxygen consumed was then subtracted from this total and the result compared to that which would have existed without combustion. This produced the proportional residual mass of oxygen in the smoke. This value was then multiplied by 218 , the normal volumetric concentration of oxygen in air, to produce an estimated volumetric concentration of oxygen in the smoke gases.

For convenience, these calculations were included in ROOMFIR[16] reported as oxygen concentration.

$$
\begin{aligned}
& \mathrm{O}_{2}=21\left(\left[\left(0.23 \mathrm{P}_{\mathrm{a}} \mathrm{T}_{0} / \mathrm{T}_{\mathrm{a}}\right)-\left(0.77 \mathrm{P}_{(\mathrm{n})} \mathrm{H}_{\mathrm{c}} / \mathrm{V}\right)\right] /\left(0.23 \mathrm{P}_{\mathrm{a}} \mathrm{T}_{0} / \mathrm{T}_{\mathrm{a}}\right)\right\} \\
& \text { Where: } \mathrm{O}_{2}=\text { Oxygen concentration }(8) \\
& \mathrm{P}_{\mathrm{a}}=\text { Density of air at } \mathrm{T}_{0} \\
& \mathrm{~T}_{0}=\text { Ambient temperature (Absolute) } \\
& \mathrm{T}_{\mathrm{s}}=\text { Smoke temperature (Absolute) } \\
& \mathrm{P}_{(\mathrm{n})}=\text { Mass product concentration at time } \mathrm{n} . \\
& \mathrm{H}_{\mathrm{c}}=\text { Heat of combustion. } \\
& \mathrm{V}=\text { Volume occupied by smoke at time } \mathrm{n} .
\end{aligned}
$$

If the smoke layer descends below the top of the burning material and the oxygen drops below a critical level, the fire will go out. The critical oxygen concentration varies with temperature but for the purposes of these calculations, a critical calculation of 108 oxygen has been chosen as indicative of a fire that is either at or approaching the point of flame extinction.

The procedure used by FIRST to calculate oxygen concentration is based on the same physics but a different method of calculation.

\subsection{Visibility in Smoke Layer}

Figure 15 is a plot of the calculated visibility of the smoke layers.

The vision distance plotted is approximately the distance at which the smoke blocks 958 of the light from a well lit source. At this point of light blockage, little if any vision is possible. 
The approximations are made entirely on a light obstructing basis. They do not consider any irritating affects that might impose vision problems on a person whose head was actually in the smoke layer.

The computation of vision distance is based on work by Mulholland [21]. The concept suggested by Mulholland is based on his recent experiments and work by others. The calculations estimate the maximum vision distance through the smoke layer using the specific extinction coefficient of the fuel. A value of one meter square per gram for the specific extinction coefficient means that. the smoke produced by one gram of that fuel collected on a one square meter area would be sufficient to block approximately $65 \%$ of the light incident on that area.

For specific extinction coefficient values less than one, the area of collection required to produce a density of smoke sufficient to block 658 of the light would be proportionately less. In the evaluations in this report, the maximum vision distance was taken as that distance at which $95 \%$ of the light was blocked. This means an extinction coefficient of $1 / 3 \mathrm{~m}^{2} / \mathrm{g}$. So the vision distance is the length of light path in which the products of the fuel collected on $1 / 3$ square meter would block the passage of 958 of the light. At that value, light transmission is reduced to about $5 \%$.

The mass concentration $P_{(n)}$ is determined by equation (5). above.

Specific extinction coefficients vary extensively for various fuels. A number of these are reported by Quintiere [22]. While a significant portion of the materials involved were either cellulosic or hydrocarbon in nature, there did not appear to be more than relatively small proportions of the material that would be extremely sooty. On this basis, a working extinction coefficient of 0.1 square meters per gram of fuel burned was used in all of the calculations. Because of the limited data in this area, this choice is arbitrary. The values presented are indicative of the increasing density of the smoke rather than exact vision distances.

The equation used in ROOMFIR[16] can be expressed as follows:

$$
V_{5}=3 /\left(C_{s} P_{(n)}\right)
$$

Where:

$\mathrm{V}_{5}=$ Distance (meters) at which light is reduced by $95 \%$.

$C s=$ Specific extinction coefficient $\left(\mathrm{m}^{2} / \mathrm{g}\right)$

$P_{(n)}=$ Mass product concentration.

\subsection{Flame Length (Extension)}

The term flame length is used in this discussion to describe either the actual height of the flame above the floor or the height that the flame would have reached had it not struck a ceiling or overhead that 
prevented extension to its full height. Flame extension is used to estimate the extent that a flame that strikes a ceiling would tend to extend under that ceiling. Flame extension is estimated at 1 to 1.5 times the portion of the calculated flame height cut-off by the ceiling.

Graphs of the development of flame extension in the early burning periods in both sections of the ballroom complex is contained in Figures 11 and 12 .

Two methods of calculating flame height were used. These are:

A, South Ballroom. The approach recommended by Drysdale for free-standing flame away for walls was used for the South Ballroom. The plot in Figure 11 for the South Ballroom was developed by this equation. The equation is:

$$
\mathrm{L}=0.23 \mathrm{Q}_{\mathrm{c}}{ }^{2 / 5}
$$

Where: $\mathrm{L}=$ Flame Height Above Burning Surface (m)

$$
Q_{c}=\text { Rate of Convective Heat Release (kW) }
$$

B. North Ballroom and Foyer. The computation of pre-flashover flame extension from the South Ballroom to the North Ballroom and post flashover flame extension from the South Ballroom into the Foyer are based on flames emitted from windows. The work by Webster [23] and Yokoi [24] as correlated by Thomas, et al, [25] was used. This equation which was designed for estimating flame heights out of exterior windows. This approach is felt appropriate for the window like conditions that occurred after breakage of the partition between the South Ballroom and the Foyer. The equation is as follows:

$$
\mathrm{L}_{\mathrm{w}}=18.6(\mathrm{R} / \mathrm{W})^{2 / 3}
$$

Where: $\mathrm{L}_{\mathrm{w}}=$ Flame Length Above Top of Opening (m)

$$
\begin{aligned}
& \mathrm{R}=\text { Mass Burning Rate }(\mathrm{kg} / \mathrm{s}) \\
& \mathrm{W}=\text { Width of Opening }(\mathrm{m})
\end{aligned}
$$

NOTE: The data used to derive equation (9) was derived from tests involving wood fuels. Where other fuels are involved, it is necessary to revise the value of $R$ proportional to the comparative heats of combustion of the actual fuel verses wood. In the calculations relating to fuel emitted from the South Ballroom the value used for $R$ is 1.5 times the actual mass burning rate. 
Equation (9) was used to estimate the initial flame extension from the South Ballroom into and across the timber roof of the Foyer. For this calculation the value of $R$ was set at 1.5 time the total burning rate just after flashover in the South Ballroom (i.e., $7.79 \mathrm{~kg} / \mathrm{s} \times 1.5=$ 11.7 equivalent $\mathrm{kg} / \mathrm{s}$ of wood.) The value of $\mathrm{W}$ was set at the total length of the openings between the South Ballroom and both the North Ballroom and the Foyer (i.e., 30.5m.) This produces a value for $\mathrm{L}_{\mathrm{w}}$ of $9.8 \mathrm{~m}$ ( $32.2 \mathrm{ft}$.$) Since \mathrm{L}_{w}$ is the calculated flame length above the top of the opening and the opening is about $13 \mathrm{ft}$. below the ceiling, the flame extension across the ceiling is between 19 and $29 \mathrm{ft}$. ( 6 to $9 \mathrm{~m}$. ) The value of $19 \mathrm{ft}$. was used in calculations of rates of burning of the ceiling. This lower value was used to assure that the calculations reasonably reflected the areas of flame impact that actually imposed the heat flux used in the burning rate calculations. (See paragraphs $2.2 \mathrm{c}$ and $2.4 \mathrm{~d}$, above for discussion of the burning rate of the ceiling.)

In view of the excess of fuel entering the Foyer as compared to the rate of air entry through the opening into the lobby (See paragraph $2.3 d$, above) the actual extension of the flame may have been throttled by a lack of oxygen. The very high smoke temperatures that quickly developed in the Foyer (See Appendix C), however, would assure the continued pyrolysis of the ceiling.

Following the initial impact the further progression of the flame is closely associated with the additional fuel entering the fire plume as the result of the portions of the ceiling ignited by the initial flame, the spread of burning across the ceiling, the temperature of the smoke near the ceiling, and the availability of oxygen to allow combustion. Based only on the fuel entering the fire plume following ignition of a portion of the ceiling $36 \mathrm{ft}$. ( $11 \mathrm{~m})$ by $19 \mathrm{ft}$. (6m) across the surface of the ceiling, equation (9) indicates a further extension of 7 to 11 ft. While the knowledge of flame spread concurrent with fire flow is emerging (Quintiere [26]) the needed equations and data are not yet sufficiently developed to attempt further prediction of flame length. In addition the initial limited ventilation condition in the Foyer (see paragraph $2.4 \mathrm{c}$, above) could throttle the development of the flame as soon as the initial volume of oxygen in the Foyer was exhausted and burning within the Foyer became dependent on air drawn in through the opening to the Lobby. The latter limitation ceased with the extensive failure of either the glass in the partition between the Foyer and the Lobby or that in the exterior (north) wall of the Foyer.

It is believed (see paragraph $2.4 \mathrm{c}$, above) that the partitions held for about 2 minutes following flashover in the South Ballroom. By that time the smoke temperatures in the Foyer were in the range of $1100 \mathrm{~F}$ ( $600 \mathrm{C}$.$) The heat flux to the wood would be in the range of 4$ $\mathrm{btu} / \mathrm{ft} .^{2} / \mathrm{sec}\left(40 \mathrm{~kW} / \mathrm{m}^{2}\right.$.) At this level wood will either burn or, in the absence of oxygen, pyrolyze. Once the glass failed and oxygen reached the area of the heated wood, the entire surface of the Foyer ceiling became flaming. Since the estimated smoke temperature in the Foyer 
rises to about $900 \mathrm{~F}$ ( $485 \mathrm{C}$ ) within about 30 seconds from flashover in the South Ballroom, this would be essentially correct even if the partitions actually failed sooner that the time estimated in paragraph $2.4 \mathrm{c}$, above.

Had there been sufficient oxygen in the smoke layer in the North Ballroom for full flame development, a similar sheet of flame would have existed. However, since it is believed that the smoke layer in the North Ballroom, at this stage of the fire was virtually devoid of oxygen, it is assumed that the burning of the fuel expelled from the South Ballroom into the North Ballroom did not take place and the flame length predicted by equation (9) did not develop. Instead, it is believed that unburned fuel collected in the upper portions of the North Ballroom.

\subsection{Flame Spread}

Three of the four walls of the South Ballroom were finished with combustible materials. The initially ignited pile of furniture in cartons abutted the east wall of the South Ballroom. This wall and the south wall of were both finished with a fabric wall covering glued to the wall. The wall covering material appears to be of a polyester fiber weighing slightly more than one pound per square yard

(approximately $700 \mathrm{~g} / \mathrm{m}^{2}$ ). Tests of the flame spread properties of this covering were conducted. The test procedure uses a vertical radiant panel exposure. It is described by Quintiere and Harkleroad [27]. Wall covering samples taken from the surviving material on the wall of the North Ballroom were tested. The test specimens were glued to concrete substrate. The test results are shown in Appendix $F$. The results indicate an ignition temperature of between $1160 \mathrm{~F}(670 \mathrm{C})$ and 1270F (688C.) The method of estimating lateral flame spread described by Quintiere and Harkleroad [27] was used to estimate the lateral rate of flame spread and the distance that flame is estimated to have traveled away from the area of flame impingement prior to flashover. This equation is one of the routines included in FIREFORM [10.] The FIREFORM version was used in the computations made. This equation can be expressed as follows:

$$
\begin{aligned}
& \mathrm{V}=(\Phi / \mathrm{k} \rho \mathrm{c}) /\left(\mathrm{T}_{1 \mathrm{~g}}-\mathrm{T}_{\mathrm{s}}\right)^{2} \\
& \text { Where: } \quad \mathrm{V}=\text { Flame (pyrolysis front) velocity }(\mathrm{m} / \mathrm{s}) \\
& \Phi=\text { Flame heating parameter derived from the } \\
& \text { test. } \\
& \mathrm{k} \rho \mathrm{c}=\text { Effective thermal inertia derived from } \\
& \text { test. } \\
& \mathrm{T}_{1 \mathrm{~g}}=\text { Ignition temperature as reported by test } \\
& (\mathrm{C}) \\
& \mathrm{T}_{\mathrm{s}}=\text { Surface temperature of material before } \\
& \text { flame effects }
\end{aligned}
$$

A characteristic equilibrium time of 42 seconds was determined as part of the test procedures. This indicates that the surface temperature of 
the wall fabric $\left(T_{s}\right)$ lagged the temperature of the adjacent smoke by a approximately 42 seconds. A lag of 60 seconds has been used in the calculations in this report.

These calculation indicate a maximum flame spread (i.e., away from the flame) of less than 3 feet $(0.9 \mathrm{~m})$ per minute just prior to flashover. The maximum estimated extent of flame travel up to a few seconds before flashover is estimated at about 3 feet from the furthest point of direct flame impingement on the wall covering. This method ignores upward flame spread and any spread that may have occurred concurrent with flame lapping the wall near the ceiling. Even given this assumption, these calculations suggest that the wall covering, if attached to the South Ballroom wall in a manner similar to that in the tests conducted, had very limited spread prior to flashover of the South Ballroom. Following flashover, however, the material would have been very quickly involved as discussed in paragraph 2.2 , above.

The north wall of the South Ballroom consisted of a partitioning material that has been described as a high pressure laminated plastic sandwich with a foam plastic core. The data on these panels is so sketchy that it is impossible to make an accurate estimate of preflashover surface flame spread. For the purposes of this appraisal, it was assumed that the panels fell from their housing before flame propagated across them. This assumption is potentially in error (i.e., rapid early flame spread took place.) However, in view of the rapid development of the initial fuel package of furniture stored in cartons spread on the panel surfaces would have only minor impact on the speed of fire development and time to flashover in the South Ballroom.

In view of the conditions involved, flame extension rather than flame spread estimates were made of the movement of flame across the Foyer ceiling. (See paragraph 2.10, above.)

\subsection{Potential Response of Sprinklers.}

No sprinklers were present in the areas involved in the fire. An appraisal was made, however, of the likely response time of several different types of sprinklers in an array of feasible locations from directly over the fire to the maximum likely distance. The method used was based on the ceiling temperature and heat actuated device response correlation developed by Alpert [28]. Alpert's correlations were gathered together into a computer program by Evans which has been circulated under the title of DETACT-QS[29]. These temperature correlations, however, are based on an unconfined ceiling where the smoke layer does not develop below the ceiling jet during the time of interest. As indicated by the calculation of smoke depth (see paragraph 2.3, above) a ceiling layer did develop in the South Ballroom. The simple use of the DETACT-QS computational method would result in erroneous results indicating slower operation than should really be expected. 
Evans [30] has developed a computational procedure to account for the presence of the hot smoke layer as an adjustment in the virtual source of the fire plume. This adjustment was used. To accomplish this, with reasonable computational difficulty, the Evans adjustments in virtual source were used to connect the results from ASETB[15] calculations to DETACT-QS calculations with an adjustment to the source of the fire. These computations are incorporated in ROOMFIR[16].

To facilitate this calculation an adaptation was made to ROOMFIR that vented hot gases, to imitate the venting from the opening in the partition. When this adaption was run with an overall heat loss fraction of 0.75 the results closely tracked those obtained for the same conditions from FIRST (see paragraph 2.3, above.) This produced results recognizing the additional heating effect of the gathering hot gas layer. The results for a range of typical sprinkler head types and locations is shown below.
a. Quick Response Head
$\mathrm{RTI}=50$ (27 metric)
Operating Temperature $140 \mathrm{~F}$ (60C)

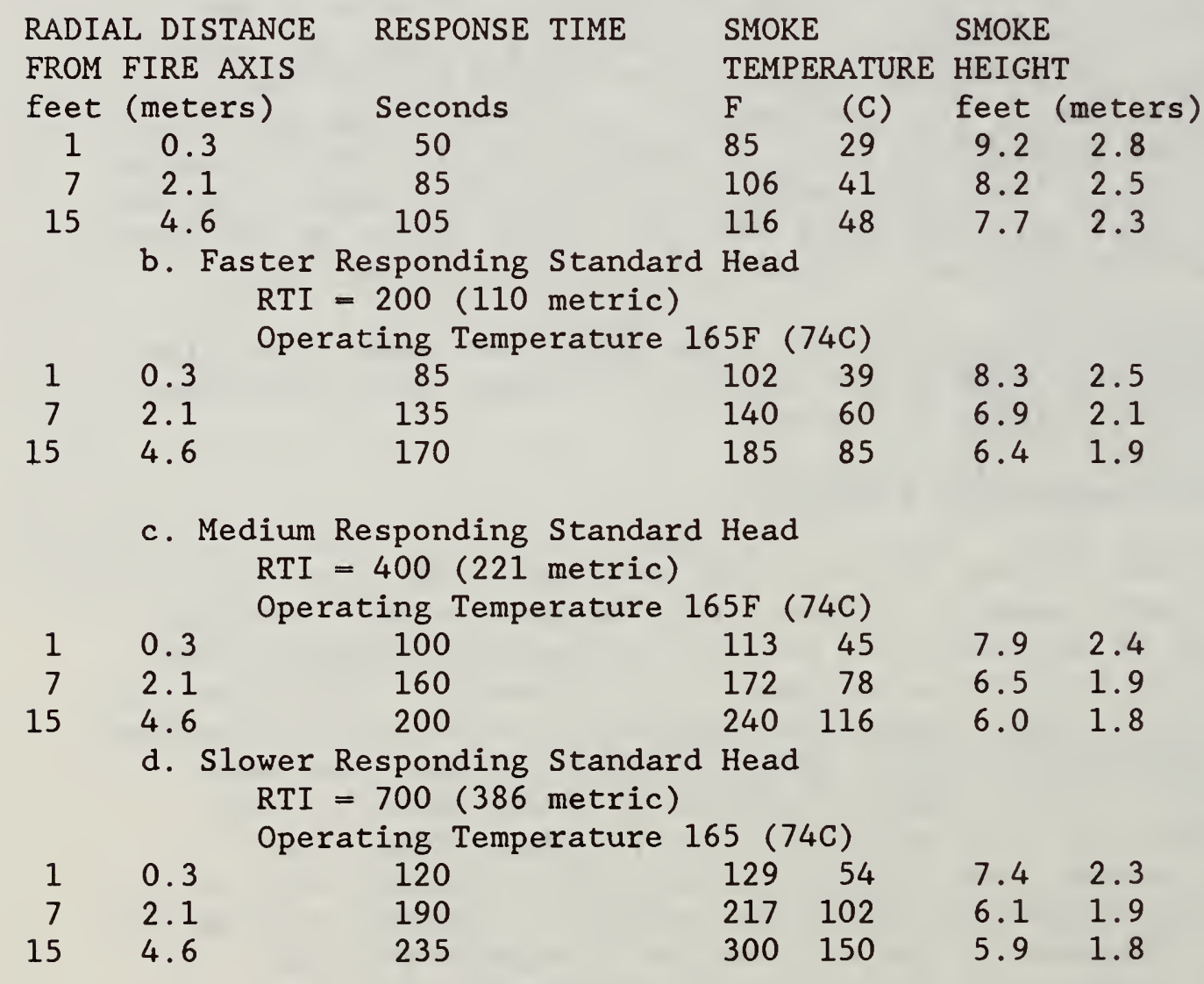

Copies of printouts of the actual computer runs used to develop the above data are contained in Appendix D. 
The results shown are felt to bound the range of types and spacings of sprinkler that might be present in a sprinkler protected assembly area like the South Ballroom. As can be seen a sprinkler head faced with the fire believed to have occurred in the South Ballroom would have responded in 1 to 4 minutes following established burning. Even the slowest response would have been well before flashover.

\subsection{Potential Response of Smoke Detectors}

There were no smoke detectors in the areas involved in the fire. Evaluations were made, however, of how quickly smoke detectors might have responded had they been located in the South Ballroom. As with sprinklers, a variety of different positions of smoke detectors were evaluated. Since most modern smoke detector have nearly identical response to growing fires of the nature involved in the South Ballroom distance was the only criteria. The approach used was based on the correlations developed by Heskestad [31] and his work for the Fire Detection Institute. Heskestad relates response of smoke detectors to a condition at the smoke detector where Alpert's correlations for ceiling temperatures [28] would indicate a rise in the jet temperature of approximately $23 \mathrm{~F}$ (13C). On this basis, the program DETACT-QS was used as though the ceiling were unconfined and the response of the smoke detectors based on time at which ceiling jet temperature would rise $23 F(13 C)$ at the positions of interest. The use of the procedure for unconfined ceilings is appropriate in the case of smoke detectors because the mass of fire products that triggers a smoke detector responds only to the production of particulate matter and not to the temperatures of the hot gas layer. Appendix E contains copies of the output from DETACT-QS. Shown below is a distribution of the expected response of detectors from a position directly over the fire to one at the remote end of the South Ballroom.

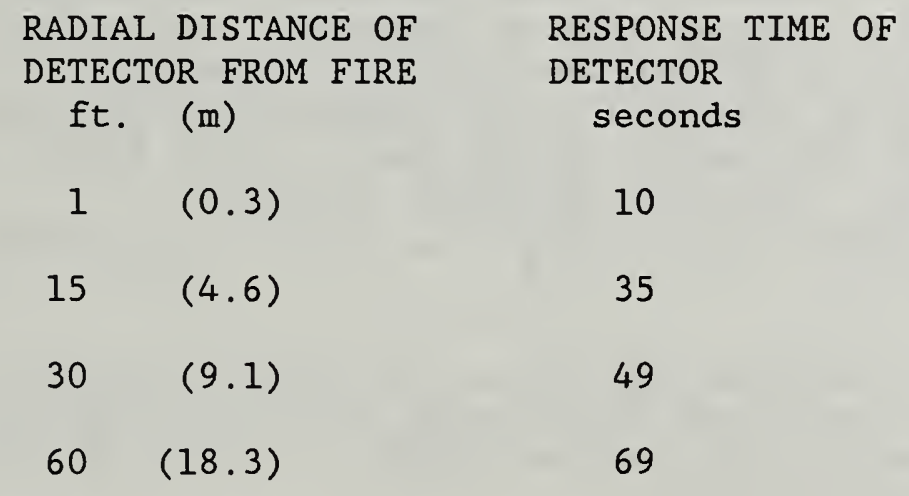

The value of the early response available from smoke detectors depends on the actions taken once the detector gives an alarm.

\subsection{Fire Duration.}

An estimate was made of the fire duration in the South Ballroom. The definition of fire duration used for this estimate is the time that the South Ballroom remained in a flashed over (ventilation limited burning) 
condition. The results of this being of principle value in estimating the impact that fire resistive barriers could have had on the development of fire conditions, had such been present.

The basis for this estimate is the expectation that the burning rates listed in Table 1 will persist until either the fuel involved is consumed or the relationship between available ventilation and burning rate reaches the point where the fire is no longer ventilation limited and the fire returns to a fuel controlled state of burning.

Of interest are those fuels that were not fully consumed prior to the return to fuel controlled burning. It is a reasonable assumption that any items that were completely consumed during the fire were gone by that time. Since only portions of the initial fuel package and the wood floor survived, the burning rates of these two elements were used in these calculations.

Based on an assumption that the burning of the fuel vented from the South Ballroom into the North Ballroom and the burning of the fuel present in the affected areas of the North Ballroom used all of the air drawn directly into that room, the calculations are based on the air for combustion in the South Ballroom coming primarily through the lower portions of the Foyer and entering the South Ballroom through the opening created by the failure of the glass partition between the South Ballroom and the Foyer. A much lesser source of air came through the open door between the South Ballroom and the service corridor. Using the method of determining ventilation limits discussed in paragraph $2.4 \mathrm{a}$, above, it is estimated that the fire returned to fuel controlled burning when the potential energy release dropped below about 65,500 btu/sec (69 MW.)

Using the values in Table 1 , the amount of floor involved contributed about $13,000 \mathrm{btu} / \mathrm{sec}$. ( $14 \mathrm{MW}$.) At the time of flashover, the initial fuel package contributed about $68,000 \mathrm{btu} / \mathrm{sec}$ (72 MW.) Since the floor did not burn through it is assumed that the contribution from the burning floor continued until the overall energy level dropped below the ventilation limit. It is, therefore, estimated that fuel controlled burning terminated when the surface area of the initial fuel package was reduced by about 258 .

Since the rate of decrease of surface area of the initial fuel package has not been determined, this knowledge is of prime value in comparing the impact of one ventilation condition against another. It is of only limited value in estimating fire duration.

It is possible, however, to use the concepts involved to bracket the probable fire duration as follows:

(1) The initial fuel package occupied a volume of about 3000 ft. ${ }^{3}\left(90 \mathrm{~m}^{3}.\right)$ If the weight is assumed to be 10 to $15 \mathrm{lb} . / \mathrm{ft} .^{3}$ (160 to $240 \mathrm{~kg} / \mathrm{m}^{3}$ ) the total mass to burn is approximately 30,000 to 45,000 lbs. $(13,000 \mathrm{~kg}$ to $20,000 \mathrm{~kg}$.) Based on the 
burning rate for the initial fuel package in Table 1 , the entire content of that package would be consumed in 70 to 105 minutes. However, after the fire, an estimated 30 to $50 \%$ of the original fuel remained. This would tend to bracket the duration of flashover conditions at between 30 and 75 minutes.

(2) The maximum burn of flooring occurred near the edge of the initial fuel package. It is reasonable to conclude that this represented the portion of the flooring ignited at the start of flashover conditions and that burning at this point either terminated or grossly slowed down after conditions returned to fuel controlled burning. The depth of burn in this area appeared to be between 1.5 and 2 inches (38 to $58 \mathrm{~mm}$ ) deep. Using a typical density for wood of $40 \mathrm{lb} . / \mathrm{ft} .{ }^{3}\left(0.66 \mathrm{~g} / \mathrm{cm}^{3}\right)$ and the burning rates given for the floor in Table 1 , the estimated duration of flashover intensity burning was between 40 and 60 minutes.

(3) The partition panels were totally consumed in the fire. It is believed that these panels involved a light weight wood frame. It is also assumed that, for at least the major portion of involvement, the panels laid on the floor. On this basis, the panels were exposed to conditions close to that of the floor. The minimum dimension of the frame was probably at least 1.5 inches ( $38 \mathrm{~mm}$. ) The wood frame was also covered by a thin sheet of high pressure laminated plastic. The thickness of the plastic being about 0.06 inches $(1.5 \mathrm{~mm}$.) Following the same calculations as used for the floor and adding a brief but indeterminate time for the protection provided by the laminated plastic, it is estimated that the fire had to be in the flashed over phase for more than 40 minutes.

The prediction of fire duration is relevant to evaluating the impact that fire resistive separations could have had on the development and impact of the fire. If separations had been fire resistive, the amount of ventilation following flashover would have been limited to openings into the South Ballroom. Provided that the openings were sufficient to allow flashover to occur, the post flashover condition would persist until either the fuel was exhausted or the rate of burning dropped below the ventilation limit. Therefore, with smaller openings the duration would be longer but never more than the 70 to 105 minutes estimated as needed to consume all the available fuel. 


\section{Chapter 3 - Summary}

This report presents a series of computations which lead to a description of the tragic course of this fire that fits the information available to the author. The analysis also provides a basis for evaluating the impacts that differences in conditions, arrangements, or fire protection measures could have made in the course of events.

Additionally, this exercise demonstrates the potential value of analytical methods in understanding the course of fire and the effect of the individual materials or elements involved. It also demonstrates the utility of an engineering approach in understanding the fire potential in an existing building. By analytically imitating the impact of fire, the level of safety of a building can be appraised by simulation in a manner akin to examination of the structural capabilities of the same facility.

While this exercise was successful in meeting its objectives, it was purposely designed to use the least sophisticated instruments required to do the job. Had more sophisticated studies been made, undoubtedly additional information and understanding could have resulted.

More detailed examination and testing to discover the appropriate properties of the various materials along with large scale fire tests to imitate the fuel and conditions would provide more data and additional confidence in the results.

The computations presented herein represent a practical selection of tools in view of the resource limitations on this study. The choices were based on the author's experience and consultation with many of his colleagues at the Center for Fire Research. In each case, the method used has been described or referenced so it can be accessed by any interested party. All of the references are available through the Fire Research Information Service of the National Bureau of Standards or the author.

Since the fire, many hundreds of hours of data gathering and investigation have been carried on by various groups. It is likely that some of these have discovered information that would change the descriptions used by the author. Others may feel that different computational approaches are superior. The data and methods presented in this report will assist in any analysis that others may care to make. Also, where obligations allow, it is desireable that such analysis be made public and other views and methods of analysis be shared with the entire fire safety community to advance the state-ofthe-art.

Analyses of fires provide an excellent means of improving, testing, and evaluating the usefulness of quantitative tools. The fire protection community should make such analyses and expand the scope to include- 
proof testing as a regular aspect of fire investigation. This can only results in improved understanding. Through such understanding, improved levels of performance, economy, and acceptance of fire safety may result.

\section{Acknowledgements}

The author wishes to acknowledge the assistance and guidance provided by $\mathrm{Dr}$. James G. Quintiere. It is only through his guidance that a consistent and complete analysis. was possible. Special thanks is also due to $\mathrm{Mr}$. Peter Lee who provided engineering technical support. The consideration and cooperation of the National Response Team of the Bureau of Alcohol, Tobacco, and Firearms, the U.S. Fire Administration, and the National Fire Protection Association for on-site and after-thefact assistance, exchange of information, the provision of details and other support is gratefully acknowledged. Special thanks are due to the U.S. Fire Administration for the sectional diagrams of the building and to the National Fire Protection Association for the floor plans. 


\section{REFERENCES}

1. Interim Report and Findings of the National Fire Protection Association, Fire at the Dupont Plaza Hotel and Casino, 96 fatalities, December 31, 1986; National Fire Protection Association, Quincy, MA, 1987

2. Drysdale, Dougal; An Introduction to Fire Dynamics; Section 5.2, Burning of Solids; John Wiley and Sons; New York; 1985

3. Proposed Test Method for Heat and Visible Smoke Release Rates for Materials and Products Using an Oxygen Consumption Calorimeter, ASTM E5 Proposal P 190, American Society for Testing and Materials, Philadelphia, PA; November, 1986

4. Alpert, Ronald L. and Ward, Edward J.; Evaluating Unsprinklered Fire Hazards; SFPE Technology Report 82-2; Society of Fire Protection Engineers; Boston, MA; 1983

5. NFPA 204M Guide for Smoke and Heat Venting; National Fire Protection Association, Quincy, MA, 1985

6. Gross, Daniel; Data Sources for Parameters Used in Predictive Modeling of Fire Growth and Smoke Spread; NBS Report NBSIR 85-3223, National bureau of Standards; Gaithersburg, MD; 1985

7. Nelson, Harold E.; Concepts for Life Safety Analysis; IN: The 7th Society of Fire Protection Engineers Symposium. Quantitative Methods for Life Safety Analysis. University of Maryland, College Park MD. March 5-7, 1986.

8. Fleming, Russe11 P.; "Update on the Quick Response Sprinkler Research Program"; Fire Journal; Vol. 81 No.1; January/February 1987; pp. $34-38$

9. Mitler, Henri E. and Rockett, John A.; Users' Guide to First, A Comprehensive Single-Room Fire Mode1; NBS report to be published, National Bureau of Standards, Gaithersburg, MD

10. Drysdale, Dougal; An Introduction to Fire Dynamics; Section 10.1, Regimes of Burning; John Wiley and Sons; New York; 1985

11. Quintiere, J. S.; A Simple Correlation for Predicting Temperature in a Room Fire; Report NBSIR 82-2712; National Bureau of Standards; Gaithersburg, MD, 1983 
12. Nelson, H. E.; "FIREFORM" - A Computerized Collection of Convenient Fire Safety Computations; Report NBSIR 86-3308; National Bureau of Standards; Gaithersburg, MD; 1986

13. Nelson, H. E.; UTEMP, a computer program for estimating the upper level temperature in a vented room. This program uses the formulas contained in reference 11 . The program was developed for the analysis contained in this report and will be separately released at a later date.

14. Cooper, L. Y., and Stroup, D. W.; Calculating Available Safe Egress Time from Fires; Report NBSIR 82-2587; National Bureau of Standards; Gaithersburg, MG; 1982

15. Walton, W. D.; ASETB A Room Fire Program for Personal Computers; Report NBSIR 85-3144, National Bureau of Standards; Gaithersburg, MD; 1985

16. Nelson, H. E.; ROOMFIR, a computer program for estimating upper level temperature, interface level, heat actuated devise response, and vision distance and oxygen concentration in the smoke layer of an unvented room. This program uses formulas and procedures covered in references 12, 14, 17 and 18. The program was developed for the analysis contained in this report and will be separately released at a later date.

17. Nelson, H. E.; HOTVENT, a computer program for estimating the mass flow and level of the neutral plane in an opening venting high temperature fire products from a space fully involved in fire. The procedure is that contained in references 16 and 28 and discussed in Appendix G. This program was developed for the analysis contained in this report and will be separately released at a later date.

18. Kawagoe, K.D., and Sekine,T.; Estimation of Fire Temperature - Time Curve for Rooms, Ministry of Construction, Japanese Government, June 1963.

19. Lawson, J. R., and Quintiere, J. G.; "Slide Rule Estimates of Fire Growth"; Fire Technology, Vol 21, No. 4, pp. 267-292; National Fire Protection Association, Quincy, MA; 1985.

20. Huggett, $C$,; Rate of Heat Release - Implications for Engineering Decisions by C. Huggett. IN: Engineering Applications of Fire Technology Workshop Proceedings. April 16-18, 1980, NBS Gaithersburg, MD. Co-Sponsored by Society of Fire Protection Engineers and Center for Fire Research. H.E. Nelson, Editor; Society of Fire Protection Engineers; Boston, MA

21. Mulholland, G.; Personal communication February 14, 1987 
22. Quintiere, James G., An Assessment of Correlations Between Laboratory and Full-Scale Experiments for the FAA Aircraft Fire Safety Program, Part 1: Smoke; NBSIR 82-2508; National Bureau of Standards, Gaithersburg, MD; July 1982.

23. Thomas, P. H.; Buoyant Diffusion Flames. Letter to Combustion and Flame, Vol. 4, No. 4, pp 381-382, 1960.

24. Yokoi, S.; Study on the Prevention of Fire-Spread Caused by Hot Upward Current. Building Research Institute Report NO. 34, Ministry of Construction, Japanese Government, 1960.

25. Thomas, P. H., and Law, Margaret; The Projection of Flames From Burning Buildings, F.R. Note NO. 921, Joint Fire Research Organization, Borehamwood, England

26. Quintiere, J., Harkleroad, M., and Hasemi, Y.; Wall Flames and Implications for Upward Flame Spread; Report DOT/FAA/CT-85/2; U.S. Department of Transportation Federal Aviation Administration, Technical Center, Atlantic City, NJ, June 1985

27. Quintiere, J. and Harkleroad, M.; New Concepts for Measuring Flame Spread Properties; Symposium on Application of Fire Science to Fire Engineering; American Society for Testing and Materials and the Society of Fire Protection Engineers; Denver, CO; June 27, 1984

28. Alpert, R. L.; Calculation of Response Time of Ceiling-Mounted Fire Detectors; Fire Technology, Vol/ 8, No. 3, 181-195; Aug. 1972

29. Evans, D. D. ; DETACT-QS, A computer program for estimating the actuation response of heat detectors. Program is available from Society of Fire Protection Engineers, Boston, MA

30. Evans, D. D.;Calculating Fire Plume Characteristics in a Two-Layer Environment; Fire Technology, Vol. 20, No. 3, 39-63, Aug. 1984

31. Heskestad, G. and Delichatsios; Environment of Fire Detectors Phase 1: Effects of Fire Size, Ceiling Heights, and Material, Volume II - Analysis, Technical Report Series No. 22427, RC 77-T-11, Factory Mutual Research Corporation; Norwood, MA; 1977

32. Steckler, K.D., Quintiere, J.G., Rinkinen, W.J., Flow Induced by Fire in a Compartment, Nineteenth Symposium (International) on Combustion, The Combustion Institute, pp. 913-920, 1982

33. Quintiere, J.G., Steckler, K., Corley, D., An Assessment of Fire Induced Flows in Compartments, Fire Science and Technology, Vo1. 4, No. 1, p. 1-14, June 1984 


\section{Estimated Post Flashover Burning Rates of Materials in South Ballroom}

\begin{tabular}{|c|c|c|c|c|}
\hline Material & $\begin{array}{l}\text { Exposed } \\
\text { Surface Area } \\
\text { sq.ft. (sq.m) }\end{array}$ & $\begin{array}{l}\text { Heat Flux } \\
\text { btu/sq.ft/- } \\
\text { min } \\
(\mathrm{kW} / \mathrm{sq} \cdot \mathrm{m})\end{array}$ & $\begin{array}{l}\text { Heat of } \\
\text { Gassifica- } \\
\text { tion } \\
\mathrm{kJ} / \mathrm{g}\end{array}$ & $\begin{array}{l}\text { Post } \\
\text { F1ashover } \\
\text { Pyrolysis } \\
\text { Rate } \\
\text { 1b/min } \\
(\mathrm{g} / \mathrm{s})\end{array}$ \\
\hline $\begin{array}{l}\text { Initial Fuel } \\
\text { Package }\end{array}$ & $\begin{array}{l}825 \\
(77)\end{array}$ & ${ }^{7}(80)$ & 2 & $\begin{array}{l}407 \\
\quad(3080)\end{array}$ \\
\hline $\begin{array}{l}\text { Fabric Wal1 } \\
\text { Covering }\end{array}$ & $\begin{array}{l}980 \\
(91)\end{array}$ & $\begin{array}{l}7 \\
(80)\end{array}$ & 8 & $\begin{array}{l}120 \\
(910)\end{array}$ \\
\hline Partition & $\begin{array}{l}600 \\
(56)\end{array}$ & ${ }^{7}(80)$ & 2 & $\begin{array}{l}296 \\
(2240)\end{array}$ \\
\hline $\begin{array}{l}\text { Stacked } \\
\text { Chairs }\end{array}$ & $\begin{array}{l}150 \\
(15)\end{array}$ & ${ }^{7}(80)$ & 2 & $\begin{array}{l}79 \\
(600)\end{array}$ \\
\hline $\begin{array}{l}\text { Wood Floor } \\
(50 \%)\end{array}$ & $\begin{array}{l}1050 \\
(108)\end{array}$ & $\begin{array}{r}1.75 \\
(20)\end{array}$ & 2 & $\begin{array}{l}127 \\
(960)\end{array}$ \\
\hline $\begin{array}{l}\text { Total Burning } \\
\text { Rate }\end{array}$ & & & & $\begin{array}{l}1029 \\
(7790)\end{array}$ \\
\hline
\end{tabular}




\section{TABLE 2}

Estimated Pre-Flashover Energy Flow From South Ballroom to North Ballroom

\begin{tabular}{|c|c|c|c|c|}
\hline & Temp. & Mass Flow & Fue1 & Energy Release \\
\hline Time & Rise & 1bs/min & Fraction & Fuel Flow Total \\
\hline$t+\sec$ & $F \quad(C)$ & $(g / s)$ & 8 & $\mathrm{btu} / \mathrm{sec} \quad(\mathrm{kW})$ \\
\hline 60 & 102 (39) & 31 (23) & .055 & $\begin{array}{l}12 \\
(13)\end{array}$ \\
\hline 120 & 147 (64) & 155 (117) & .166 & $\begin{array}{l}122 \\
(129)\end{array}$ \\
\hline 180 & $223(106)$ & $228(210)$ & .396 & $\begin{array}{ll}211 & 428 \\
(222) & (452)\end{array}$ \\
\hline 240 & ${ }^{335}$ (168) & ${ }^{781}(591)$ & .732 & $\begin{array}{ccc}1149 & 941 & 2090 \\
(1211) & (992) & (2203)\end{array}$ \\
\hline 300 & 487 (253) & $829(627)$ & 1.08 & $\begin{array}{l}1799 \quad 1505 \quad 3303 \\
(1896) \quad(1586) \quad(3482)\end{array}$ \\
\hline 360 & ${ }^{645}(341)$ & ${ }^{886}(670)$ & 1.48 & $\begin{array}{lll}2634 & 2167 & 4801 \\
(2776) & (2284) & (5060)\end{array}$ \\
\hline 420 & ${ }^{803}(428)$ & ${ }^{935}(707)$ & 1.95 & $\begin{array}{l}3662 \quad 2910 \quad 6573 \\
(3860) \quad(3067) \quad(6928)\end{array}$ \\
\hline 480 & 962 (517) & ${ }^{968}(732)$ & 2.49 & $\begin{array}{ccc}4842 & 3589 & 8431 \\
(5104) & (3783) & (8887)\end{array}$ \\
\hline 540 & $1093(589)$ & 1031 (280) & 3.18 & $\begin{array}{l}6589 \quad 4365 \quad 10,954 \\
(6945) \quad(4602)(11,545)\end{array}$ \\
\hline 590 & $1112(600)$ & $910(688)$ & 6.51 & $\begin{array}{lll}11,898 & 3917 & 15,815 \\
(12,541) & (4128)(16,669)\end{array}$ \\
\hline
\end{tabular}


ํํำ

की 00

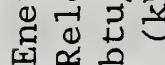

กิ

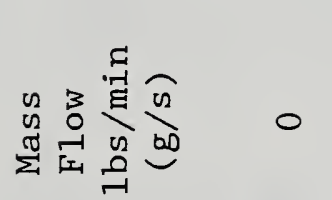

苟点齐

के ڤ

m 4

牙 $\begin{gathered}3 \\ 0\end{gathered}$

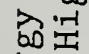

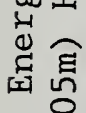

के

$>$

点

도엄

is 5

당

(4)

藏

.

ज्ञ

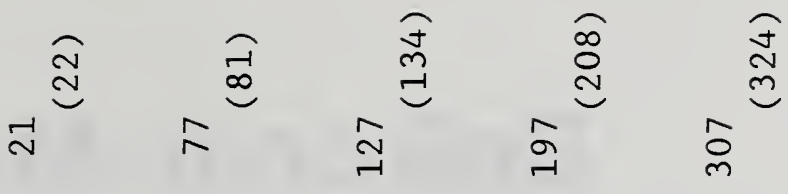

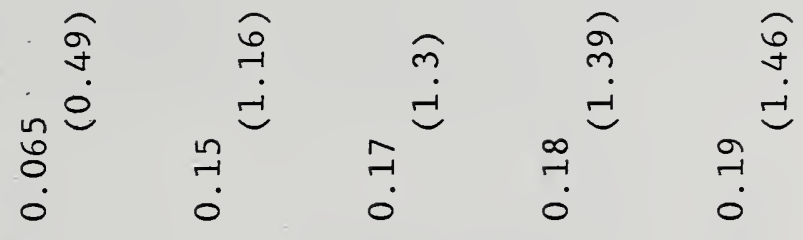

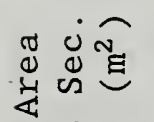

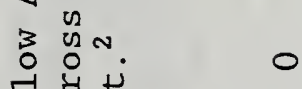

㞋过茁

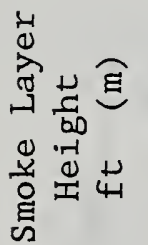

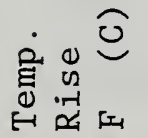

道獣

을

으

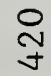

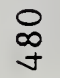

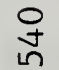

กำ 


\section{Ballroom Area Level}

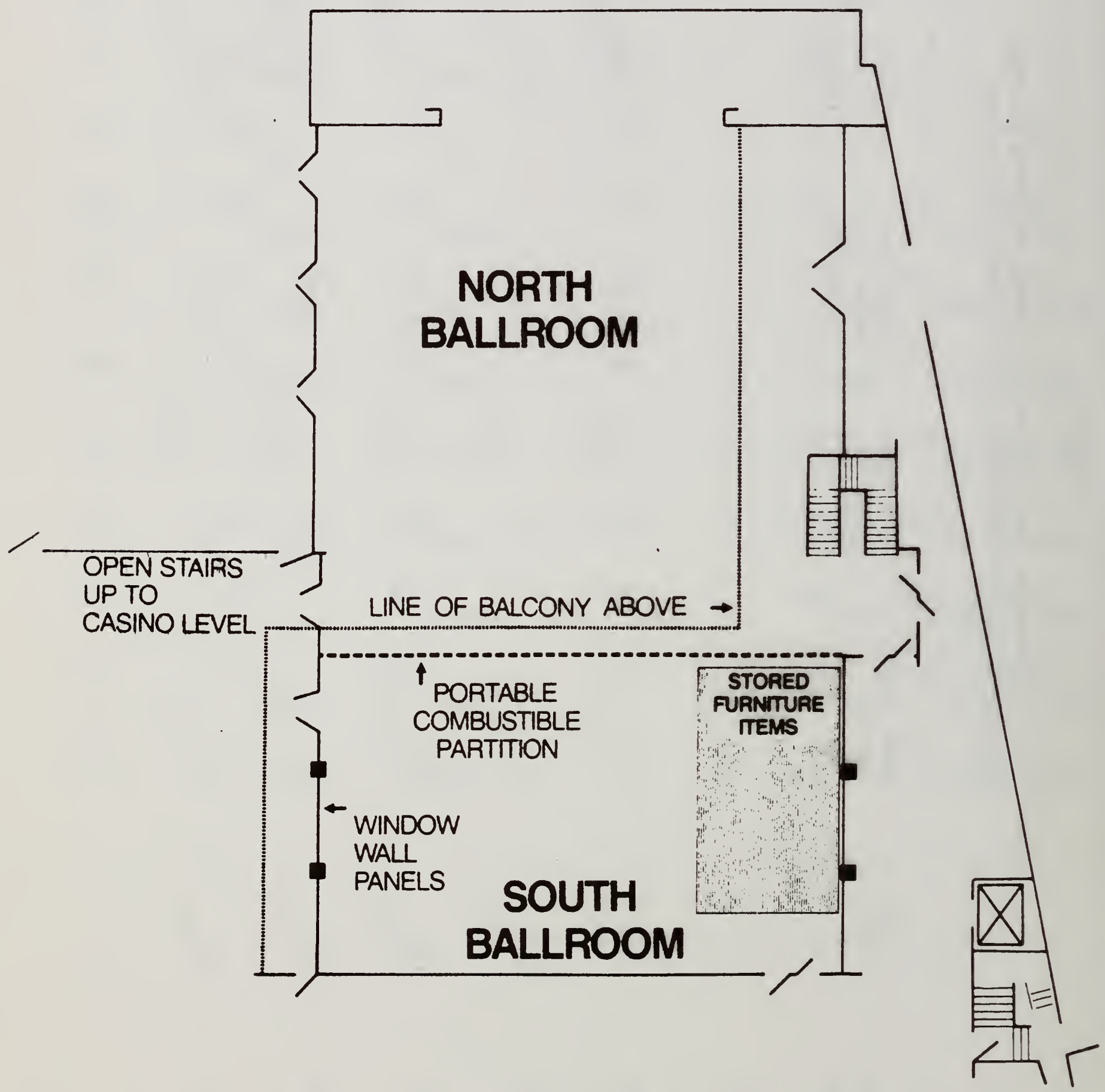

Figure 1. Partial Floor Plan of Ground Floor 


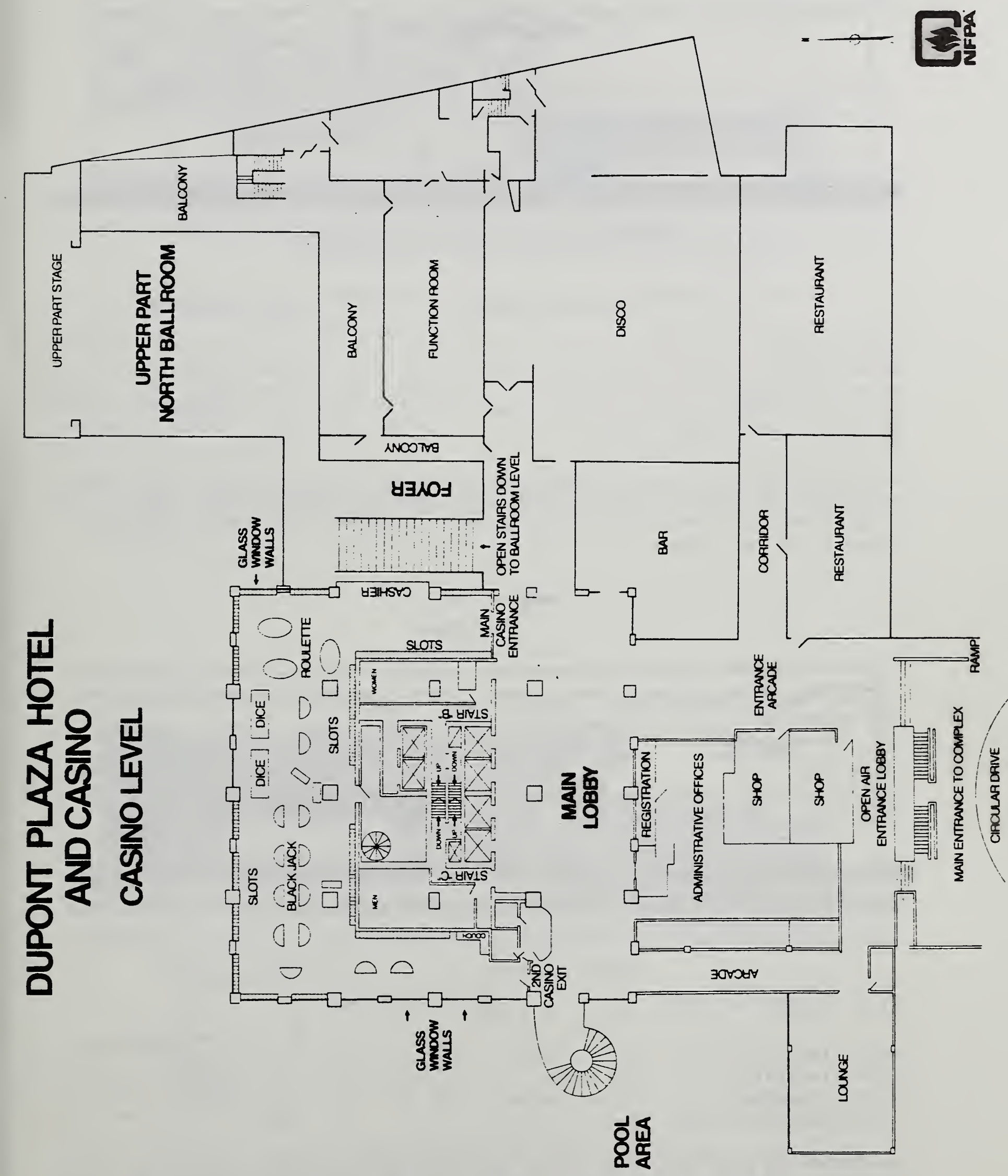




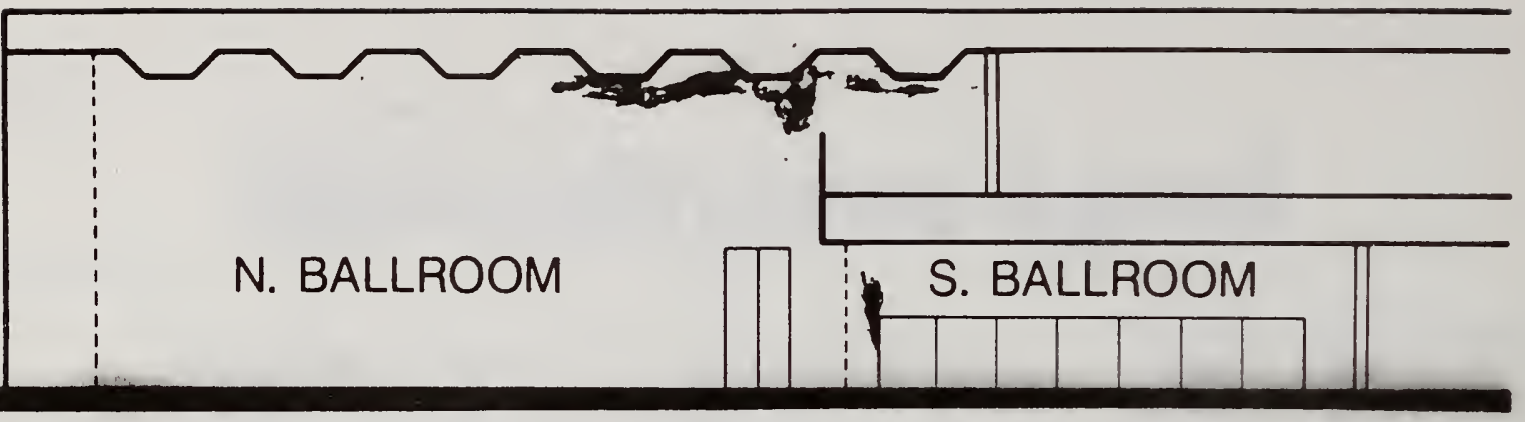

FIGURE 3. SITUATION IN BALLROOM COMPLEX AT T+6O SECONDS

NORTH BALLROOM

FLAME HEIGHT

SMOKE LAYER

SMOKE TEMPERATURE

VISION DISTANCE

OXYGEN CONCENTRATION

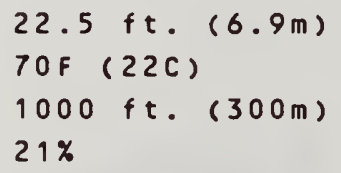

SOUTH BALLROOM

$4.5 \mathrm{ft} .(1.5 \mathrm{~m})$

$8 \mathrm{ft} .(2.5 \mathrm{~m})$

$102 \mathrm{~F}$ (39C)

$58 \mathrm{ft} .(18 \mathrm{~m})$

$21 \%$

ANY SMOKE DETECTOR THAT HAD BEEN LOCATED IN THE SOUTH BALLROOM WITHIN ABOUT 40 ft. (12 m) OF THE FIRE SOURCE WOULD HAVE DETECTED SMOKE BY THIS TIME.

A QUICK RESPONSE SPRINKLER LOCATED DIRECTLY OVER THE FIRE WOULD ALSO HAVE OPERATED BY THIS TIME.
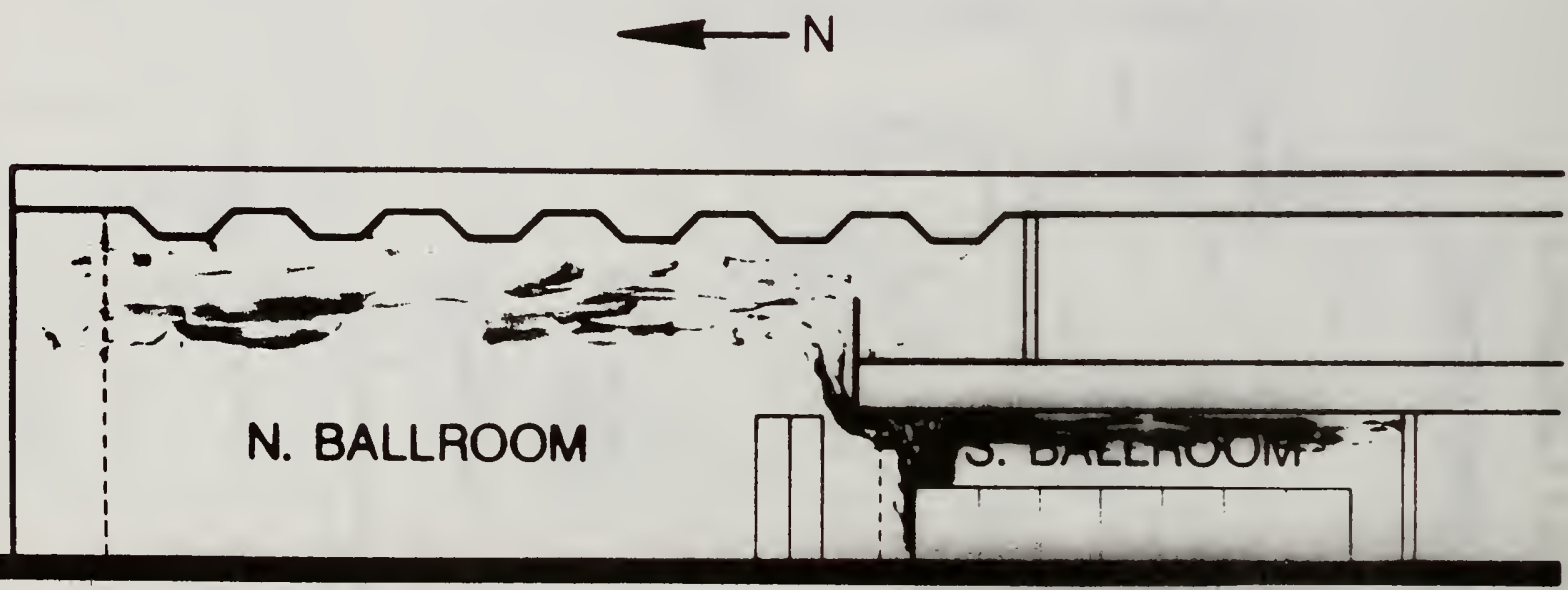

FIGURE 4. SITUATION IN BALLROOM COMPLEX AT $T+180$ SECONDS

$\begin{array}{lll} & \text { NORTH BALLROOM } & \text { SOUTH BALLROOM } \\ \text { FLAME HEIGHT } & 13 \mathrm{ft}(3.9 \mathrm{~m}) & 12 \mathrm{ft}(3.5 \mathrm{~m}) \\ & & (2-4 \mathrm{ft} E X T E N S I O N) \\ \text { SMOKE LAYER } & 19 \mathrm{ft}(6 \mathrm{~m}) & 6 \mathrm{ft}(1.8 \mathrm{~m}) \\ \text { SMOKE TEMPERATURE } & 82 \mathrm{~F}(28 \mathrm{C}) & 354 \mathrm{~F}(179 \mathrm{C}) \\ \text { VISION DISTANCE } & 72 \mathrm{ft}(22 \mathrm{~m}) & 18 \mathrm{ft}(6 \mathrm{~m}) \\ \text { OXYGEN CONCENTRATION } & 21 \% & 20 \%\end{array}$

ANY SPRINKLER HEAD HAVING AN RTI OF LESS THAN 200 WITHIN 15 FEET OF THE FIRE SOURCE OR HIGHER RTI RATED HEAD WITHIN 7 FEET OF THE SOURCE WOULD HAVE ACTUATED. 

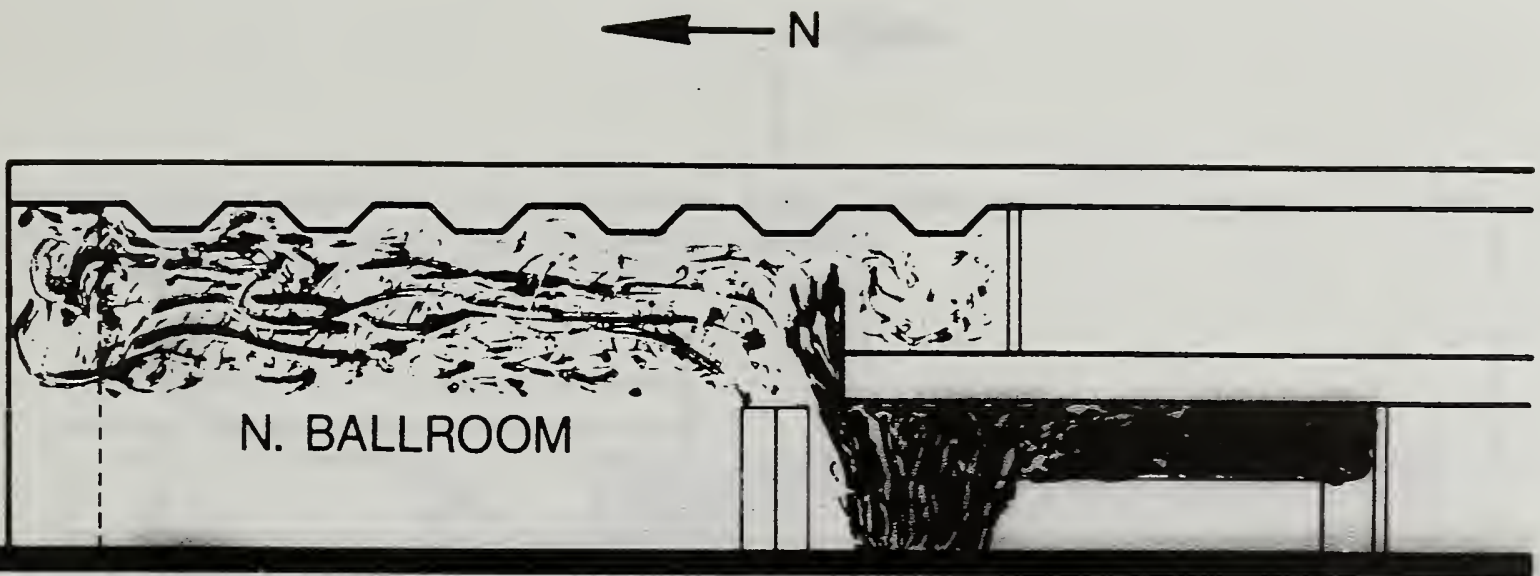

FIGURE 5. SITUATION IN BALLROOM COMPLEX AT T+420 SECONDS

NORTH BALLROOM

FLAME HEIGHT

SMOKE LAYER

SMOKE TEMPERATURE

VISION DISTANCE

OXYGEN CONCENTRATION
$18.0 \mathrm{ft} .(5.5 \mathrm{~m})$

$10 \mathrm{ft.}(3 \mathrm{~m})$

$256 \mathrm{~F}(125 \mathrm{C})$

$6 \mathrm{ft} .(2 \mathrm{~m})$

$13 \%$
SOUTH BALLROOM

$23 \mathrm{ft} .(3.5 \mathrm{~m})$

( $13-20 \mathrm{ft}$. EXTENSION)

$6 \mathrm{ft} .(1.8 \mathrm{~m})$

$365 \mathrm{~F}(185 \mathrm{C})$

$15 \mathrm{ft} .(5 \mathrm{~m})$

$12 \%$

AT THIS POINT SMOKE STARTS TO FLOW UNDER THE SOFFIT OF THE OPEN 10 FOOT HIGH DOOR BETWEEN THE NORTH BALLROOM AND THE FOYER.

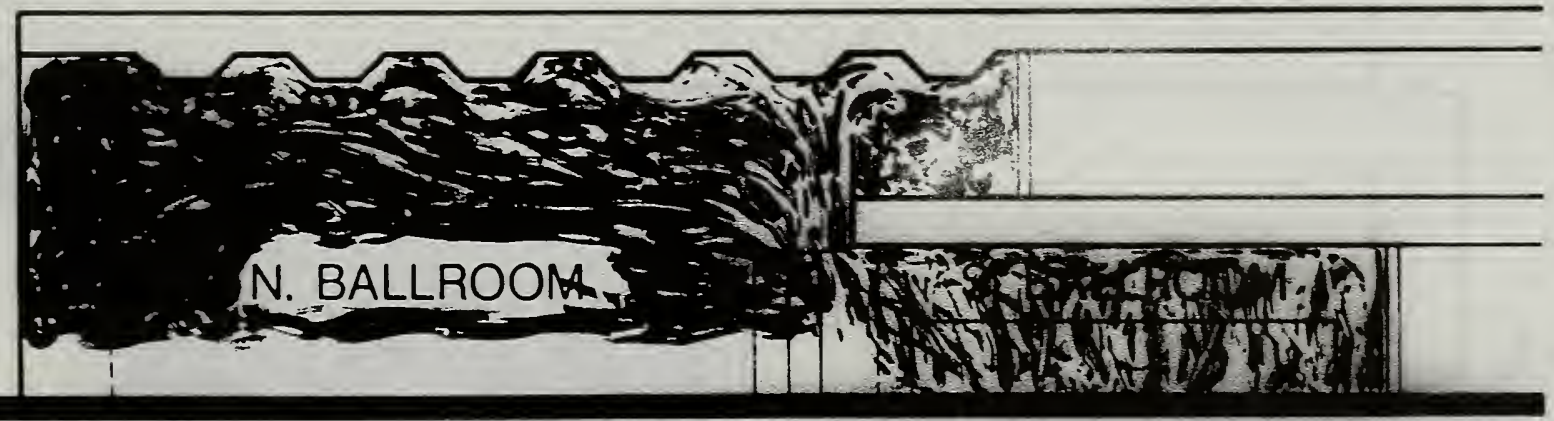

FIGURE 6. SITUATION IN BALLROOM COMPLEX JUST PRIOR TO FLASHOVER (T+58O SEC.)

NORTH BALLROOM
$6 \mathrm{ft} \cdot(1.8 \mathrm{~m})$
$500 \mathrm{~F}(310 \mathrm{C})$
$4 \mathrm{ft} \cdot(1 \mathrm{~m})$
$7 \mathrm{x}$

SMOKE LAYER SMOKE TEMPERATURE VISION DISTANCE

OXYGEN CONCENTRATION

\section{SOUTH BALLROOM \\ $7 \mathrm{ft} .(2.1 \mathrm{~m})$ \\ $1112 \mathrm{~F}(600 \mathrm{C})$ \\ $3 \mathrm{ft} .(1 \mathrm{~m})$ \\ $7 x$}

WiTH FLASHOVER AT ABOUT T+583 SECONDS THE SMOKE TEMPERATURE IN THE SOUTH BALLROOM RISES TO OVER 15OOF (815C); SMOKE LEVELS GO TO NEARLY THE FLOOR LEVEL; VISION DROPS TO ZERO; AND THE OXYGEN CONTENT IN THE SMOKE AND GASSES IN BOTH BALLROOM APPROACHES ZERO. HITH FLASHOVER THE GLASS PARTITION BETWEEN THE SOUTH BALLROOM AND THE FOYER FAILS. 


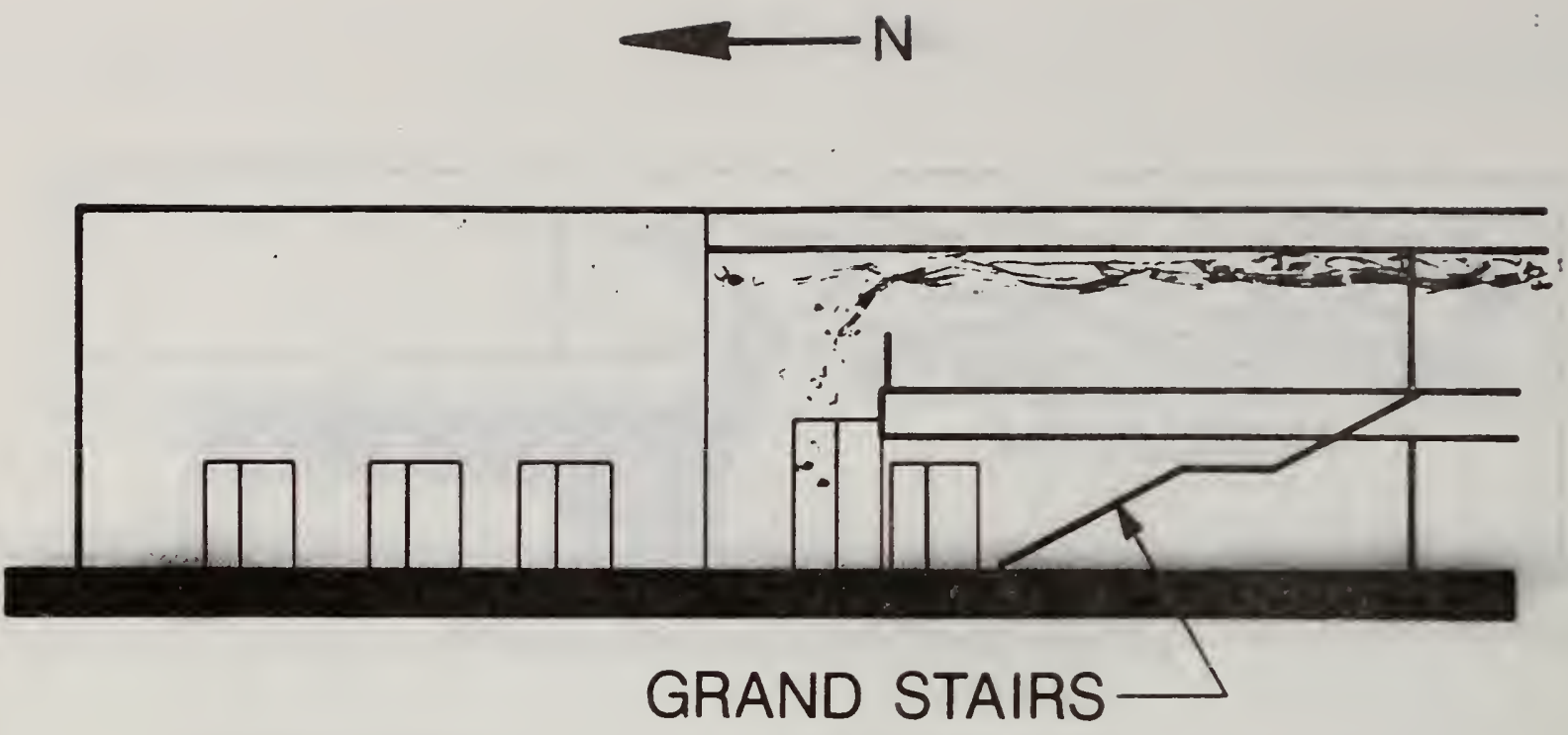

\section{FIGURE 7. SITUATION IN FOYER AND LOBBY FROM $t+420$ TO $t+580$ SECONDS.}

HOT GASES FLOW FROM DOOR BETHEEN NORTH BALLROOM AND FOYER. ACTUAL ENERGY CONTENT OF THESE GASES IS SLIGHT. CONDITIONS LISTED ARE AT T+58O SECONDS.

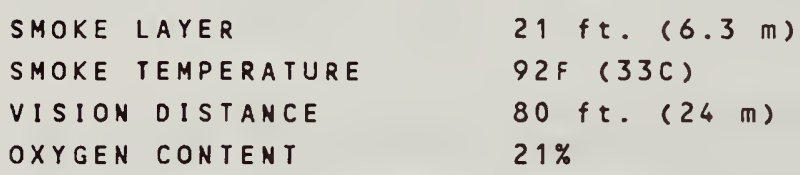

THE CONDITIONS DESCRIBED EXISTED IN THE FOYER AND LOBBY. THE LAYER DID NOT BECOME DEEP ENOUGH TO PASS UNDER THE DOOR WAY SOFFIT TO THE CASINO OR INTO OTHER SPACES SEPARATED FROM THE LOBBY BY DOOR WAYS.
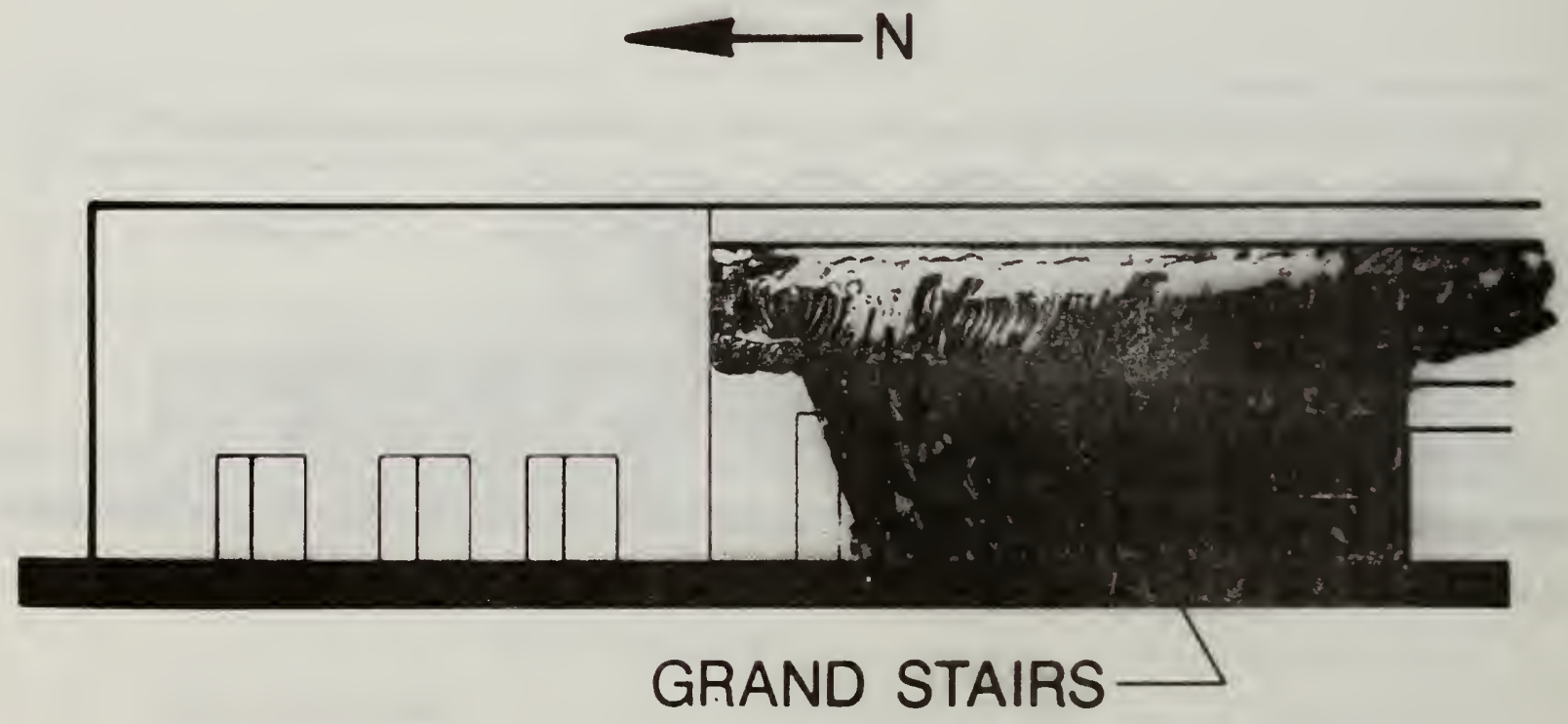

FIGURE 8. SITUATION IN FOYER FOLLOWING FLASHOVER OF SOUTH BALLROOM T+6OO SECONOS.

FLAME HEIGHT/EXTENSION

FLAME LAPS BETHEEN $1 / 2$ AND $3 / 4$ THE HIOTH OF THE TIMBER CEILING.

SMOKE LAYER

SMOKE TEMPERATURE

VISION DISTANCE

OXYGEN CONTENT

ABOUT 10 . 12 ft. $(3.3 .5 \mathrm{~m})$ ABOVE THE FLOOR.

ABOUT $900 F(480 C)$

NIL

NEAR ZERO

A SHEET OF FLAME AT LEAST AS HIDE AS THE OPENING CAUSED BY FAILURE OF THE GLASS PARTITION BETHEEN THE SOUTH BALLROOM AND THE FOYER (36FT. (1I M)) RISES FROM THE PARTITION OPENING AND ACROSS MOST OF THE TIMBER CEILING OF THE FOYER. 


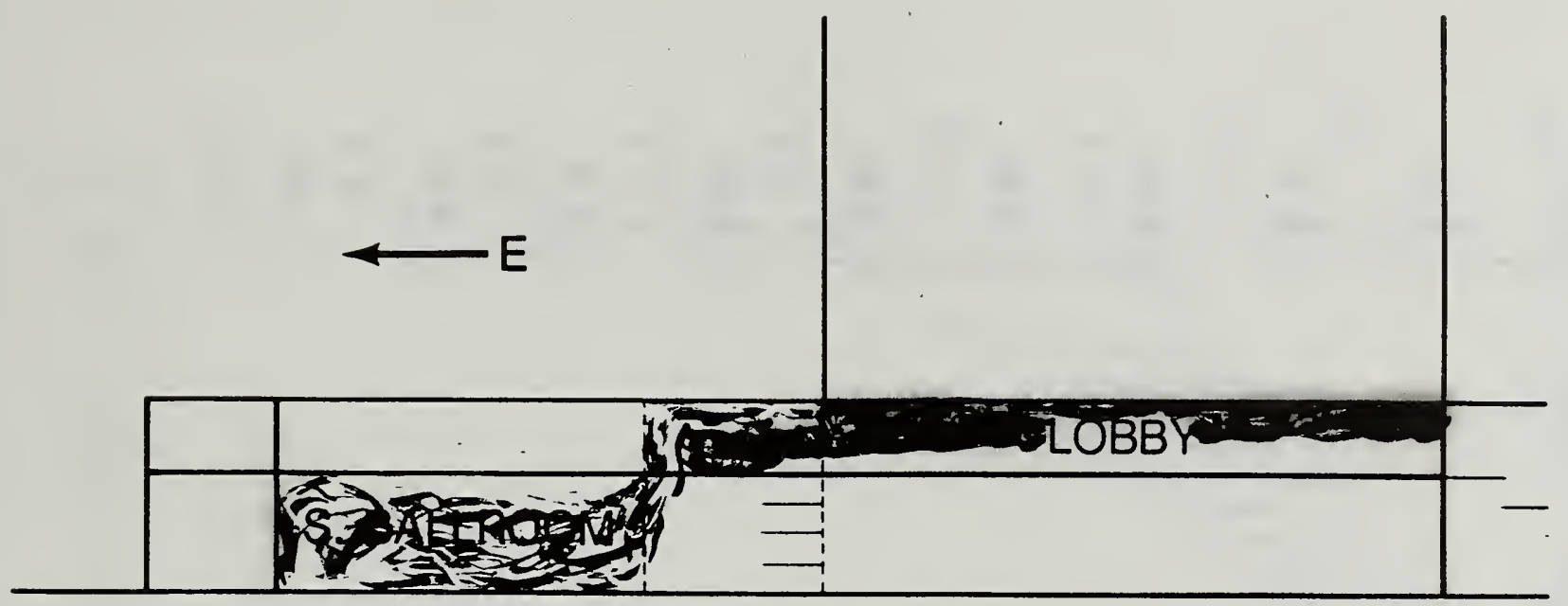

FIGURE 9. SITUATION IN LOBBY FROM FLASHOVER OF THE SOUTH BALLROOM (ABOUT T+59O SECONDS TO ABOUT $T+630$ SECONDS.

SMOKE FLOWS THROUGH THE LOBBY AT ABOUT $2.2 \mathrm{ft./SEC.} \mathrm{(1} \mathrm{m/s.)}$

SMOKE ENTERS FROM FOYER AT ABOUT $1000 \mathrm{~F}$ (540C.)

SMOKE TEMPERATURE DROPS AS IT TRAVERSES LOBBY BUT IS STILL INTOLERABLE AS IT EXITS FAR END OF LOBBY.

SMOKE IS OPAQUE AND HAS LETHAL CONCENTRATION OF CARBON MONOXIDE.

SMOKE BLOCKS EAST DOOR TO CASINO ALMOST IMMEDIATELY AFTER FLASHOVER OF SOUTH BALLROOM AND WEST DOOR ABOUT 40 SECONDS LATTER.

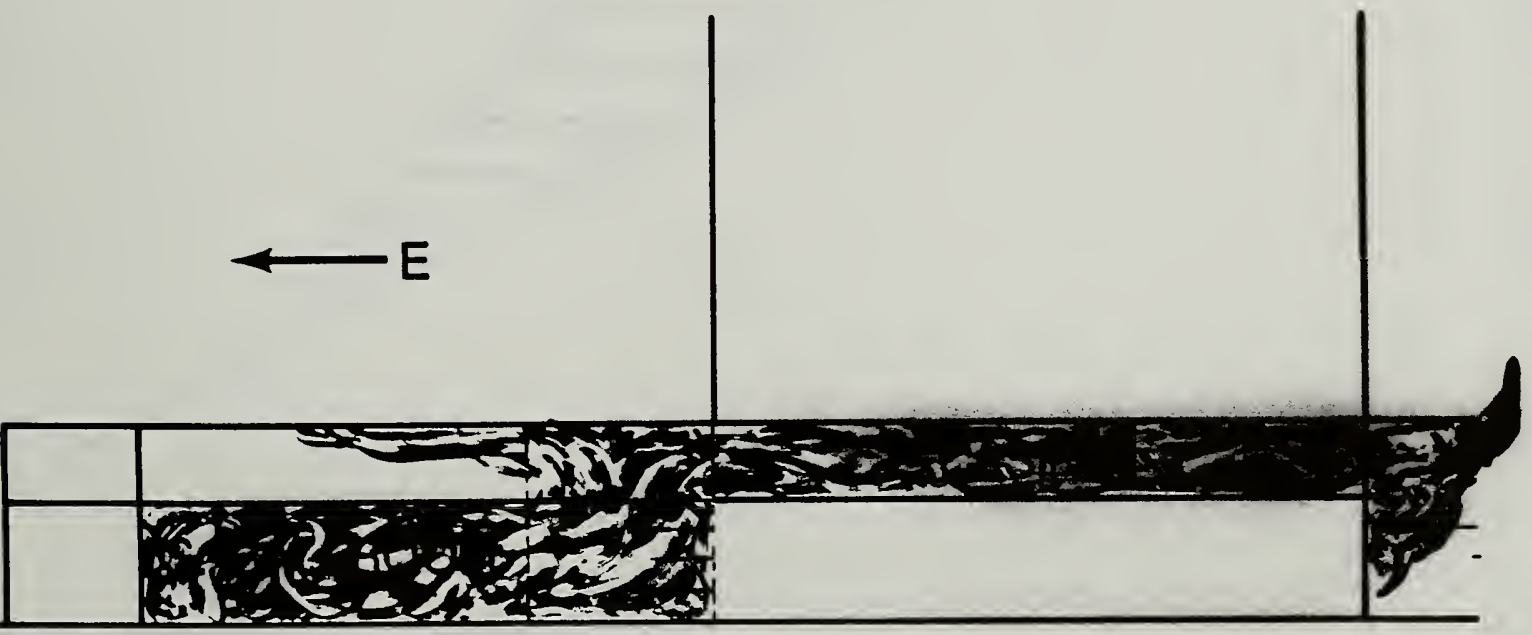

FIGURE 10. SITUATION IN CASINO FOLLOWING BREAKAGE OF GLASS PARTITION BETWEEN CASINO AND FOYER. ABOUT $t+720$ TO $t+740$ SECONDS.

FLAME AND FUEL RICH SMOKE ARE DISCHARGED FROM THE FOYER INTO THE CASINO. A FLAME FRONT TRAVERSES THE CASINO AT A SPEED OF ABOUT 6 ft./SEC. ( 2 m/S.) FLAME COURSES CASINO IN ABOUT 20 SECONDS.-

FLAME BREAKS OUT HEST HINDOHS. EDDIES LAP TONGUES OF FLAME DOWN TO POOL DECK LEVEL. 


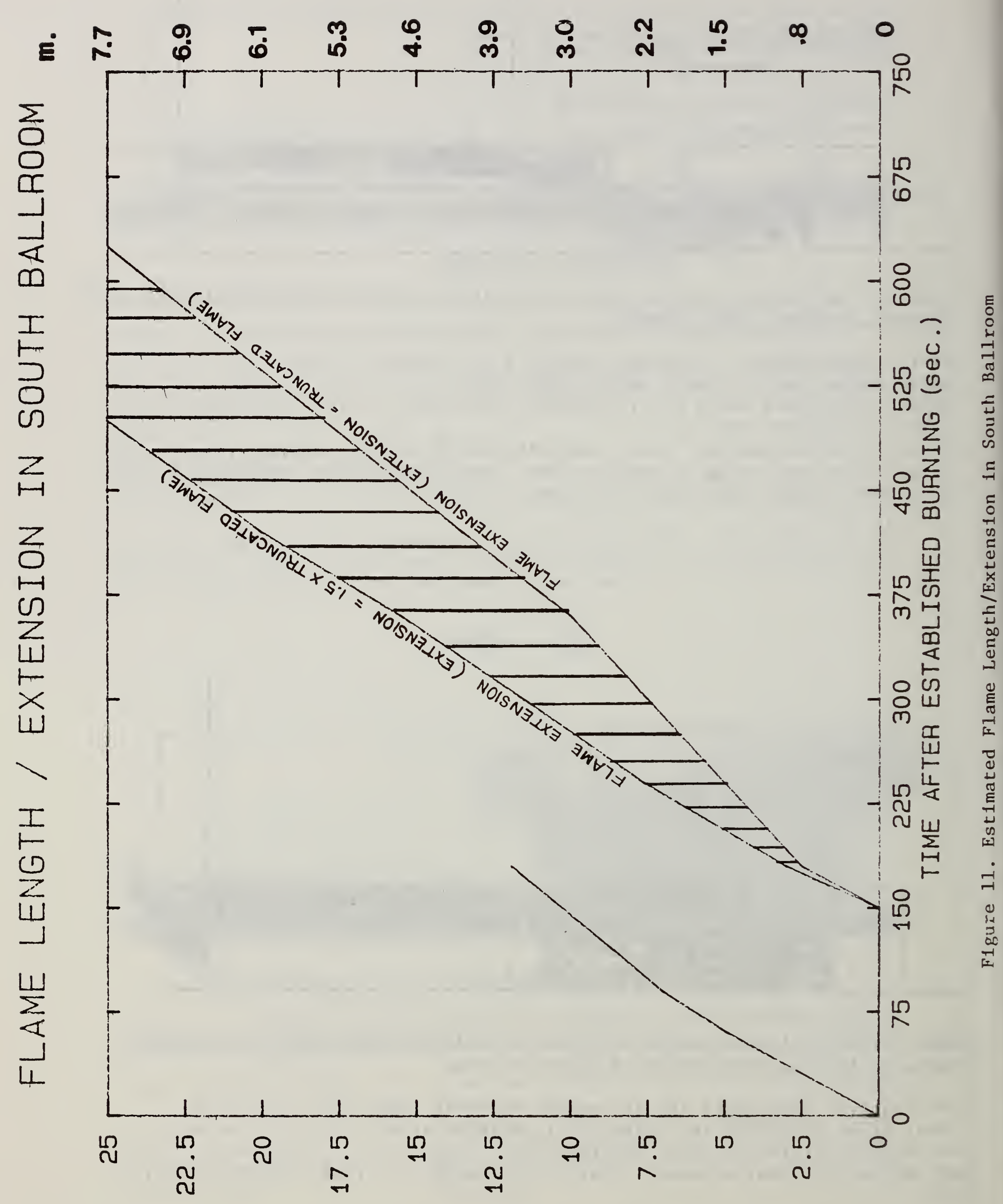

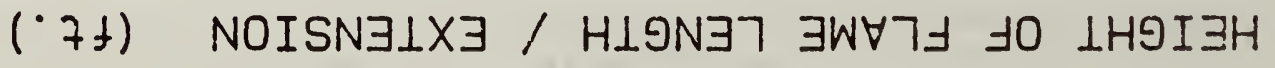




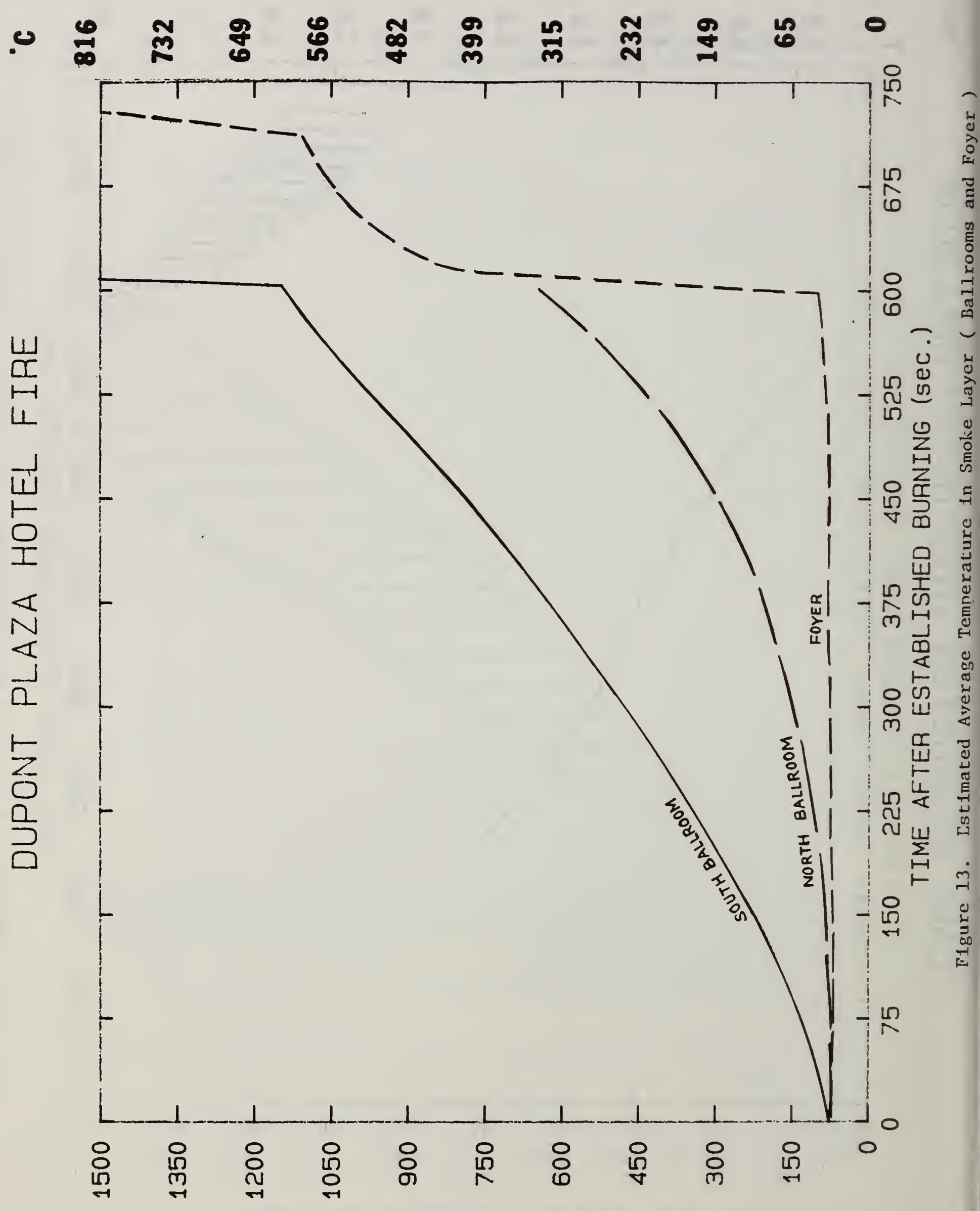

(ঊ) $\exists \forall \cap \perp \forall \forall \exists d W \exists \perp \quad \forall \exists \wedge \forall 7 \quad \forall \exists d d \cap$ 


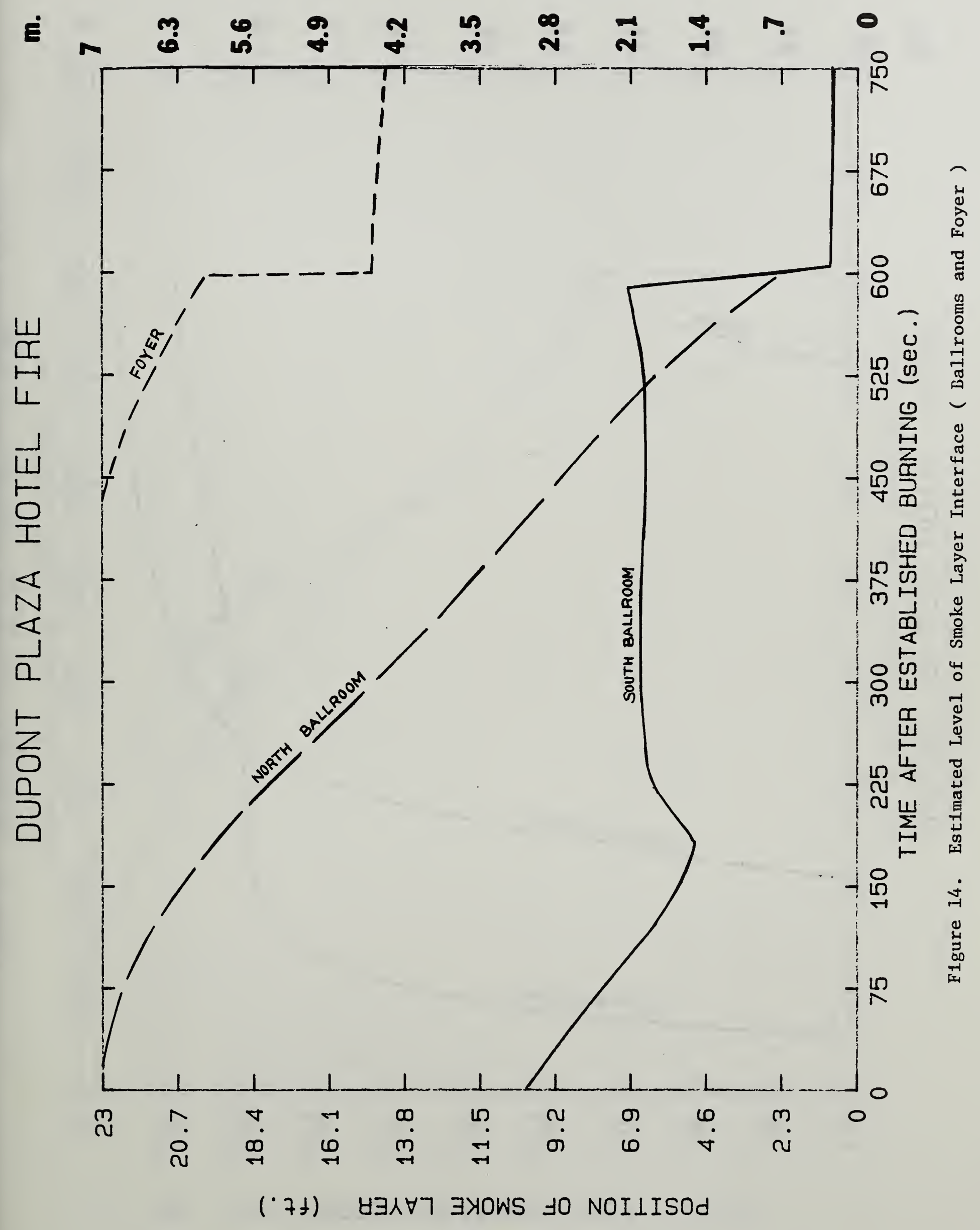




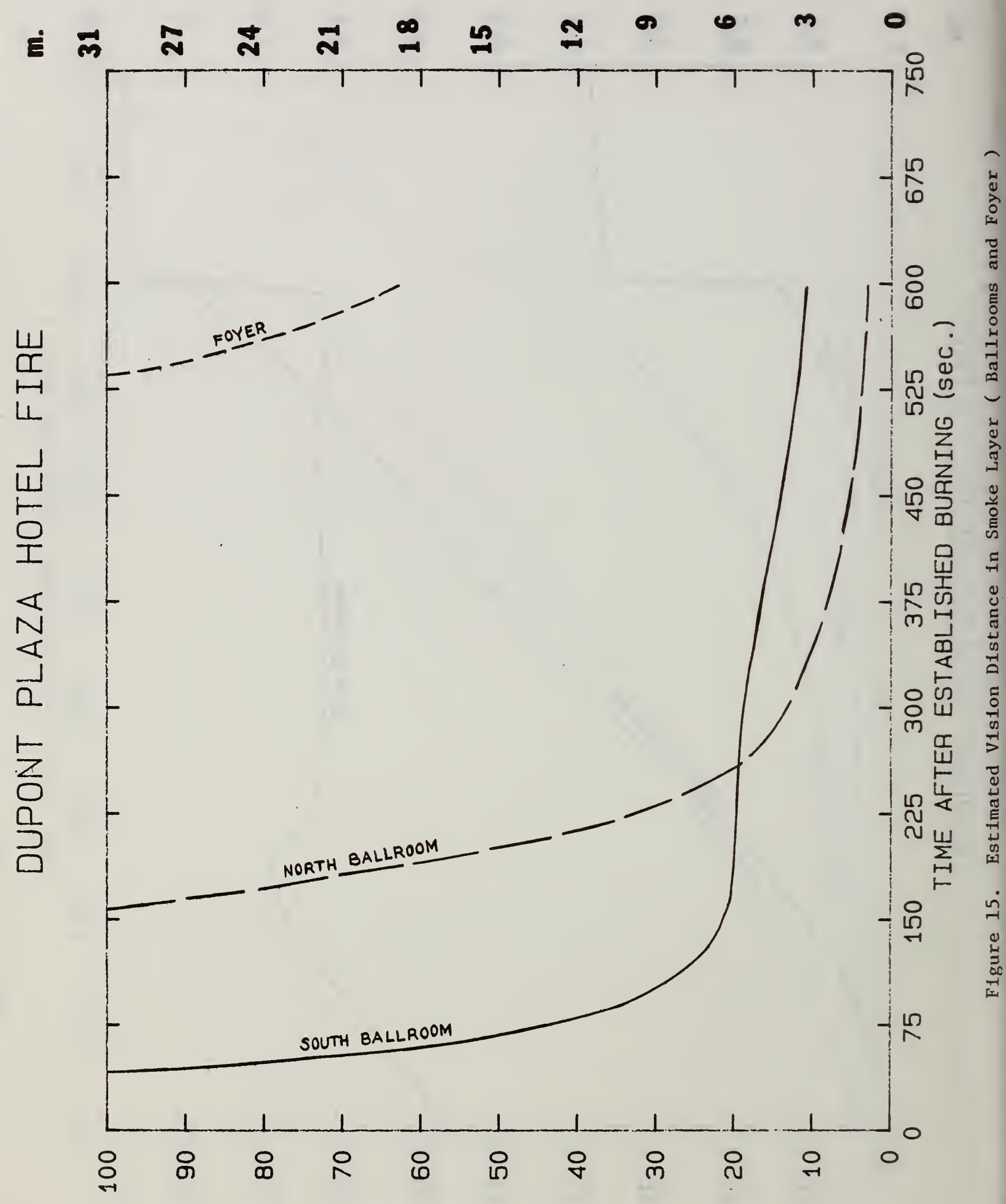

$(\cdot 7 t) \quad \exists$ ONHISIO NOISIA 


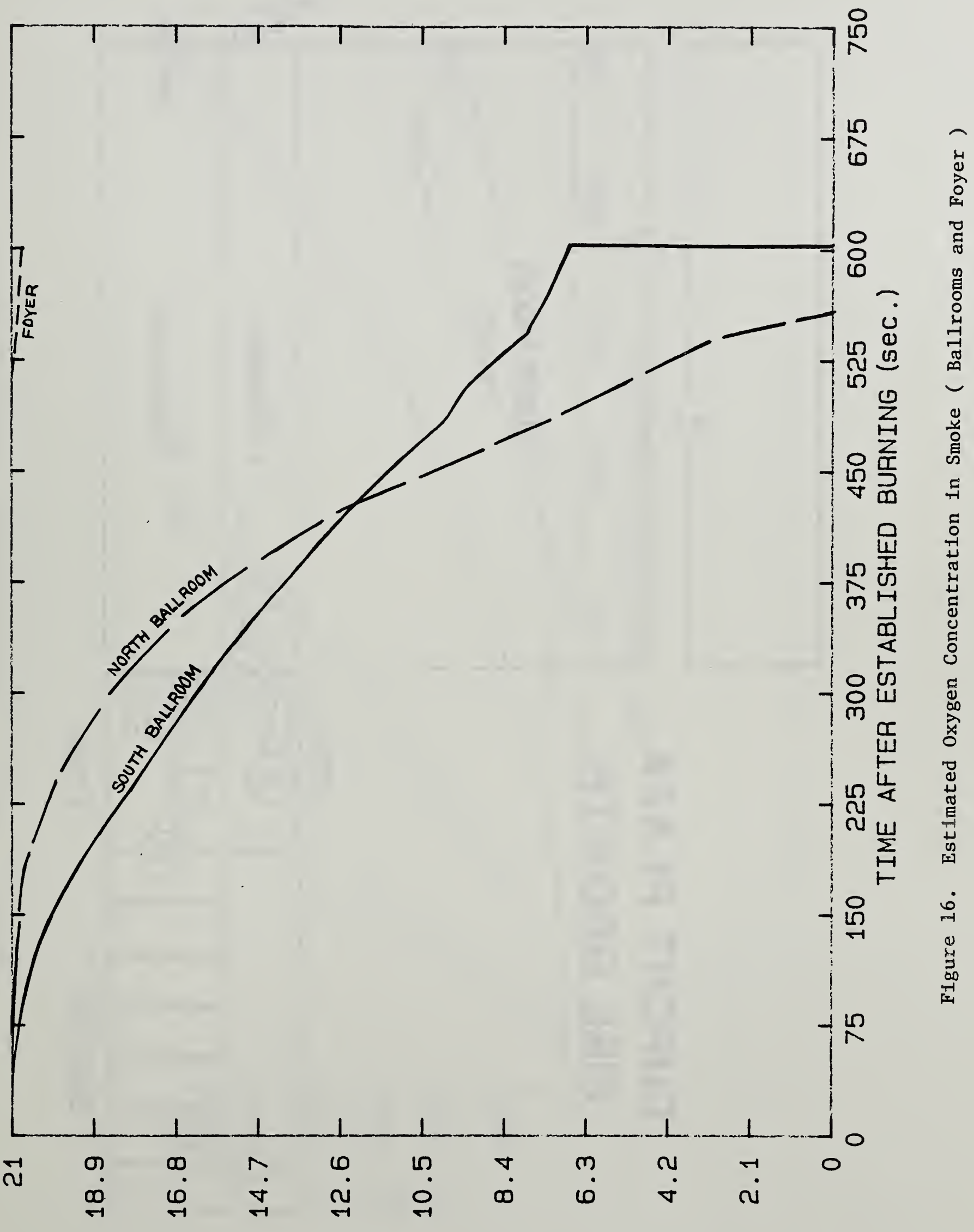

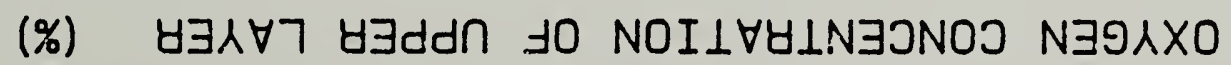




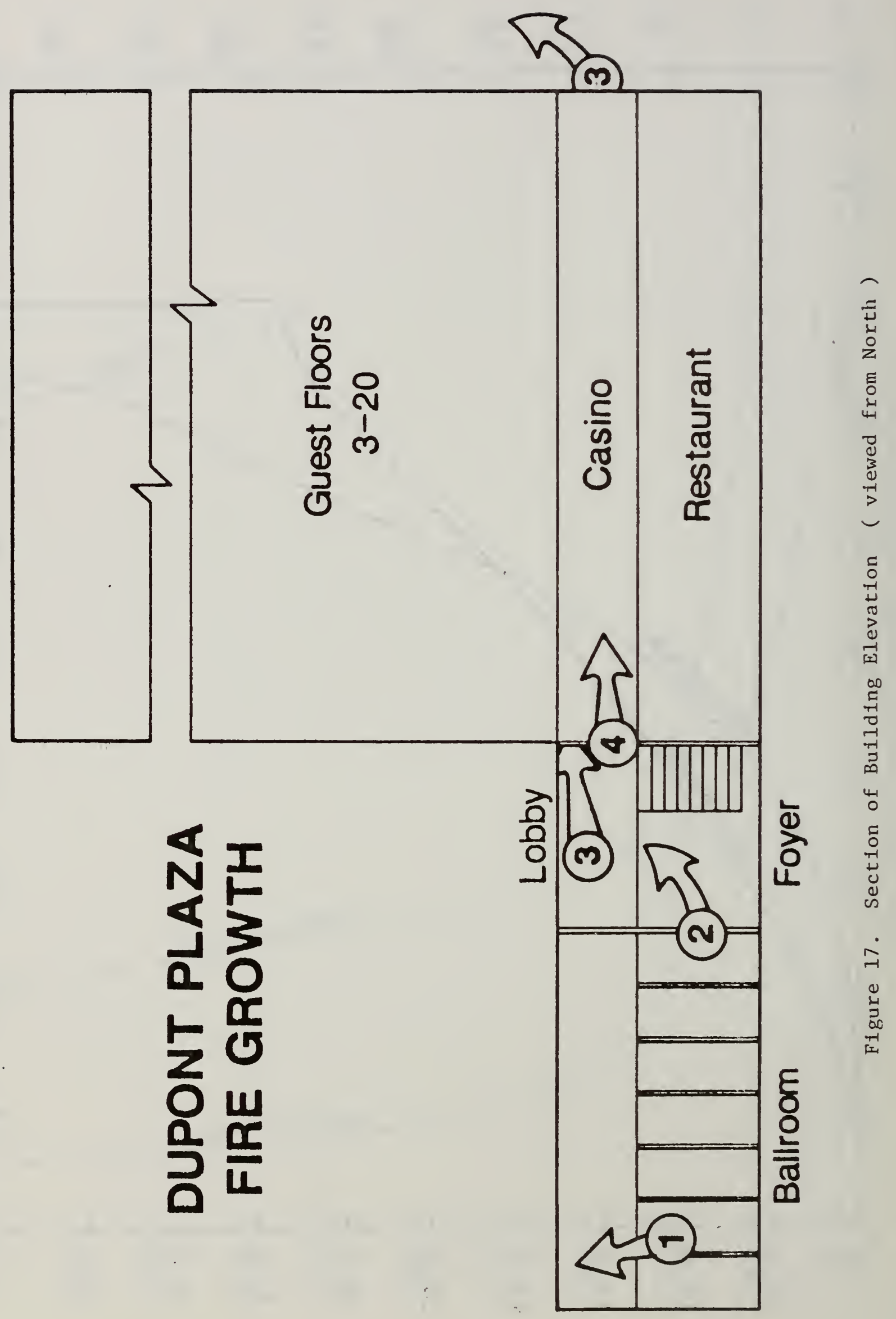




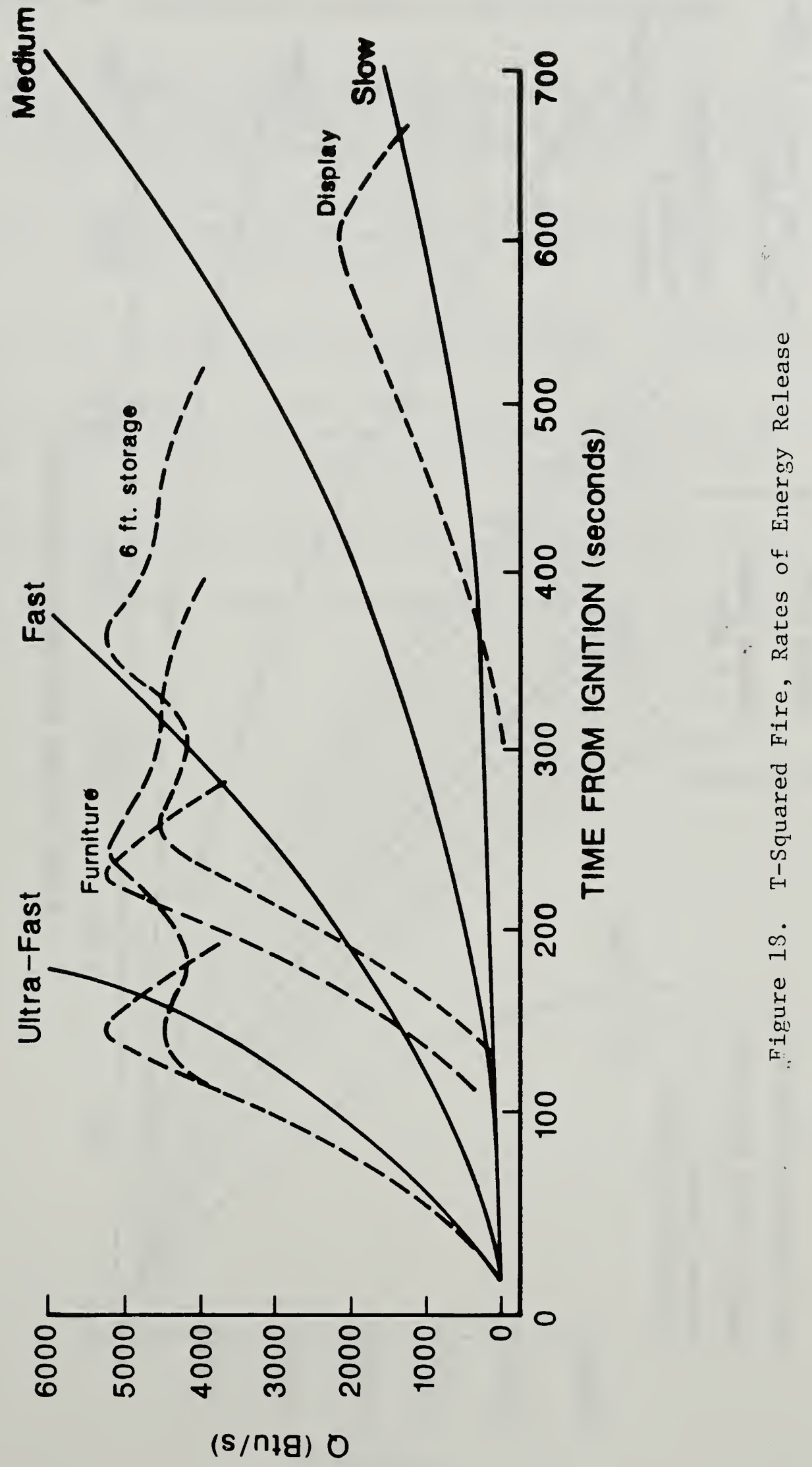




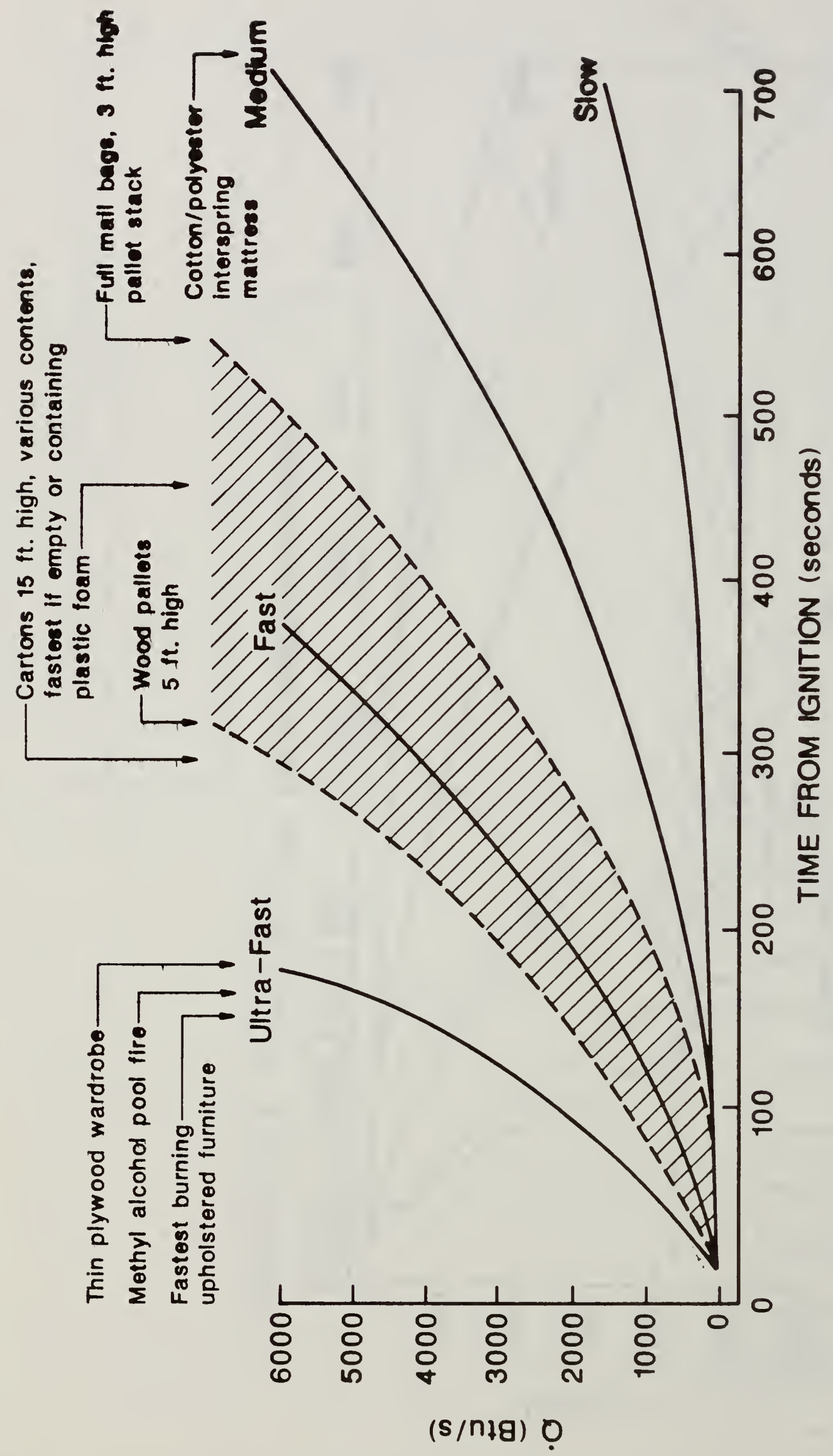

D 


\section{APPENDIX A}

\section{RESULTS OF COMPUTATIONS RELATED TO THE SOUTH BALIROOM}

This appendix contains tables, graphs and computer printouts that give additional details of the computational results from procedures used to estimate the development of conditions in the South Ballroom as follows:

a. Printout from computer program UTEMP[13] used to estimate smoke temperature. This program executes the pre and post flashover correlations proposed by Quintiere [10.]

b. Table of results obtained from FIRST [9.] FIRST was used to estimate the smoke level and the oxygen content of the smoke.

c. Printout from computer program ROOMFIR[16]. This program is an adaption of ASETB [15] as discussed in paragraph 2.4b. ROOMFIR was used to estimate vision distance in the smoke in the South Ballroom.

d. Printout from computer program HOTVENT used to estimate post flashover neutral plane between the South Ballroom and the Foyer.

e. Figure A-1, Graphic summary of estimated conditions in the South Ballroom. 
SOUTH BALLROOM

ROOM SURFACES ARE:

SURFACE NO. 12304 SQ. FT. OF 1.5 INCH THICK WOOD FLOOR

SURFACE NO. 22304 SQ. FT. OF 1 INCH THICK MINERAL CEILING

SURFACE NO. 3600 SQ. FT. OF .06 INCH THICK PARTITION PANELS

SURFACE NO. 4360 SQ. FT. OF .25 INCH THICK GLASS

SURFACE NO. 51000 SQ. FT. OF 6 INCH THICK FABRIC COVERED CONCRETE

FIRE ROOM OPENINGS

DOOR: $\quad 10$ FT. HIGH BY 16 FT. WIDE

WINDOW: 7 FT. HIGH BY 2.83 FT. WIDE

WINDOW IS OPEN TO A HEIGHT OF 7 FT. AND A WIDTH OF 2.83 FT

FIRE IS ENTERED AS AN EXPONITIONAL FIRE GROWTH FORMULA

WITH A GROWTH RATE CONSTANT OF .0444 AND AN EXPONENT OF 2

$\begin{array}{ccr}\text { TIME } & \text { RATE OF HEAT RELEASE } \\ (\text { SEC) } & (\text { BTU/SEC) } & (\mathrm{kW}) \\ 0 & 0 & 0 \\ 30 & 40 & 42 \\ 60 & 160 & 168 \\ 90 & 360 & 379 \\ 120 & 639 & 674 \\ 150 & 999 & 1,053 \\ 180 & 1,439 & 1,516 \\ 210 & 1,958 & 2,064 \\ 240 & 2,557 & 2,696 \\ 270 & 3,237 & 3,412 \\ 300 & 3,996 & 4,212 \\ 330 & 4,835 & 5,096 \\ 360 & 5,754 & 6,065 \\ 390 & 6,753 & 7,118 \\ 420 & 7,832 & 8,255 \\ 450 & 8,991 & 9,477 \\ 480 & 10,230 & 10,782 \\ 510 & 11,548 & 12,172 \\ 540 & 12,947 & 13,646 \\ 570 & 14,426 & 15,205\end{array}$

THE UPPER LEVEL TEMPERATURE INDICATES FLASHOVER AT 600
16,847
UPPER LEVEL SMOKE TEMPERATURE (DEGREES F) 70

(DEGREES C)

84

110

141

178

219

264

313

364

418

475

534

595

659

724

792

861

932

1,005

1,080

583 SEC.

2,093

21

29

43

61

81

104

129

156

184

215

246

279

313

348

385

422

461

500

541

582

I, 145 
Table of results for SOUTH BALLROOM (from FIRST)

TIME

(sec)

60

90

120

150

180

210

240

270

300

330

360

390

420

450

480

510

540

570

600
UPPER LAYER TEMP.

(F)

(C)

$\begin{array}{rr}101.9 & 39.0 \\ 121.4 & 49.6 \\ 146.6 & 63.7 \\ 180.9 & 82.9 \\ 222.9 & 106.1 \\ 270.2 & 132.4 \\ 335.1 & 168.4 \\ 409.8 & 209.9 \\ 487.2 & 252.9 \\ 567.3 & 297.4 \\ 645.9 & 341.1 \\ 725.9 & 385.5 \\ 803.0 & 429.6 \\ 883.3 & 472.9 \\ 962.2 & 516.7 \\ 1046.7 & 558.2 \\ 1093.7 & 590.7 \\ 1106.6 & 597.0 \\ 1111.6 & 599.8\end{array}$

SMOKE LAYER POS.

(ft.) (m)

8.17

7.02

6.00

5.28

4.80

5.97

6.43

6.52

6.52

6.46

6.46

6.43

6.39

6.43

6.49

6.36

6.62

7.02

7.38
2.49

2.14

1.83

1.61

1.47

1.82

1.96

1.99

1.99

1.97

1.97

1.96

1.95

1.96

1.98

1.94

2. 02

2. 14

2.25
O2 CONCENTRATION

(\%)

20.90

20.72

20.45

19.99

19.35

18.62

17.89

17.07

16.34

15.43

14.51

13.51

12.42

11.23

9.95

9.22

7.86

7.30

6.75 
ROOMFIR VERSION 1.0

04-14-1987 VISION DISTANCE (SOUTH BALLROOM)

HEAT LOSS FRACTION $=.75$

FIRE HEIGHT $=0 \mathrm{ft} \quad 0 \mathrm{~m}$

ROOM HEIGHT $=10 \mathrm{ft} \quad 3.048 \mathrm{~m}$

ROOM AREA $=2304 \mathrm{sq}$ ft $214.0416 \mathrm{sq} \mathrm{m}$

THERE IS A WALL OPENING $10 \mathrm{ft.} \mathrm{HIGH} 16 \mathrm{ft.} \mathrm{WIDE} \mathrm{WITH} \mathrm{A} 0$ ft. HIGH SILL

ALPHA VALUE FOR T-SQUARED FIRE $=.0444$

$\begin{array}{ccccccc}\text { TIME } & \text { TEMP } & \text { TEMP } & \text { LAYER } & \text { LAYER } & \text { FIRE } & \text { FIRE } \\ \text { seC } & \text { F } & \text { C } & \text { ft } & \mathrm{m} & \mathrm{kW} & \text { BTU/sec } \\ 0.0 & 70.2 & 21.2 & 10.0 & 3.0 & 0.1 & 0.1 \\ \text { ion distance (smoke } & \text { layer) } & = & 3000.00 & \mathrm{~m}(9840.00 \mathrm{ft}) & \end{array}$

Vision distance (smoke layer) $=3000.00 \mathrm{~m}$ (9840.00 ft)

$\begin{array}{llllll}60.0 & 89.2 & 31.8 & 9.0 & 2.7 & 159.8\end{array}$

Vision distance (smoke layer) $=17.69 \mathrm{~m}$ ( $58.01 \mathrm{ft}$ )

$\begin{array}{lllllll}120.0 & 130.1 & 54.5 & 7.7 & 2.3 & 639.4 & 606.4\end{array}$

Vision distance (smoke layer) $=7.17 \mathrm{~m}$ ( $23.51 \mathrm{ft}$ )

$\begin{array}{lllllll}180.0 & 206.3 & 96.8 & 7.3 & 2.2 & 1438.6 & 1364.5\end{array}$

Vision distance (smoke layer) $=5.56 \mathrm{~m}$ ( $18.25 \mathrm{ft}$ )

Vision distance (smoke layer) $=5.49 \mathrm{~m}$ ( $18.02 \mathrm{ft}$ )

$\begin{array}{lllllll}300.0 & 452.9 & 233.8 & 7.4 & 2.3 & 3996.0 & 3790.2\end{array}$

Vision distance (smoke layer) $=5.45 \mathrm{~m}$ ( $17.88 \mathrm{ft}$ )

$\begin{array}{lllllll}360.0 & 595.2 & 312.9 & 7.4 & 2.2 & 5754.2 & 5457.9\end{array}$

Vision distance (smoke layer) $=5.10 \mathrm{~m}$ ( $16.71 \mathrm{ft}$ )

$\begin{array}{lllllll}420.0 & 748.9 & 398.3 & 7.3 & 2.2 & 7832.2 & 7428.8\end{array}$

Vision distance (smoke layer) $=4.59 \mathrm{~m}$ ( $15.06 \mathrm{ft}$ )

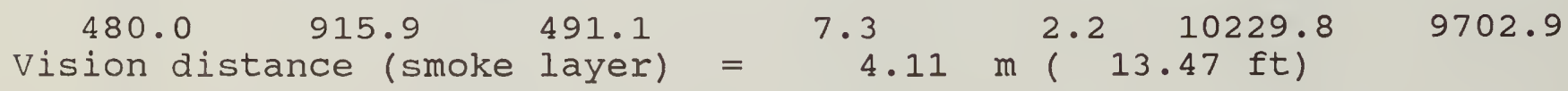

$\begin{array}{lllllll}540.0 & 1097.0 & 591.6 & 7.2 & 2.2 & 12947.0 & 12280.3\end{array}$

Vision distance (smoke layer) $=3.69 \mathrm{~m}$ ( $12.12 \mathrm{ft}$ )

$\begin{array}{lllllll}600.0 & 1292.4 & 700.2 & 7.1 & 2.2 & 15984.0 & 15160.8\end{array}$

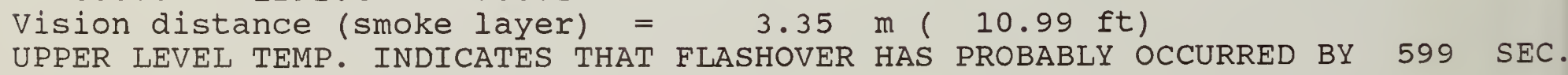




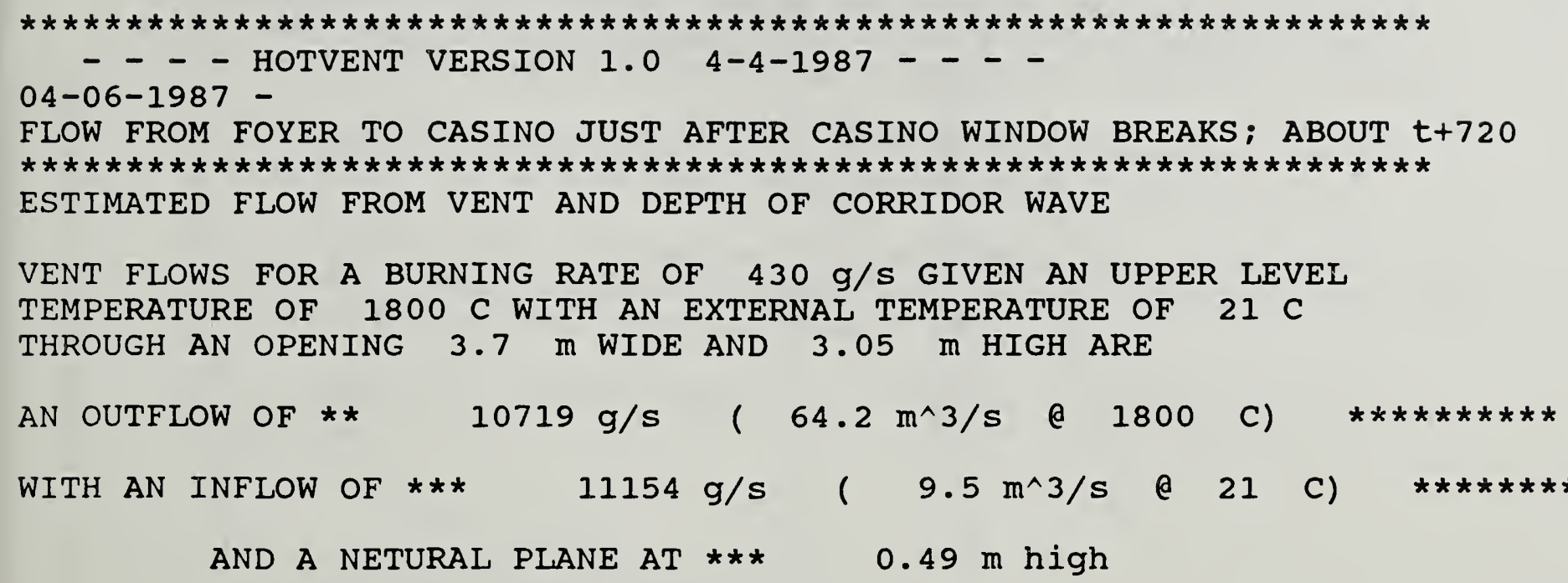



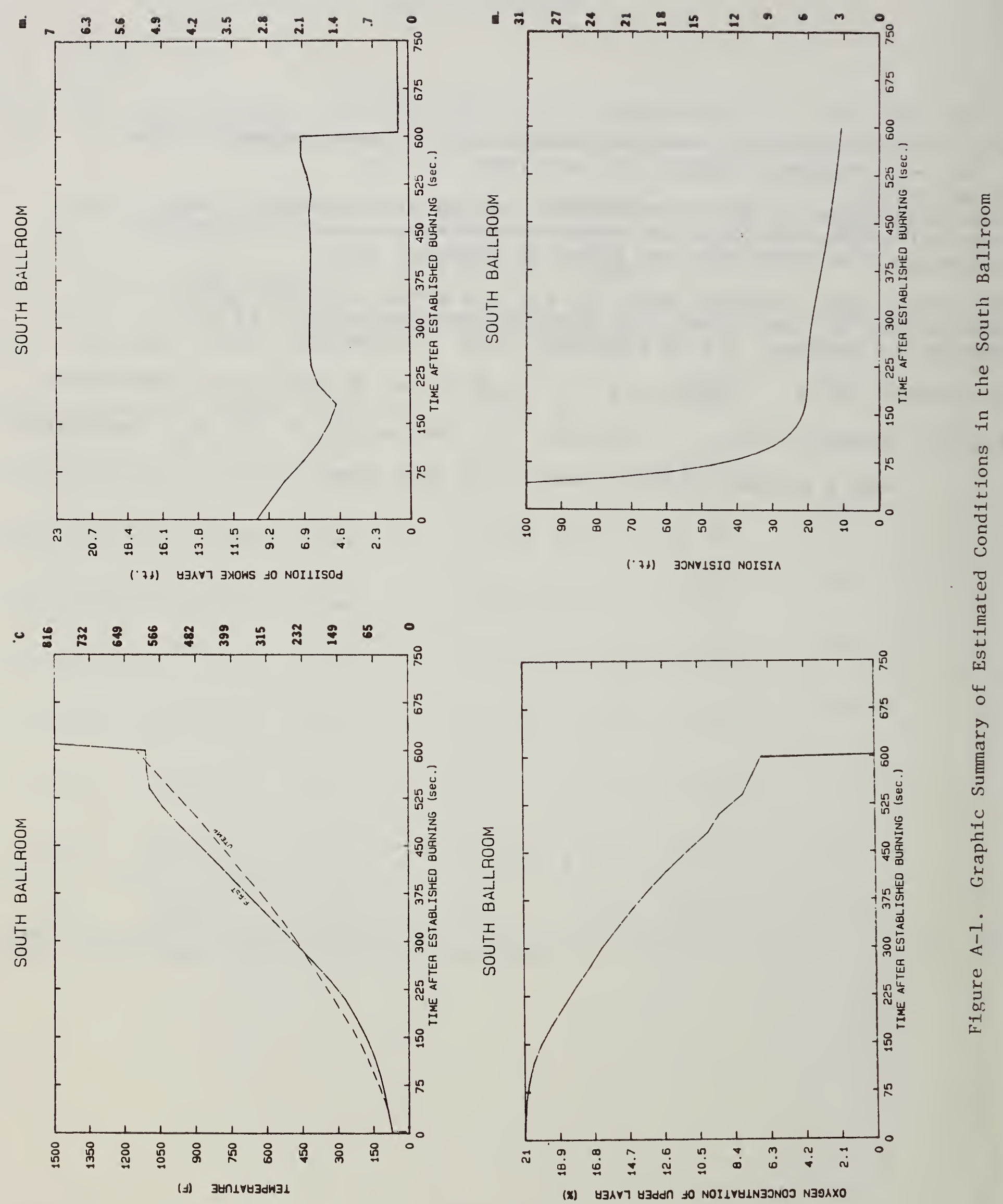


\section{APPENDIX B}

\section{RESULTS OF COMPUTATION RELATED TO THE NORTH BALIROOM}

This appendix contains tables, graphs and computer printouts that give additional details of the computational results from procedures used to estimate the development of conditions in the North Ballroom as follows:

a. Table of energy vented from the South Ballroom into the North Ballroom. The data in this table was obtained from FIRST [9.]

b. Printout from the computer program ROOMFIR[16]. ROOMFIR was used to estimate smoke temperature, smoke level, oxygen content in the smoke and vision through the smoke in the North Ballroom.

c. Figure B-1, Graphic summary of estimated conditions in the North Ballroom. 


$\begin{array}{lccc}\begin{array}{c}\text { TIME } \\ (\mathrm{sec})\end{array} & \begin{array}{c}\text { MASS FLOW } \\ (\mathrm{kg} / \mathrm{s})\end{array} & \begin{array}{c}\text { FUEL FRACTION } \\ (\mathrm{kg} / \mathrm{kg})\end{array} & \begin{array}{c}\text { LAYER TEMPERATURE } \\ (\mathrm{k})\end{array} \\ 60 & & 5.52 \mathrm{E}-04 & 3.07 \mathrm{E}+02 \\ 120 & 0.228 & 1.66 \mathrm{E}-03 & 3.37 \mathrm{E}+02 \\ 180 & 1.17 & 3.96 \mathrm{E}-03 & 3.79 \mathrm{E}+02 \\ 240 & 2.10 & 7.32 \mathrm{E}-03 & 4.41 \mathrm{E}+02 \\ 300 & 5.91 & 1.08 \mathrm{E}-02 & 5.26 \mathrm{E}+02 \\ 360 & 6.27 & 1.48 \mathrm{E}-02 & 6.14 \mathrm{E}+02 \\ 420 & 6.70 & 1.95 \mathrm{E}-02 & 7.93 \mathrm{E}+02 \\ 480 & 7.07 & 2.49 \mathrm{E}-02 & 8.63 \mathrm{E}+02 \\ 540 & 7.32 & 3.18 \mathrm{E}-02 & 8.73 \mathrm{E}+02 \\ 600 & 7.80 & 6.51 \mathrm{E}-02 & \end{array}$

Energy vented into NORTH BALLROOM from SOUTH BALLROOM

$\begin{array}{cccc}\text { TIME } & E(\text { CONV }) & E(U N B U R N) & E(S U M) \\ (\mathrm{sec} .) & (\mathrm{kW}) & (\mathrm{kW}) & (\mathrm{kW})\end{array}$

$\begin{array}{lrrr}60 & 3.1 & 3.6 & 6.8 \\ 120 & 51.3 & 55.7 & 107.0 \\ 180 & 180.3 & 238.7 & 419.0 \\ 240 & 873.8 & 1241.6 & 2115.4 \\ 300 & 1459.9 & 1943.4 & 3403.3 \\ 360 & 2149.7 & 2845.9 & 4995.6 \\ 420 & 2897.6 & 3956.7 & 6854.3 \\ 480 & 3636.9 & 5231.1 & 8868.0 \\ 540 & 4444.8 & 7118.7 & 11563.5 \\ 600 & 3989.4 & 12854.4 & 16843.8\end{array}$


ROOMFIR VERSION 1.0

04-14-1987 NORTH BALLROOM

HEAT LOSS FRACTION $=.8$

FIRE HEIGHT $=6 \mathrm{ft} \quad 1.8288 \mathrm{~m}$

ROOM HEIGHT $=23 \mathrm{ft} 7.0104 \mathrm{~m}$

ROOM AREA $=5186 \mathrm{sq}$ ft $481.7794 \mathrm{sq} \mathrm{m}$

THERE IS A WALL OPENING 0 ft. HIGH 0 ft. WIDE WITH A 0 ft. HIGH SILL

FIRE TIMES AND HEAT RELEASE RATES

TIME (sec) HEAT RELEASE RATE (kW)

60

6.8

$120 \quad 107$

$180 \quad 419$

$240 \quad 2115.4$

$300 \quad 3403.3$

$360 \quad 4995.6$

$420 \quad 6854.3$

$480 \quad 8868$

$540 \quad 11563.5$

$600 \quad 16843.8$

$\begin{array}{cccccrc}\text { TIME } & \text { TEMP } & \text { TEMP } & \text { LAYER } & \text { LAYER } & \text { FIRE } & \text { FIRE } \\ \text { seC } & \text { F } & \text { C } & \text { ft } & \text { m } & \mathrm{kW} & \text { BTU/seC } \\ 0.0 & 70.1 & 21.2 & 23.0 & 7.0 & 0.1 & 0.1\end{array}$

Product Factor (smoke layer) $=0.00 \mathrm{BTU} / \mathrm{cu}$. ft. ( $0 \mathrm{~kJ} / \mathrm{cu} . \mathrm{m}$ )

Vision distance (smoke layer) $=3000.00 \mathrm{~m}$ (9840.00 ft)

oxygen Concentration (smoke layer) $=21.0 \%$ (\%)

60.0

70.9

21.6

Product Factor (smoke layer)

Vision distance (smoke layer)

oxygen concentration (smoke layer
74.5

23.6

$=$

22.5

6.9

6.8 $0.08 \mathrm{BTU} / \mathrm{Cu}$. ft. $296.81 \mathrm{~m}(973.55 \mathrm{ft})$

(\%)

21.3

6.5

107.0

Product Factor (smoke layer) =

$0.39 \mathrm{BTU} / \mathrm{Cu}$. ft.

$57.45 \mathrm{~m}(188.42 \mathrm{ft})$

oxygen Concentration (smoke layer) $=20.9 \%$ (\%)

$180.0 \quad 82.1$

27.8

19.6

6.0

6.0

$1.03 \mathrm{BTU} / \mathrm{Cu}$. ft.

$21.87 \mathrm{~m}(71.72 \mathrm{ft})$

Vision distance (smoke layer) = $21.87 \mathrm{~m}$ (
oxygen concentration (smoke layer) $=20.7 \%$ (\%)
$240.0 \quad 105.9$

41.1

17.1

5.2

2115.4

$2.93 \mathrm{BTU} / \mathrm{cu}$. ft. (
$7.67 \mathrm{~m}(25.15 \mathrm{ft})$

Vision distance (smoke layer) $=7.67 \mathrm{~m}$ (25.15 ft)

oxygen Concentration (smoke layer) $=19.9 \%$ (\%)

300.0

142.5

61.4

\begin{abstract}
14.5
\end{abstract}
4.4

3403.3

$5.59 \mathrm{BTU} / \mathrm{Cu}$. ft.

$$
4.02 \mathrm{~m}(13.19 \mathrm{ft})
$$

Vision distance (smoke layer) $=4.02 \mathrm{~m}$ (
oxygen Concentration (smoke layer) $=18.5 \%$ (\%)

360.0

$$
190.3
$$

87.9

12.1

3.7

$8.60 \mathrm{BTU} / \mathrm{Cu}$.

$8.60 \mathrm{BTU} / \mathrm{CU}$ Product Factor (smoke layer) =

$$
\begin{aligned}
& \text { oke layer) }= \\
& \text { (smoke layer) }
\end{aligned}
$$$$
2.61 \mathrm{~m}(
$$ 
$420.0 \quad 256.1$

\section{4}

Product Factor (smoke layer) =

Vision distance (smoke layer) = oxygen Concentration (smoke layer

\section{0}

347.0

175.0

Product Factor (smoke layer) =

Vision distance (smoke layer) = oxygen concentration

540.0

471.8

244.3

Product Factor (smoke layer) =

Vision distance (smoke layer) =

oxygen Concentration

$\begin{array}{ccc}600.0 \quad 647.2 & 341.8 \\ \text { Product Factor (smoke layer) } & = & 1.9 \\ \text { Vision distance }\end{array}$

$\begin{array}{ccc}600.0 \quad 647.2 & 341.8 \\ \text { Product Factor (smoke layer) } & = & 1.9 \\ \text { Vision distance }\end{array}$

(smoke 1 (a)

341.8

Vision distance (smoke layer) =

oxygen Concentration (smoke layer)

Oxygen concentration (smoke layer) $=-7.3 \%$ (\%)

THE DROP OF THE UPPER LEVEL TO THE TOP OF THE BURNING ITEM AND

AND THE LACK OF OXYGEN IN THE SMOKE INDICATE VITIATION OF THE COMBUSTION COMBUSTION AIR WITH FIRE PRODUCTS. IT IS LIKELY THAT THE BURNING

RATE WILL BE DEPRESSED POSSIBLY SMOTHERED. 

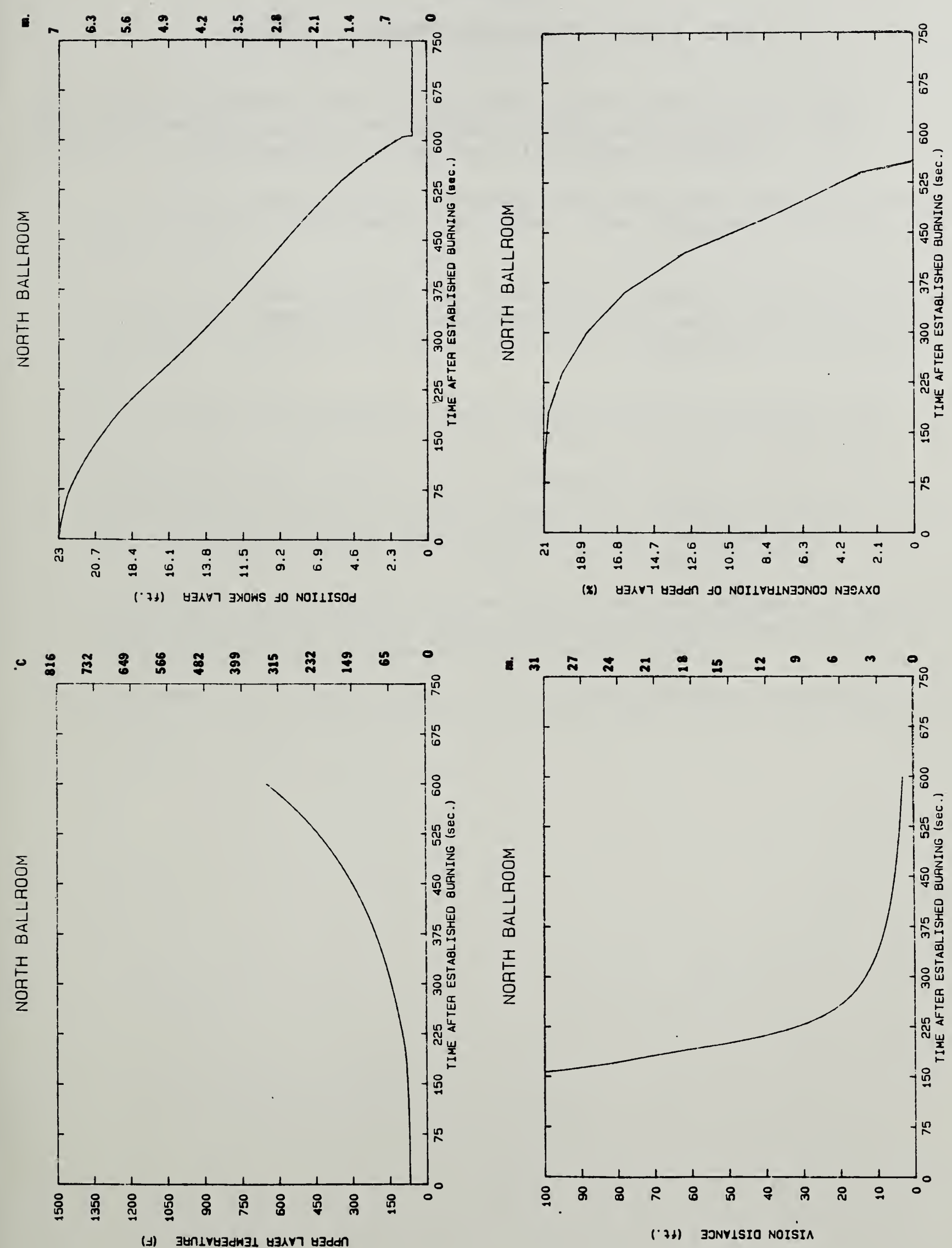

Iี 



\section{APPENDIX C \\ RESULTS OF COMPUTATIONS RELATED TO THE FOYER}

This appendix contains tables, graphs and computer printouts that give additional details of the computational results from procedures used to estimate the development of condition in the Foyer as follows:

a. Table of values used in computing the preflashover venting of energy from the North Ballroom into the Foyer. See paragraph $2.3 \mathrm{c}$. for discussion.

b. Printout from computer program ROOMFIR[16] used to estimate smoke temperature, smoke level, oxygen content in the smoke and vision distance in the smoke in the Foyer, prior to flashover of the South Ballroom.

c. Printout from computer program UTEMP[13] used to estimate smoke temperature in the Foyer following flashover in the South Ballrooin.

d. Printout from computer program HOTVENT[17] used to estimate the neutral plan in and the volume of smoke flow through the opening between the Foyer and the Lobby after flashover of the South Ballroom. This program executes the calculations described in paragraph 2.6.

e. Printout from computer program HOTVENT used to estimate the flow of flame and hot gases from the Foyer into the Casino following window failure in the wall between the Foyer and the Casino.

f. Figure C-1, Graphic summary of estimated conditions in the foyer. 
Summary of parameters for smoke venting into the FOYER

\begin{tabular}{|c|c|c|c|c|c|}
\hline $\begin{array}{l}\text { TIME } \\
\text { (sec) }\end{array}$ & $\begin{array}{c}\text { SMOKE LAYER } \\
\text { TEMP. (F) }\end{array}$ & $\begin{array}{lc}\text { SMOKE } & \text { LAYER } \\
\text { POS. } & \text { (ft) }\end{array}$ & $\begin{array}{c}\text { VENT AREA } \\
(s q \cdot f t)\end{array}$ & $\begin{array}{l}\text { SMOKE } \\
(\mathrm{cfm})\end{array}$ & $\begin{array}{l}\text { TED } \\
\text { (cms) }\end{array}$ \\
\hline 420 & 256.09 & 9.92 & .24 & 9 & $4.24 \mathrm{E}-03$ \\
\hline 440 & 283.24 & 9.19 & 2.43 & 309 & 0.145 \\
\hline 460 & 313.47 & 8.46 & 4.62 & 861 & 0.406 \\
\hline 480 & 346.97 & 7.72 & 6.84 & 1654 & 0.780 \\
\hline 500 & 384.36 & 6.95 & 9.15 & 2731 & 1.290 \\
\hline 520 & 426.11 & 6.15 & 11.55 & 4121 & $1: 940$ \\
\hline 540 & 471.84 & 6.00 & 12.00 & 4630 & 2.180 \\
\hline 570 & 551.37 & 6.00 & 12.00 & 5069 & 2.390 \\
\hline 600 & 647.19 & 6.00 & 12.00 & 5550 & 2.620 \\
\hline
\end{tabular}

Summary of parameters for energy vented into the Foyer

$\begin{array}{lcccr}\begin{array}{l}\text { TIME } \\ (\mathrm{seC})\end{array} & \begin{array}{c}\text { SMOKE LAYER } \\ \text { TEMP. }(\mathrm{K})\end{array} & \begin{array}{c}\text { SPECIFIC DENSITY } \\ (\mathrm{kg} / \mathrm{m} 3)\end{array} & \begin{array}{c}\text { DELTA TEMP. } \\ (\mathrm{K})\end{array} & \begin{array}{c}\text { ENERGY VENT } \\ (\mathrm{kW})\end{array} \\ 420 & & .74 & 104.49 & 0.32 \\ 440 & 397.64 & .71 & 119.58 & 12.31 \\ 460 & 412.73 & .68 & 136.37 & 37.64 \\ 480 & 429.52 & .65 & 154.98 & 78.57 \\ 500 & 448.91 & .63 & 175.76 & 142.84 \\ 520 & 468.91 & .59 & 198.95 & 227.71 \\ 540 & 492.10 & .56 & 224.36 & 273.71 \\ 570 & 517.51 & .52 & 268.54 & 333.74 \\ 600 & 561.69 & .47 & 321.77 & 396.22\end{array}$


ROOMFIR VERSION 1.0

04-14-1987 FOYER

HEAT LOSS FRACTION $=.6$

FIRE HEIGHT $=7 \mathrm{ft} 2.1336 \mathrm{~m}$

ROON HEIGHT $=23 \mathrm{ft} \quad 7.0104 \mathrm{~m}$

ROOM AREA $=8500 \mathrm{sq}$ ft $789.65 \mathrm{sq} \mathrm{m}$

THERE IS A WALL OPENING 0 ft. HIGH 0 ft. WIDE WITH A 0 ft. HIGH SILL

FIRE TIMES AND HEAT RELEASE RATES

$\begin{array}{cc}\text { TIME (sec) } & \text { HEAT RELEASE RATE (kW) } \\ 20 & .32 \\ 40 & 12.31 \\ 60 & 37.64 \\ 80 & 78.57 \\ 100 & 142.84 \\ 120 & 227.71 \\ 140 & 273.89 \\ 170 & 333.74 \\ 200 & 396.22\end{array}$

$\begin{array}{cccccrc}\text { TIME } & \text { TEMP } & \text { TEMP } & \text { LAYER } & \text { LAYER } & \text { FIRE } & \text { FIRE } \\ \text { Sec } & \text { F } & \text { C } & \text { ft } & \mathrm{m} & \mathrm{kW} & \text { BTU/seC } \\ 0.0 & 70.1 & 21.2 & 23.0 & 7.0 & 0.1 & 0.1\end{array}$

Product Factor (smoke layer) $=0.00 \mathrm{BTU} / \mathrm{cu}$. ft. ( $0 \mathrm{~kJ} / \mathrm{cu}$. m) Vision distance (smoke layer) $=3000.00 \mathrm{~m}(9840.00 \mathrm{ft})$ oxygen concentration (smoke layer) $=21.0 \%(\%)$
20.0
70.2
$21.2 \quad 23.0$
7.0
0.3
0.3

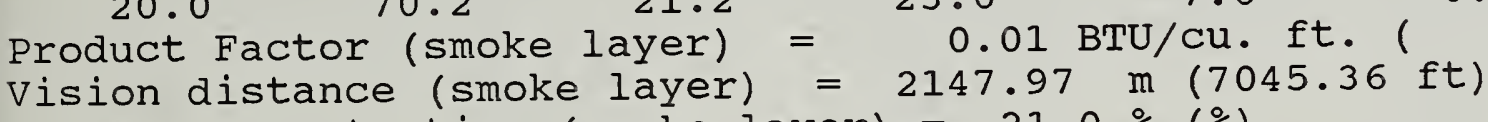

oxygen concentration (smoke layer) $=21.0 \%(\%)$

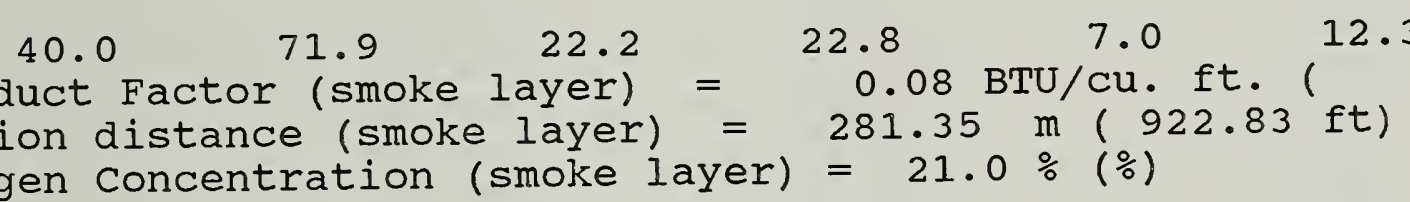

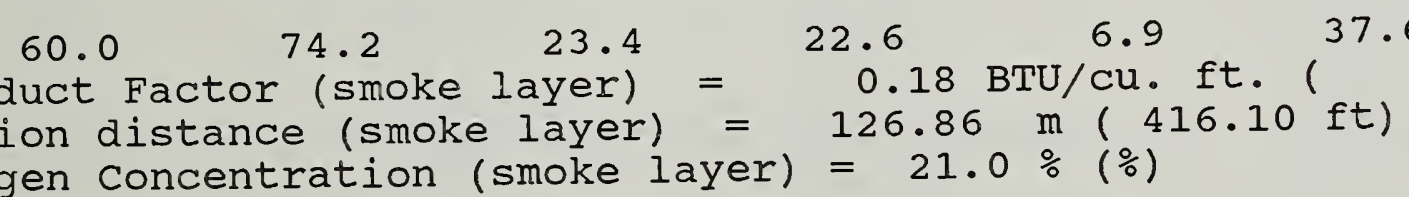

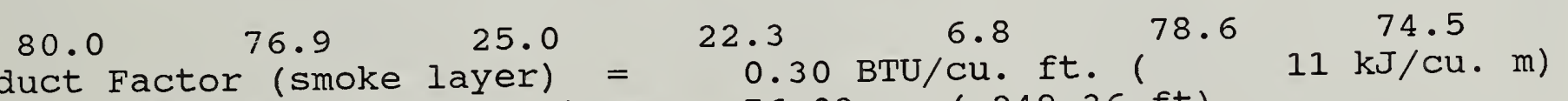

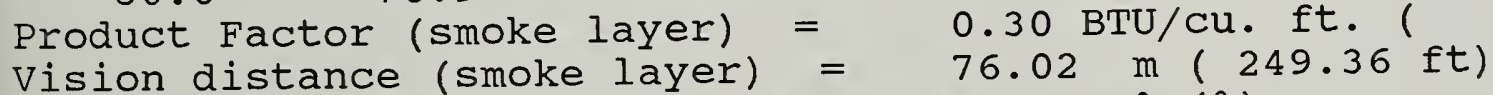

oxygen concentration (smoke layer) $=20.9 \%(\%)$

$100.0 \quad 80.4 \quad 26.9 \quad 22.0 \quad 6.7 \quad \mathrm{ft} \quad 142.8$

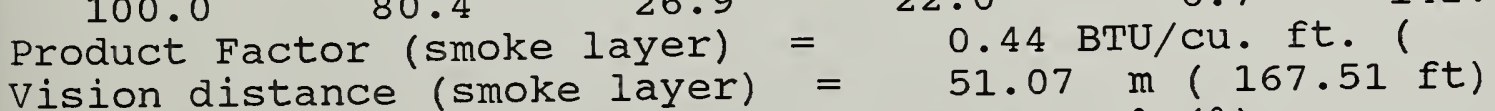

oxygen concentration (smoke layer) $=20.9 \%(\%)$

$\begin{array}{llllll}120.0 & 84.5 & 29.1 & 21.6 & 6.6 & 227.7\end{array}$

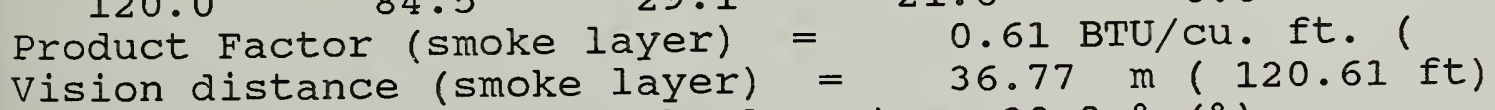

oxygen concentration (smoke layer) $=20.8 \%$ (\%)
140.0
88.5
31.4
21.2
6.5
273.9
259.8 


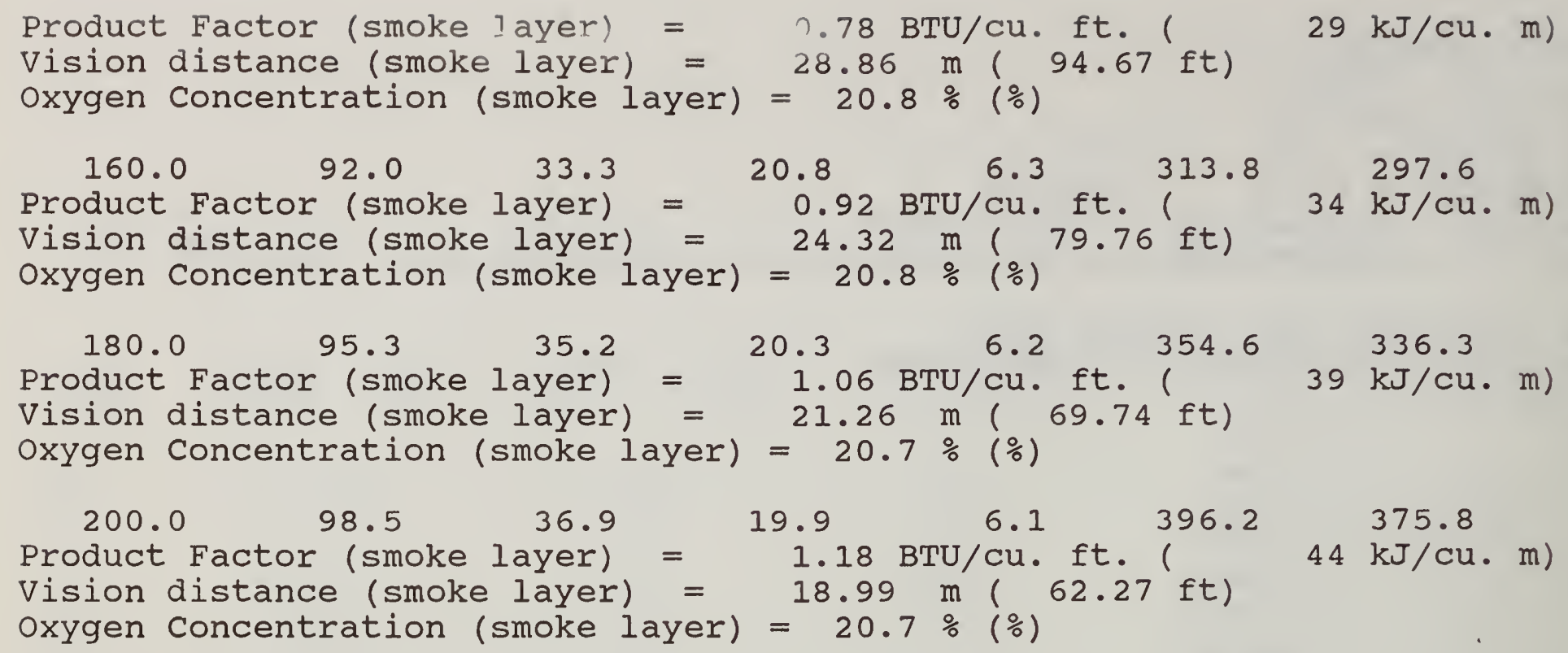




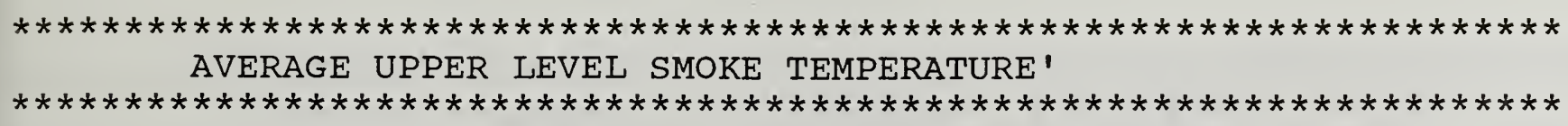

TIME

sec.

TIME

(SEC)

0
RATE OF HEAT RELEASE
btu/sec
$(\mathrm{kW})$

RATE OF HEAT RELEASE (BTU/SEC)

17,920
UPPER LEVEL SMOKE TEMPERATURE
(DEGREES F) 178
(DEGREES C) 81

THE BURNING RATE AND RESULTING UPPER LEVEL TEMPERATURE IS LIMITED

BY THE VENTILATION CAPACITY OF THE ROOM OPENINGS. FROM THIS POINT

ON THE AMOUNT OF ENERGY THAT CAN BE RELEASED WITHIN THE ROOM IS

LIMITED TO 24978.03 BTU/SEC. ROOM TEMPERATURE MAY CONTINUE TO RISE

$\begin{array}{lll}10 & 24,978 & 26,327 \\ 20 & 24,978 & 26,327 \\ 30 & 24,978 & 26,327 \\ 40 & 24,978 & 26,327 \\ 50 & 24,978 & 26,327 \\ 60 & 24,978 & 26,327 \\ 70 & 24,978 & 26,327 \\ 80 & 24,978 & 26,327 \\ 90 & 24,978 & 26,327 \\ 100 & 24,978 & 26,327 \\ 110 & 24,978 & 26,327\end{array}$

THE UPPER LEVEL TEMPERATURE INDICATES FLASHOVER AT

120

130

140

150
24,978

24,978

24,978
26,327

26,327

26,327
772

855

908

947

980

1,007

1,030

1,051

1,070

1,088

1,103

$116 \mathrm{SEC}$.

1,307

1,323

1,338

1,353
411

457

487

509

526

542

555

566

577

586

595

708

717

726

734 
- - - HOTVENT VERSION 1.0 4-4-1987 - - -

04-06-1987 - POST FLASHOVER SOUTH BALLROOM TO FOYER

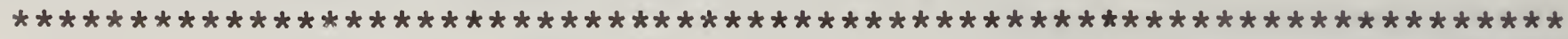
ESTIMATED FLOW FROM VENT AND DEPTH OF CORRIDOR WAVE

VENT FLOWS FOR A BURNING RATE OF $2758 \mathrm{~g} / \mathrm{s}$ GIVEN AN UPPER LEVEL TEMPERATURE OF $1145 \mathrm{C}$ WITH AN EXTERNAL TEMPERATURE OF $21 \mathrm{C}$ THROUGH AN OPENING $11 \mathrm{~m}$ WIDE AND $3.05 \mathrm{~m}$ HIGH ARE

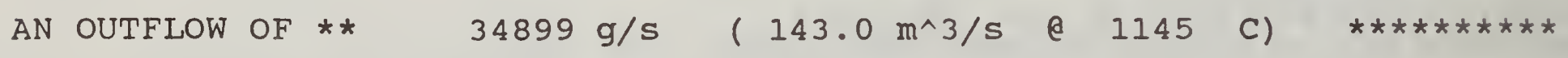

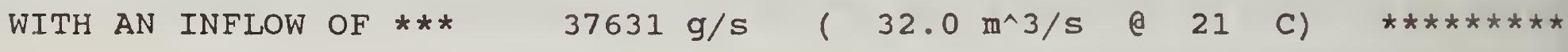

AND A NETURAL PLANE AT *** $0.53 \mathrm{~m} \mathrm{high}$ 
VENT FLOWS FOR A BURNING RATE OF $1394 \mathrm{~g} / \mathrm{s}$ GIVEN AN UPPER LEVEL TEMPERATURE OF 577 C WITH AN EXTERNAL TEMPERATURE OF $21 \mathrm{C}$ THROUGH AN OPENING $4.27 \mathrm{~m}$ WIDE AND $3.05 \mathrm{~m}$ HIGH ARE
AN OUTFLOW OF **
$14265 \mathrm{~g} / \mathrm{s}$
$35.0 \mathrm{~m}^{\wedge} 3 / \mathrm{s}$ \& 577
$15648 \mathrm{~g} / \mathrm{s}$
$13.3 \mathrm{~m}^{\wedge} 3 / \mathrm{s}$
e 21
C)
WITH AN INFLOW OF $* * *$
$0.60 \mathrm{~m} \mathrm{high}$
AND A NETURAL PLANE AT *** 

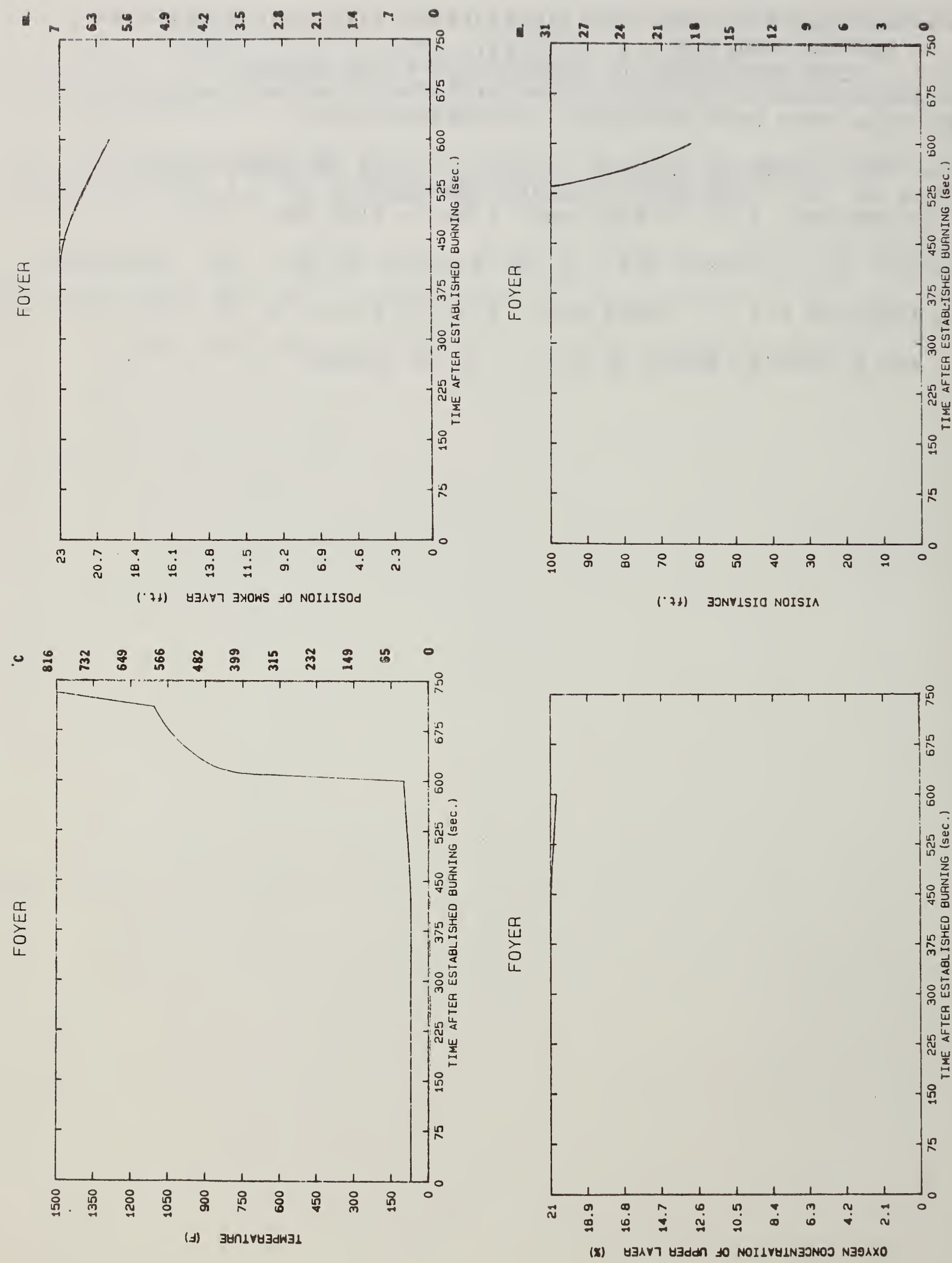

ปี 


\section{APPENDIX D}

\section{RESULTS OF COMPUTATIONS RELATED TO SPRINKILRRS}

This appendix contains printouts from the program ROOMFIR[16] covering a variety of sprinkler head locations and response time index situations. Discussion of the manner in which ASETB [15] and sprinkler response prediction equations are combined in these computations is discussed in paragraph 2.12. Each page in this appendix is a separate situation coordinated with the listing of potential sprinkler head activations in paragraph 2.12 . 
ROOMFIR VERSION 1.0

04-14-1987 IF SPRINKLER HAS BEEN IN SOUTH BALLROOM

HEAT LOSS FRACTION $=.75$

FIRE HEIGHT $=0 \mathrm{ft} \quad 0 \mathrm{~m}$

ROOM HEIGHT $=10 \mathrm{ft} \quad 3.048 \mathrm{~m}$

ROOM AREA $=2304 \mathrm{sq}$ ft $214.0416 \mathrm{sq} \mathrm{m}$

RADIAL DISTANCE FROM FIRE TO DETECTOR $=1 \mathrm{ft}(.3048 \mathrm{~m})$

DETECTOR RTI $=50[(\mathrm{ft}-\mathrm{sec}) \wedge .5]\left(27.60435\left[(\mathrm{~m}-\mathrm{sec})^{\wedge} .5\right]\right)$

THERE IS A WALL OPENING $10 \mathrm{ft}$. HIGH $16 \mathrm{ft}$. WIDE WITH A 0 ft. HIGH SILL

ALPHA VALUE FOR T-SQUARED FIRE $=.0444$

\begin{tabular}{|c|c|c|c|c|c|}
\hline TIME & TEMP & TEMP & LAAYER & LAYER & FIRE \\
\hline sec & F & C & ft & m & $\mathrm{kW}$ \\
\hline 0.0 & 70.2 & 21.2 & 10.0 & 3.0 & 0.1 \\
\hline TEMP & TURE & $=$ & 70.0 DEGS F & 21.1 & DEGS C) \\
\hline ing $\mathrm{J}$ & Temperature & $=$ & 71.1 DEGS F & 21.7 & DEGS C) \\
\hline ing $\mathrm{J}$ & elocity & $=$ & $0.92 \mathrm{ft} / \mathrm{sec}$ & 0.28 & $\mathrm{~m} / \mathrm{sec}$ ) \\
\hline
\end{tabular}

$\begin{array}{lll}10.0 & 71.6 & 22.0\end{array}$

LINK TEMPERATURE

Ceiling Jet Temperature $=$

Ceiling Jet Velocity=

$20.0 \quad 74.1$

LINK TEMPERATURE

Ceiling Jet Temperature =

Ceiling Jet Velocity=

$\begin{array}{lll}30.0 & 77.2 & 25.1\end{array}$

LINK TEMPERATURE

Ceiling Jet Temperature

Ceiling Jet Velocity=

$$
\begin{array}{lll}
40.0 & 80.7 & 27.1
\end{array}
$$

LINK TEMPERATURE

Ceiling Jet Temperature =

Ceiling Jet Velocity=

$$
50.0
$$

84.8

LINK TEMPERATURE

Ceiling Jet Temperature =

ceiling Jet Velocity=

$=$

9.5

156.9 DEGS F (

$8.56 \mathrm{ft} / \mathrm{sec}$ (

29.3

\section{$=$}

142.4 DEGS F

187.5 DEGS F (

$9.93 \mathrm{ft} / \mathrm{sec}$
3.0

22.1 DEGS

28.6 DEGS C)

$1.04 \mathrm{~m} / \mathrm{sec}$ )

3.0 26.5 DEGS C)

40.1 DEGS C)

$1.65 \mathrm{~m} / \mathrm{sec}$ )

2.9

34.8 DEGS C)

53.9 DEGS C)

$2.16 \mathrm{~m} / \mathrm{sec}$ )

2.9

46.7 DEGS C)

69.4 DEGS C)

$2.61 \mathrm{~m} / \mathrm{sec}$ )

$\begin{array}{ll}2.8 & 111.0 \\ 61.3 & \text { DEGS C) } \\ 86.4 & \text { DEGS C) } \\ 3.03 & \text { m/sec) }\end{array}$

67.4

FIRE

$\mathrm{BTU} / \mathrm{sec}$

0.1

$4 \cdot 2$

16.8

37.9

105.3 
ROOMFIR VERSION 1.0

04-14-1987 IF SPRINKLER HAS BEEN IN SOUTH BALLROOM

HEAT LOSS FRACTION $=.75$

FIRE HEIGHT $=0 \mathrm{ft} \quad 0 \mathrm{~m}$

ROOM HEIGHT $=10 \mathrm{ft} \quad 3.048 \mathrm{~m}$

ROOM AREA $=2304 \mathrm{sq}$ ft $214.0416 \mathrm{sq} \mathrm{m}$

RADIAL DISTANCE FROM FIRE TO DETECTOR $=7$ ft $(2.1336 \mathrm{~m})$

DETECTOR RTI $=50\left[(\mathrm{ft}-\mathrm{sec})^{\wedge} .5\right]\left(27.60435\left[(\mathrm{~m}-\mathrm{sec})^{\wedge} .5\right]\right)$

THERE IS A WALL OPENING $10 \mathrm{ft}$. HIGH $16 \mathrm{ft}$. WIDE WITH A 0 ft. HIGH SILL

ALPHA VALUE FOR T-SQUARED FIRE $=.0444$

$\begin{array}{ccccccc}\text { TIME } & \text { TEMP } & \text { TEMP } & \text { LAYER } & \text { LAYER } & \text { FIRE } & \text { FIRE } \\ \text { seC } & \text { F } & \text { C } & \text { ft } & \mathrm{m} & \mathrm{kW} & \text { BTU/sec } \\ 0.0 & 70.2 & 21.2 & 10.0 & 3.0 & 0.1 & 0.1\end{array}$

LINK TEMPERATURE
Ceiling Jet Temperature $=$
Ceiling Jet Velocity $=$

$15.0 \quad 72.8 \quad 22.7$

70.0 DEGS F ( 21.1 DEGS $C)$

70.6 DEGS F ( 21.4 DEGS C)

$0.25 \mathrm{ft} / \mathrm{sec}(0.08 \mathrm{~m} / \mathrm{sec})$

LINK TEMPERATURE

Ceiling Jet Temperature $=$

ceiling Jet Velocity =

$\begin{array}{lll}30.0 & 77.2 & 25.1\end{array}$

$\begin{array}{ll}\text { LINK TEMPERATURE } & = \\ \text { Ceiling Jet Temperature }= \\ \text { Ceiling Jet Velocity }=\end{array}$

\section{$\begin{array}{lll}45.0 & 82.7 & 28.2\end{array}$}

LINK TEMPERATURE

Ceiling Jet Temperature $=$

Ceiling Jet Velocity =

$\begin{array}{lll}60.0 & 89.3 & 31.8\end{array}$

LINK TEMPERATURE

Ceiling Jet Temperature $=$

Ceiling Jet Velocity =

$75.0 \quad 97.2 \quad 36.2$

LINK TEMPERATURE

Ceiling Jet Temperature $=$

Ceiling Jet Velocity =

$$
90.0 \quad 106.6 \quad 41.4
$$

LINK TEMPERATURE =

Ceiling Jet Temperature $=$

Ceiling Jet Velocity=

$\begin{array}{llllll} & 9.9 & & 3.0 & 10.0 \\ 71.3 & \text { DEGS F } & \text { ( } & 21.8 & \text { DEGS C) } \\ 81.0 & \text { DEGS F } & 27.2 & \text { DEGS C }) \\ 1.23 & \mathrm{ft} / \mathrm{sec} & ( & 0.37 & \mathrm{~m} / \mathrm{sec})\end{array}$

9.7

$1.95 \mathrm{ft} / \mathrm{sec}$ (

$9.4 \quad 2.9$

88.9 DEGS F

118.8 DEGS F

$2.57 \mathrm{ft} / \mathrm{sec}$

$\begin{array}{rl}9.0 \\ 105.9 & \text { DEGS F } \\ 142.7 & \text { DEGS F } \\ 3.13 & \mathrm{ft} / \mathrm{sec}\end{array}$

8.7

127.8 DEGS F

169.8 DEGS F

$3.64 \mathrm{ft} / \mathrm{sec}$

8.4

154.0

DEGS F

200.1

4.13
2.9

25.1

36.7

0.60

\section{6}

48.2

0.78

40.0

DEGS C)

DEGS C)

$\mathrm{m} / \mathrm{sec}$ )

89.9

DEGS C)

DEGS C)

$\mathrm{m} / \mathrm{sec}$ )

2.8

41.1

159.8

151.6

9.5

37.9

85.3

61.5

0.95

DEGS C)

DEGS C)

$\mathrm{m} / \mathrm{sec}$ )

2.6

53.2

249.8

236.9

76.6

DEGS C)

1.11

DEGS C)

$\mathrm{m} / \mathrm{sec}$ )

2.5

359.6

341.1

67.8 DEGS C)

93.4 DEGS C)

$1.26 \mathrm{~m} / \mathrm{sec}$ ) 
ROOMFIR VERSION 1.0

04-15-1987 IF SPRINKLER HAS BEEN IN SOUTH BALLROOM

HEAT LOSS FRACTION $=.75$

FIRE HEIGHT $=0 \mathrm{ft} \quad 0 \mathrm{~m}$

ROOM HEIGHT $=10 \mathrm{ft} \quad 3.048 \mathrm{~m}$

ROOM AREA $=2304 \mathrm{sq}$ ft $214.0416 \mathrm{sq} \mathrm{m}$

RADIAL DISTANCE FROM FIRE TO DETECTOR $=1 \mathrm{ft}(.3048 \mathrm{~m})$

DETECTOR RTI $=200\left[(\mathrm{ft}-\mathrm{sec})^{\wedge} .5\right]\left(110.4174\left[(\mathrm{~m}-\mathrm{sec})^{\wedge} .5\right]\right)$

THERE IS A WALL OPENING $10 \mathrm{ft.} \mathrm{HIGH} 16 \mathrm{ft}$. WIDE WITH A 0 ft. HIGH SILL ALPHA VALUE FOR T-SQUARED FIRE $=.0444$

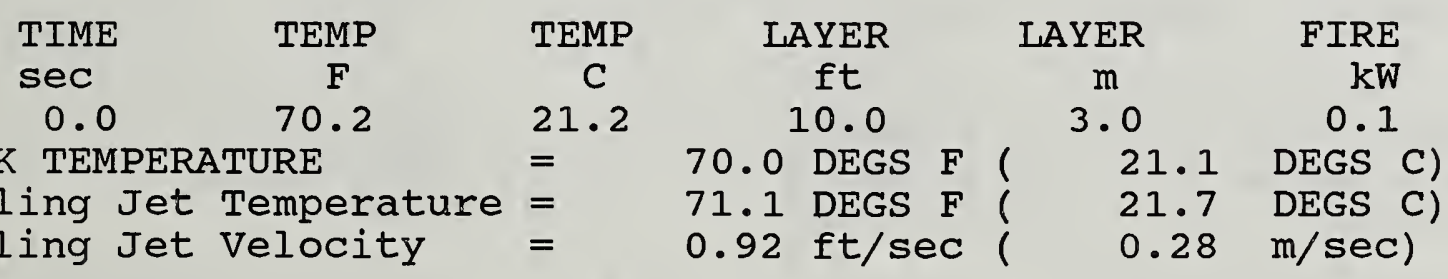

$\begin{array}{lll}15.0 & 72.8 & 22.7\end{array}$

LINK TEMPERATURE =

Ceiling Jet Temperature =

ceiling Jet Velocity =

$\begin{array}{lll}30.0 & 77.2 & 25.1\end{array}$

LINK TEMPERATURE

Ceiling Jet Temperature = Ceiling Jet Velocity=

$\begin{array}{lll}45.0 & 82.7 & 28.2\end{array}$

LINK TEMPERATURE

Ceiling Jet Temperature = Ceiling Jet Velocity =

$$
60.0
$$

89.3

31.8

LINK TEMPERATURE

Ceiling Jet Temperature Ceiling Jet Velocity=

$$
75.0
$$

97.2

LINK TEMPERATURE

Ceiling Jet Temperature

ceiling Jet Velocity =

$$
90.0 \quad 106.6
$$

LINK TEMPERATURE

Ceiling Jet Temperature =

Ceiling Jet Velocity =

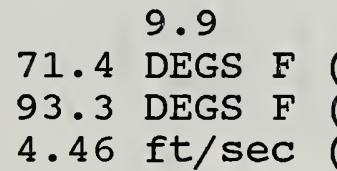

$4.46 \mathrm{ft} / \mathrm{sec}$

9.7

78.1 DEGS

129.0 DEGS $F$

$7.07 \mathrm{ft} / \mathrm{sec}$

9.4

92.2 DEGS

171.9 DEGS

$9.26 \mathrm{ft} / \mathrm{sec}$

9.0

114.7 DEGS $F$

$11.20 \mathrm{ft} / \mathrm{sec}$

36.2

145.5

8.7

274.8

DEGS $F$

DEGS $F$

$12.98 \mathrm{ft} / \mathrm{sec}$

41.4

184.6 DEGS F

334.1 DEGS

14.63
220.7 DEGS
3.0

21.9

34.1

1.36

2.9

25.6

53.9

2.16

2.9

33.5

77.7

2.82

2.8

45.9

104.8

3.42

10.0

DEGS C)

DEGS C)

$\mathrm{m} / \mathrm{sec}$ )

40.0

DEGS C)

DEGS C)

$\mathrm{m} / \mathrm{sec}$ )

89.9

DEGS C)

DEGS C)

$\mathrm{m} / \mathrm{sec}$ )

9.5

37.9

FIRE

BTU/sec

0.1

159.8

DEGS C)

DEGS C)

$\mathrm{m} / \mathrm{sec}$ )

2.6

63.1

249.8

134.9

DEGS C)

DEGS C)

$3.96 \mathrm{~m} / \mathrm{sec}$ )

2.5

84.8

359.6

DEGS C)

DEGS C)

167.8

$\mathrm{m} / \mathrm{sec}$ )
236.9

151.6

341.1 
ROOMFIR VERSION 1.0

04-15-1987 IF SPRINKLER HAS BEEN IN SOUTH BALLROOM

HEAT LOSS FRACTION $=.75$

FIRE HEIGHT $=0 \mathrm{ft} \quad 0 \mathrm{~m}$

ROOM HEIGHT $=10 \mathrm{ft} 3.048 \mathrm{~m}$

ROOM AREA $=2304 \mathrm{sq}$ ft $214.0416 \mathrm{sq} \mathrm{m}$

RADIAL DISTANCE FROM FIRE TO DETECTOR $=7$ ft $(2.1336 \mathrm{~m})$

DETECTOR RTI $=200\left[(\mathrm{ft}-\mathrm{sec})^{\wedge} .5\right]\left(110.4174 \quad\left[(\mathrm{~m}-\mathrm{sec})^{\wedge} .5\right]\right)$

THERE IS A WALL OPENING $10 \mathrm{ft}$. HIGH $16 \mathrm{ft}$. WIDE WITH A 0 ft. HIGH SILI

ALPHA VALUE FOR T-SQUARED FIRE $=.0444$

$\begin{array}{cc}\text { TIME } & \text { TEMP } \\ \text { SeC } & \text { F } \\ 0.0 & 70.2\end{array}$

LINK TEMPERATURE

Ceiling Jet Temperature $=$

ceiling Jet velocity =

$\begin{array}{ll}30.0 \quad 77.2 & 2 \\ \text { LINK TEMPERATURE } & = \\ \text { Ceiling Jet Temperature } & = \\ \text { Ceiling Jet Velocity } & =\end{array}$

$$
\begin{array}{lll}
60.0 & 89.3 \quad 31.8
\end{array}
$$

LINK TEMPERATURE =

Ceiling Jet Temperature $=$

Ceiling Jet Velocity =

$$
90.0 \quad 106.5 \quad 41.4
$$

LINK TEMPERATURE

Ceiling Jet Temperature $=$

Ceiling Jet Velocity=

$$
120.0 \quad 130.6
$$

LINK TEMPERATURE
Ceiling Jet Temperature $=$

Ceiling Jet Velocity =

$150.0 \quad 163.8$

LINK TEMPERATURE

ceiling Jet Velocity

TEMP
$\quad C$
21.2
$=$
$=$
$=$
$=$
$=$
$=$
$=$
$=$
$=$
LAYER
ft

10.0

70.6 DEGS F

$0.25 \mathrm{ft} / \mathrm{sec}$

$$
9.7
$$

72.1 DEGS

98.1 DEGS $F$

$1.95 \mathrm{ft} / \mathrm{sec}$

$\begin{array}{rl}82.6 & \text { DEGS F } \\ 142.7 & \text { DEGS F } \\ 3.13 & \mathrm{ft} / \mathrm{seC}\end{array}$

8.3

104.9 DEGS $F$

200.0 DEGS F

$4.14 \mathrm{ft} / \mathrm{sec}$

54.8

$=$

$=$

73.2

$=$

192.9 DEGS F

356.9 DEGS F

141.2 DEGS F

270.9 DEGS $F$
70.0 DEGS $\mathrm{F}$

$=5.90 \mathrm{ft} / \mathrm{sec}(1.80 \mathrm{~m} / \mathrm{sec})$

LAYER
m
3.0
21.1
21.4
0.08

FIRE
$\mathrm{kW}$

0.1

DEGS C)

DEGS C)

$\mathrm{m} / \mathrm{sec}$ )

2.9

22.3

36.7

0.60

40.0

DEGS C)

DEGS C)

$\mathrm{m} / \mathrm{sec}$ )

$2.7 \quad 159.8$

151.6

28.1

61.5

0.95

DEGS C)

DEGS C)

$\mathrm{m} / \mathrm{sec}$ )

2.5

40.5

359.6

341.1

93.4

1.26

DEGS C)

DEGS C)

$\mathrm{m} / \mathrm{sec}$ )
2.4
60.7
639.4
132.7
DEGS C)
1.54
DEGS C)
$\mathrm{m} / \mathrm{sec}$ )

606.4
2.3
DEGS C)
180.5 DEGS C)

$=5.90 \mathrm{ft} / \mathrm{sec}(1.80 \mathrm{~m} / \mathrm{sec})$

FIRE

$\mathrm{BTU} / \mathrm{sec}$

0.1

37.9 
ROOMFIR VERSION 1.0

04-15-1987 IF SPRINKLER HAS BEEN IN SOUTH BALLROOM

HEAT LOSS FRACTION $=.75$

FIRE HEIGHT $=0 \mathrm{ft} \quad 0 \mathrm{~m}$

ROOM HEIGHT $=10 \mathrm{ft} \quad 3.048 \mathrm{~m}$

ROOM AREA $=2304 \mathrm{sq}$ ft $214.0416 \mathrm{sq} \mathrm{m}$

RADIAL DISTANCE FROM FIRE TO DETECTOR $=15$ ft $(4.572 \mathrm{~m})$

DETECTOR RTI $=200[(\mathrm{ft}-\mathrm{sec}) \wedge .5](110.4174[(\mathrm{~m}-\mathrm{sec}) \wedge .5])$

THERE IS A WALL OPENING 10 ft. HIGH 16 ft. WIDE WITH A 0 ft. HIGH SILL

ALPHA VALUE FOR T-SQUARED FIRE $=.0444$

$\begin{array}{ccccccc}\text { TIME } & \text { TEMP } & \text { TEMP } & \text { LAYER } & \text { LAYYER } & \text { FIRE } & \text { FIRE } \\ \text { seC } & \text { F } & \text { C } & \text { ft } & \text { m } & \mathrm{kW} & \text { BTU/sec } \\ 0.0 & 70.2 & 21.2 & 10.0 & 3.0 & 0.1 & 0.1\end{array}$

LINK TEMPERATURE =

Ceiling Jet Temperature $=$

ceiling Jet Velocity=

$$
\begin{array}{lrl}
30.0 & 77.2 & 25.1
\end{array}
$$

LINK TEMPERATURE =

Ceiling Jet Temperature $=$

ceiling Jet Velocity=

70.0 DEGS $F(21.1$ DEGS $C)$

70.4 DEGS $F(21.4$ DEGS $C)$

$0.13 \mathrm{ft} / \mathrm{sec}(0.04 \mathrm{~m} / \mathrm{sec}$ )

$\begin{array}{lll}71.1 & 9.7 \\ 8 E G S ~ F & ( \\ 89.7 & \text { DEGS F } & \\ 1.03 & \text { ft } / \text { sec } & (\end{array}$

2.9

DEGS C)

32.1 DEGS C)

$0.32 \mathrm{~m} / \mathrm{sec}$ )

37.9

$60.0 \quad 89.3 \quad 31.8$

LINK TEMPERATURE
Ceiling Jet Temperature $=$
Ceiling Jet Velocity

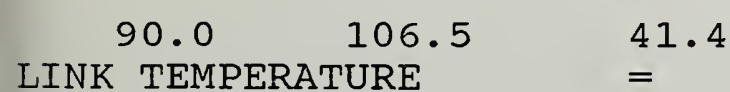

9.0

76.7 DEGS F

121.4 DEGS $F$

$1.66 \mathrm{ft} / \mathrm{sec}$

8.3

89.1 DEGS $F$

162.8 DEGS $F$

$2.19 \mathrm{ft} / \mathrm{sec}$

7.8

54.8

120.0

130.6

$=$

$=$

$=$

150.0

163.8

73.2

$=$

$=$

$=$

180.0

207.1

97.3

$=$

$=$

$=$
110.0

215.0

2.68
DEGS $F$

DEGS $F$

7.6

279.9 DEGS $F$

$3.13 \mathrm{ft} / \mathrm{sec}$

7.5

184.2 DEGS

358.8 DEGS

$3.56 \mathrm{ft} / \mathrm{sec}$ ft/sec

141.2 DEGS $F$
2.7

24.8

49.7

0.50

2.5

31.7

72.6

0.67

159.8

DEGS C)

DEGS C)

$\mathrm{m} / \mathrm{sec}$ )

359.6

DEGS C)

DEGS C)

$\mathrm{m} / \mathrm{sec}$ )

2.4

43.3

639.4

DEGS C)

101.7 DEGS C)

$0.82 \mathrm{~m} / \mathrm{sec}$ )

$2.3 \quad 999.0$

60.7 DEGS $C$ )

137.7 DEGS C)

$0.95 \mathrm{~m} / \mathrm{sec}$ )

$2.3 \quad 1438.6$

84.6 DEGS C)

181.5 DEGS C)

$1.09 \mathrm{~m} / \mathrm{sec}$ )
151.6

341.1

606.4

947.6

1364.5 
ROOMFIR VERSION 1.0

04-15-1987 IF SPRINKLER HAS BEEN IN SOUTH BALLROOM

HEAT LOSS FRACTION $=.75$

FIRE HEIGHT $=0 \mathrm{ft} \quad 0 \mathrm{~m}$

ROOM HEIGHT $=10 \mathrm{ft} \quad 3.048 \mathrm{~m}$

ROOM AREA $=2304 \mathrm{sq}$ ft $214.0416 \mathrm{sq} \mathrm{m}$

RADIAL DISTANCE FROM FIRE TO DETECTOR $=1 \mathrm{ft}(.3048 \mathrm{~m})$

DETECTOR RTI $=400\left[(\mathrm{ft}-\mathrm{sec})^{\wedge} .5\right]\left(220.8348\left[(\mathrm{~m}-\mathrm{sec})^{\wedge} .5\right]\right)$

THERE IS A WALL OPENING $10 \mathrm{ft.} \mathrm{HIGH} 16 \mathrm{ft}$. WIDE WITH $A$ 0 ft. HIGH SILL

ALPHA VALUE FOR T-SQUARED FIRE $=.0444$

$\begin{array}{cccccrc}\text { TIME } & \text { TEMP } & \text { TEMP } & \text { LAYER } & \text { LAYER } & \text { FIRE } & \text { FIRE } \\ \text { SEC } & \text { F } & \text { C } & \text { ft } & \mathrm{m} & \mathrm{kW} & \text { BTU/SeC } \\ 0.0 & 70.2 & 21.2 & 10.0 & 3.0 & 0.1 & 0.1\end{array}$

LINK TEMPERATURE $=70.0$ DEGS F ( 21.1 DEGS C $)$

Ceiling Jet Temperature $=71.1$ DEGS F ( 21.7 DEGS C)

Ceiling Jet Velocity $=0.92 \mathrm{ft} / \mathrm{sec}(0.28 \mathrm{~m} / \mathrm{sec})$

$$
15.0 \quad 72.8 \quad 22.7
$$

LINK TEMPERATURE =

Ceiling Jet Temperature $=$

ceiling Jet Velocity=

$$
30.0 \quad 77.2 \quad 25.1
$$

LINK TEMPERATURE =

Ceiling Jet Temperature =

ceiling Jet Velocity=

$$
\begin{array}{lll}
45.0 & 82.7 & 28.2
\end{array}
$$

LINK TEMPERATURE =

Ceiling Jet Temperature =

ceiling Jet Velocity=

$$
60.0
$$

89.3

LINK TEMPERATURE

Ceiling Jet Temperature =

ceiling Jet Velocity =

$$
75.0
$$

97.2

LINK TEMPERATURE

Ceiling Jet Temperature

ceiling Jet velocity =

$$
90.0
$$

106.6

LINK TEMPERATURE

Ceiling Jet Temperature =

ceiling Jet velocity =

$$
105.0
$$

$$
117 \cdot 7
$$

LINK TEMPERATURE

$$
\begin{aligned}
& 47.6 \\
& =
\end{aligned}
$$

Ceiling Jet Temperature =

ceiling Jet Velocity
31.8

$=$

$=$

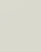

36.2

$=113.8$

274.8

9.9

70.7 DEGS $F$

93.3 DEGS $F$ (

$4.46 \mathrm{ft} / \mathrm{sec}($

9.7

74.2 DEGS F

129.0 DEGS $F$

$7.07 \mathrm{ft} / \mathrm{sec}$

$\begin{array}{rl}82.0 & \text { DEGS F } \\ 171.9 & \text { DEGS F } \\ 9.26 & \mathrm{ft} / \mathrm{sec}\end{array}$

9.0

95.0 DEGS $F$

220.7 DEGS $F$

$11.20 \mathrm{ft} / \mathrm{sec}$

8.7

DEGS $F$

12.98

DEGS $F$

$\mathrm{ft} / \mathrm{sec}$

8.4

138.7 DEGS

334.1 DEGS $F$

$14.63 \mathrm{ft} / \mathrm{sec}$

8.1

170.0 DEGS

398.4 DEGS F

16.16
3.0

21.5

34.1

1.36

2.9

23.5

53.9

2.16

2.9

27.8

77.7

2.82

2.8

35.0

104.8

3.42

10.0

DEGS C)

DEGS C)

$\mathrm{m} / \mathrm{sec}$ )

40.0

DEGS C)

DEGS C)

$\mathrm{m} / \mathrm{sec}$ )

9.5

37.9

89.9

DEGS C)

DEGS C)

$\mathrm{m} / \mathrm{sec}$ )

2.6

45.5

159.8

DEGS C)

DEGS C)

$\mathrm{m} / \mathrm{sec}$ )

134.9

3.96

249.8

DEGS C)

DEGS C)

$\mathrm{m} / \mathrm{sec}$ )

2.5

359.6

59.3 DEGS C)

167.8

4.46

DEGS C)

$\mathrm{m} / \mathrm{sec}$ )

2.5

489.5

76.7 DEGS C)

203.6 DEGS C)

$4.93 \mathrm{~m} / \mathrm{sec}$ )
85.3

151.6

236.9

341.1

464.3 
ROOMFIR VERSION 1.0

04-15-1987 IF SPRINKLER HAS BEEN IN SOUTH BALLROOM

HEAT LOSS FRACTION $=.75$

FIRE HEIGHT $=0 \mathrm{ft} \quad 0 \mathrm{~m}$

ROOM HEIGHT $=10 \mathrm{ft} \quad 3.048 \mathrm{~m}$

ROOM AREA $=2304 \mathrm{sq}$ ft $214.0416 \mathrm{sq} \mathrm{m}$

RADIAL DISTANCE FROM FIRE TO DETECTOR $=7$ ft $(2.1336 \mathrm{~m})$

DETECTOR RTI $=400\left[(\mathrm{ft}-\mathrm{sec})^{\wedge} .5\right]\left(220.8348\left[(\mathrm{~m}-\mathrm{sec})^{\wedge} .5\right]\right)$

THERE IS A WALL OPENING $10 \mathrm{ft.} \mathrm{HIGH} 16$ ft. WIDE WITH A 0 ft. HIGH SILL ALPHA VALUE FOR T-SQUARED FIRE $=.0444$

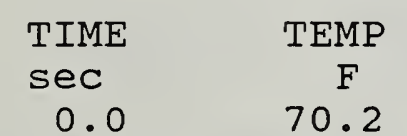

LINK TEMPERATURE

Ceiling Jet Temperature = ceiling Jet Velocity=

$$
30.0
$$

77.2

LINK TEMPERATURE

Ceiling Jet Temperature = ceiling Jet Velocity =

$$
60.0
$$

89.3

LINK TEMPERATURE

Ceiling Jet Temperature = Ceiling Jet Velocity=

$$
90.0 \quad 106.5
$$

LINK TEMPERATURE

Ceiling Jet Temperature = ceiling Jet Velocity=

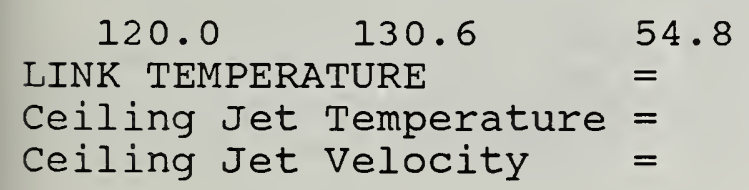

$$
150.0
$$$$
163.8
$$

LINK TEMPERATURE

Ceiling Jet Temperature = Ceiling Jet Velocity=

$$
180.0
$$$$
207.1
$$

LINK TEMPERATURE

Ceiling Jet Temperature = ceiling Jet Velocity

25.1

$=$

$=$

31.8

$=$

$=$

41.4

$=$

$=$

73.2

$=$

97.3

TEMP
$\quad C$
21.2
$=$
$=$
$=$

$4.14 \mathrm{ft} / \mathrm{sec}$ (

$\begin{array}{rl}111.1 & 7.8 \\ 270.9 & \text { DEGS F } \\ 5.05 & \mathrm{ft} / \mathrm{sec}\end{array}$

$\begin{array}{rl}143.9 & 7.6 \\ 3 E G S ~ F & ( \\ 356.9 & \text { DEGS F } \\ 5.90 & \mathrm{ft} / \mathrm{sec}\end{array}$

2.3

$$
\begin{array}{rl}
62.2 & \text { DEGS C) } \\
180.5 & \text { DEGS C) } \\
1.80 & \mathrm{~m} / \mathrm{sec} \text { ) }
\end{array}
$$

$$
\begin{array}{ll}
2.7 & 159.8 \\
24.8 & \text { DEGS C) } \\
61.5 & \text { DEGS C) } \\
0.95 & \mathrm{~m} / \mathrm{sec} \text { ) }
\end{array}
$$
$2.5 \quad 359.6$
31.9 DEGS C)
93.4 DEGS C)
$1.26 \mathrm{~m} / \mathrm{sec}$ )
$2.4 \quad 639.4$
44.0 DEGS C)
132.7 DEGS C)
$1.54 \mathrm{~m} / \mathrm{sec}$ )

$=189.4$ DEGS F

459.3 DEGS $F$ (

$6.72 \mathrm{ft} / \mathrm{sec}$
$2.3 \quad 1438.6$
87.4 DEGS C)
237.4 DEGS C)
$2.05 \mathrm{~m} / \mathrm{sec}$ )

FIRE

$\mathrm{BTU} / \mathrm{sec}$

0.1

37.9

151.6

341.1

606.4

947.6

1364.5 
ROOMFIR VERSION 1.0

04-15-1987 IF SPRINKLER HAS BEEN IN SOUTH BALLROOM

HEAT LOSS FRACTION $=.75$

FIRE HEIGHT $=0 \mathrm{ft} \quad 0 \mathrm{~m}$

ROOM HEIGHT $=10 \mathrm{ft} 3.048 \mathrm{~m}$

ROOM AREA $=2304 \mathrm{sq} f t \quad 214.0416 \mathrm{sq} \mathrm{m}$

RADIAL DISTANCE FROM FIRE TO DETECTOR $=15 \mathrm{ft}(4.572 \mathrm{~m})$

DETECTOR RTI $=400\left[(\mathrm{ft}-\mathrm{sec})^{\wedge} .5\right]\left(220.8348\left[(\mathrm{~m}-\mathrm{sec})^{\wedge} .5\right]\right)$

THERE IS A WALL OPENING $10 \mathrm{ft.} \mathrm{HIGH} 16$ ft. WIDE WITH A 0 ft. HIGH SILL ALPHA VALUE FOR T-SQUARED FIRE $=.0444$

$\begin{array}{cc}\text { TIME } & \text { TEMP } \\ \text { seC } & \text { F } \\ 0.0 & 70.2\end{array}$

LINK TEMPERATURE

Ceiling Jet Temperature =

ceiling Jet Velocity =

$$
30.0
$$

77.2

LINK TEMPERATURE

Ceiling Jet Temperature = ceiling Jet Velocity =

\section{0 \\ 89.3 \\ LINK TEMPERATURE \\ Ceiling Jet Temperature $=$ ceiling Jet Velocity=}

$$
90.0 \quad 106.5
$$

LINK TEMPERATURE

Ceiling Jet Temperature

Ceiling Jet Velocity =

$$
120.0
$$$$
130.6
$$

LINK TEMPERATURE

Ceiling Jet Temperature =

\begin{tabular}{|c|c|c|}
\hline 180.0 & 207.1 & \\
\hline LINK TEMF & ATURE & \\
\hline Ceiling J & Temperature & $=$ \\
\hline ceiling J & Velocity & \\
\hline
\end{tabular}
Ceiling Jet Velocity =

$150.0 \quad 163.8$
LINK TEMPERATURE
Ceiling Jet Temperature
Ceiling Jet Velocity

73.2

$=$

54.8

$=$

$\begin{array}{rl} & 7.8 \\ 92.3 & \text { DEGS F } \\ 215.0 & \text { DEGS F } \\ 2.68 & \mathrm{ft} / \mathrm{sec}\end{array}$

8.3

80.3 DEGS $F$

162.8 DEGS $F$

$2.19 \mathrm{ft} / \mathrm{sec}$

$\begin{aligned} & 7.6 \\ 110.9 & \text { DEGS F } \\ 279.9 & \text { DEGS F } \\ 3.13 \mathrm{ft} / \mathrm{sec} & (\end{aligned}$

7.5

137.7 DEGS

358.8 DEGS $F$

$3.56 \mathrm{ft} / \mathrm{sec}$

$210.0 \quad 259.7$

126.5

LINK TEMPERATURE

$=$

Ceiling Jet Temperature $=$

Ceiling Jet Velocity=

$\begin{array}{rl} & 7.5 \\ 173.9 & \text { DEGS F } \\ 450.8 & \text { DEGS F } \\ 3.98 & \mathrm{ft} / \mathrm{seC}\end{array}$

\section{LAYER \\ $\mathrm{m}$}

3.0

21.1

21.4

0.04

2.9

21.4

32.1

0.32

2. 7

23.1

49.7

0.50

2. 5

26.8

72.6

0.67

2. 4

33.5

101.7

0.82

2.3

43.8

137.7

0.95

2.3

58.7

181.5

1.09

$2 \cdot 3$

78.9

232.7

1.21
FIRE
$\mathrm{kW}$

0.1

DEGS C)

DEGS C)

$\mathrm{m} / \mathrm{sec}$ )

40.0

DEGS C)

DEGS C)

$\mathrm{m} / \mathrm{sec}$ )

159.8

DEGS C)

DEGS C)

$\mathrm{m} / \mathrm{sec}$ )

359.6

DEGS C)

DEGS C)

$\mathrm{m} / \mathrm{sec}$ )

639.4

DEGS C)

DEGS C)

$\mathrm{m} / \mathrm{sec}$ )

999.0

DEGS C)

DEGS C)

$\mathrm{m} / \mathrm{sec}$ )

341.1

1438.6

DEGS C)

DEGS C)

$\mathrm{m} / \mathrm{sec}$ )

1364.5

1958.0

DEGS C)

DEGS C)

$\mathrm{m} / \mathrm{sec}$ )

FIRE

0.1

37.9

151.6

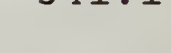

$\mathrm{BTU} / \mathrm{sec}$ 
ROOMFIR VERSION 1.0

04-15-1987 IF SPRINKLER HAS BEEN IN SOUTH BALLROOM

HEAT LOSS FRACTION $=.75$

FIRE HEIGHT $=0 \mathrm{ft} \quad 0 \mathrm{~m}$

ROOM HEIGHT $=10 \mathrm{ft} \quad 3.048 \mathrm{~m}$

ROOM AREA $=2304 \mathrm{sq}$ ft $214.0416 \mathrm{sq} \mathrm{m}$

RADIAL DISTANCE FROM FIRE TO DETECTOR $=1$ ft $(.3048 \mathrm{~m})$

DETECTOR RTI $=700\left[(\mathrm{ft}-\mathrm{sec})^{\wedge} .5\right]\left(386.4609\left[(\mathrm{~m}-\mathrm{sec})^{\wedge} .5\right]\right)$

THERE IS A WALL OPENING $10 \mathrm{ft}$. HIGH $16 \mathrm{ft}$. WIDE WITH A 0 ft. HIGH SILL

ALPHA VALUE FOR T-SQUARED FIRE $=.0444$

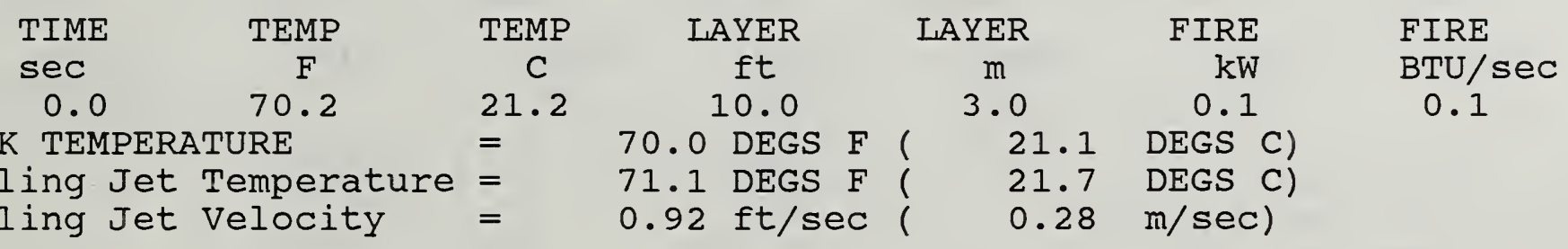

$30.0 \quad 77.2 \quad 25.1$

LINK TEMPERATURE =

Ceiling Jet Temperature $=$

ceiling Jet Velocity =

$\begin{array}{lrl}60.0 & 89.3 \quad 31.8\end{array}$

LINK TEMPERATURE =

Ceiling Jet Temperature =

Ceiling Jet Velocity=

$90.0 \quad 106.5 \quad 41.4$

LINK TEMPERATURE

Ceiling Jet Temperature

Ceiling Jet Velocity

$$
120.0 \quad 130.6
$$

LINK TEMPERATURE

Ceiling Jet Temperature =

ceiling Jet Velocity =

$$
150.0
$$

163.8

LINK TEMPERATURE

Ceiling Jet Temperature =

ceiling Jet Velocity=
$=$

$=$

$=14.64$

54.8

$=$

$\begin{array}{ll} & 7.8 \\ 158.6 & \text { DEGS F } \\ 467.9 & \text { DEGS F } \\ 17.61 & \mathrm{ft} / \mathrm{sec}\end{array}$

73.2

$=$

$=$

$=$
7.6

$\begin{array}{ll} & 7.6 \\ 224.5 & \text { DEGS F } \\ 621.1 & \text { DEGS F } \\ 20.18 \mathrm{ft} / \mathrm{sec}\end{array}$

2.9

22.5

53.9

2.16

2.7

29.5

104.8

3.42

2.5

44.9

167.9

4.46

2.4

70.3

242.2

5.37

2.3

107.0

327.3

6.15
40.0

DEGS C)

DEGS C)

$\mathrm{m} / \mathrm{sec}$ )

37.9

159.8

DEGS C)

DEGS C)

$\mathrm{m} / \mathrm{sec}$ )

359.6

DEGS C)

DEGS C)

$\mathrm{m} / \mathrm{sec}$ )

639.4

DEGS C)

DEGS C)

$\mathrm{m} / \mathrm{sec}$ )

999.0

DEGS C)

DEGS C)

$\mathrm{m} / \mathrm{sec}$ )
341.1

606.4

947.6 
ROOMFIR VERSION 1.0

04-15-1987 IF SPRINKLER HAS BEEN IN SOUTH BALLROOM

HEAT LOSS FRACTION $=.75$

FIRE HEIGHT $=0 \mathrm{ft} \quad 0 \mathrm{~m}$

ROOM HEIGHT $=10 \mathrm{ft} \quad 3.048 \mathrm{~m}$

ROOM AREA $=2304 \mathrm{sq}$ ft $214.0416 \mathrm{sq} \mathrm{m}$

RADIAL DISTANCE FROM FIRE TO DETECTOR $=7$ ft $(2.1336 \mathrm{~m})$

DETECTOR RTI $=700\left[(\mathrm{ft}-\mathrm{sec})^{\wedge} .5\right]\left(386.4609\left[(\mathrm{~m}-\mathrm{sec})^{\wedge} .5\right]\right)$

THERE IS A WALL OPENING $10 \mathrm{ft.} \mathrm{HIGH} 16$ ft. WIDE WITH A 0 ft. HIGH SILL

ALPHA VALUE FOR T-SQUARED FIRE $=.0444$

\begin{tabular}{|c|c|c|c|c|c|}
\hline TIME & TEMP & TEMP & LAYER & LAYER & FIRE \\
\hline sec & $F$ & C & ft & $\mathrm{m}$ & $\mathrm{kW}$ \\
\hline 0.0 & 70.2 & 21.2 & 10.0 & 3.0 & 0.1 \\
\hline TEMP & TURE & $=$ & 70.0 DEGS & 21.1 & DEGS C) \\
\hline 0 & Tempera & $=$ & 70.6 DEGS F & 21.4 & DEGS C) \\
\hline 20 & Velocity & $=$ & $0.25 \mathrm{ft} / \mathrm{sec}$ & 0.08 & $\mathrm{~m} / \mathrm{sec}$ ) \\
\hline
\end{tabular}

$30.0 \quad 77.2 \quad 25.1$

LINK TEMPERATURE =

Ceiling Jet Temperature =

ceiling Jet Velocity =

$60.0 \quad 89.3 \quad 31.8$

LINK TEMPERATURE

Ceiling Jet Temperature $=$

Ceiling Jet Velocity =

$90.0 \quad 106.5 \quad 41.4$

LINK TEMPERATURE

Ceiling Jet Temperature =

ceiling Jet Velocity=

$120.0 \quad 130.6 \quad 54.8$

LINK TEMPERATURE =

Ceiling Jet Temperature =

ceiling Jet Velocity=

$150.0 \quad 163.8$

LINK TEMPERATURE

9.7

70.6 DEGS $F$

98.1 DEGS $F$

$1.95 \mathrm{ft} / \mathrm{sec}$

$\begin{array}{rl}73.9 & 9.0 \\ 142.7 & \text { DEGS F F } \\ 3.13 & \mathrm{ft} / \mathrm{sec}\end{array}$

8.3

81.6 DEGS F

200.0 DEGS $F$

$4.14 \mathrm{ft} / \mathrm{sec}$

95.1

7.8

270.9

DEGS $F$

$5.05 \mathrm{ft} / \mathrm{sec}$

Ceiling Jet Temperature =

ceiling Jet Velocity =

$$
180.0 \quad 207.1
$$

IINK TEMPERATURE

Ceiling Jet Temperature =

ceiling Jet Velocity=

$$
210.0
$$

259.7

126.5

LINK TEMPERATURE

Ceiling Jet Temperature =

ceiling Jet velocity=
73.2

$=$

97.3

$=$

$\begin{array}{rl} & 7.6 \\ 116.0 & \text { DEGS F } \\ 356.9 & \text { DEGS F } \\ 5.90 & \mathrm{ft} / \mathrm{sec}\end{array}$

7.5

145.8 DEGS

459.3 DEGS

$6.72 \mathrm{ft} / \mathrm{sec}$

7.5

186.1 DEGS $F$

577.5 DEGS $F$

$7.52 \mathrm{ft} / \mathrm{sec}$
$2 \cdot 9$

21.5

36.7

0.60

40.0

DEGS C)

DEGS C)

$\mathrm{m} / \mathrm{sec}$ )

2.7

23.3

61.5

0.95

159.8

DEGS C)

DEGS C)

$\mathrm{m} / \mathrm{sec}$ )

2.5

27.5

93.4

1.26

359.6

DEGS C)

DEGS C)

$\mathrm{m} / \mathrm{sec}$ )

2.4

35.1

132.7

1.54

639.4

DEGS C)

DEGS C)

$\mathrm{m} / \mathrm{sec}$ )

2.3

46.7

180.5

1.80

999.0

DEGS C)

DEGS C)

$\mathrm{m} / \mathrm{sec}$ )

2.3

63.2

1438.6

DEGS C)

237.4

2.05

DEGS C)

$\mathrm{m} / \mathrm{sec}$ )

2.3

85.6

1958.0

DEGS C)

303.1

2.29

DEGS C)

$\mathrm{m} / \mathrm{sec}$ )
FIRE

$\mathrm{BTU} / \mathrm{sec}$

0.1

37.9

151.6

341.1

606.4

947.6

1364.5

1857.2 
ROOMFIR VERSION 1.0

04-15-1987 IF SPRINKLER HAS BEEN IN SOUTH BALLROOM

HEAT LOSS FRACTION $=.75$

FIRE HEIGHT $=0 \mathrm{ft} \quad 0 \mathrm{~m}$

ROOM HEIGHT $=10 \mathrm{ft} \quad 3.048 \mathrm{~m}$

ROOM AREA $=2304 \mathrm{sq} f t \quad 214.0416 \mathrm{sq} \mathrm{m}$

RADIAL DISTANCE FROM FIRE TO DETECTOR $=15 \mathrm{ft}(4.572 \mathrm{~m})$

DETECTOR RTI $=700\left[(\mathrm{ft}-\mathrm{sec})^{\wedge} .5\right]\left(386.4609\left[(\mathrm{~m}-\mathrm{sec})^{\wedge} .5\right]\right)$

THERE IS A WALL OPENING $10 \mathrm{ft.} \mathrm{HIGH} 16 \mathrm{ft}$. WIDE WITH A 0 ft. HIGH SILL

ALPHA VALUE FOR T-SQUARED FIRE $=.0444$

$\begin{array}{cc}\text { TIME } & \text { TEMP } \\ \text { SeC } & \text { F } \\ 0.0 & 70.2\end{array}$

LINK TEMPERATURE

Ceiling Jet Temperature =

Ceiling Jet Velocity=

$$
30.0
$$

77.2

LINK TEMPERATURE

Ceiling Jet Temperature $=$

Ceiling Jet Velocity=

$\begin{array}{lll}60.0 & 89.3 & 31.8\end{array}$

LINK TEMPERATURE =

Ceiling Jet Temperature =

ceiling Jet Velocity=

$$
90.0 \quad 106.5
$$

LINK TEMPERATURE

Ceiling Jet Temperature $=$

Ceiling Jet Velocity=

$$
120.0 \quad 130.6 \quad 54.8
$$

LINK TEMPERATURE =

Ceiling Jet Temperature $=$

ceiling Jet Velocity=

$$
150.0 \quad 163.8
$$

LINK TEMPERATURE

Ceiling Jet Temperature =

ceiling Jet Velocity=

$$
180.0 \quad 207.1
$$

LINK TEMPERATURE

Ceiling Jet Temperature =

ceiling Jet Velocity=

210.0

259.7

126.5

LINK TEMPERATURE

$=$

Ceiling Jet Temperature =

ceiling Jet Velocity

240.0

319.0

159.5

LINK TEMPERATURE

Ceiling Jet Temperature $=$

Ceiling Jet Velocity

TEMP
21.2
$=$
$=$

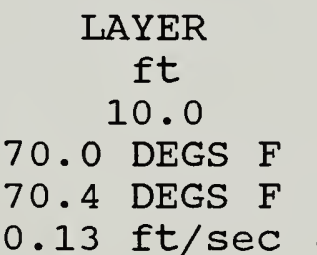

LAYER

$\mathrm{m}$

3. 0

21.1

21.4

0.04

2. 9

$21 \cdot 3$

32.1

0.32

89.7 DEGS F

$1.03 \mathrm{ft} / \mathrm{sec}$

9. 0

72.0 DEGS F

121.4

DEGS $F$

$1.66 \mathrm{ft} / \mathrm{sec}$

8.3

76.1 DEGS $F$

162.8 DEGS F

$2.19 \mathrm{ft} / \mathrm{sec}$

7.8

83.4 DEGS $F$

215.0 DEGS $F$

$2.68 \mathrm{ft} / \mathrm{sec}$

7.6

94.9 DEGS F

279.9

DEGS $F$

3.13

ft/sec

7.5

111.8 DEGS F

358.8 DEGS $F$

3.56

$\mathrm{ft} / \mathrm{sec}$

7.5

135.2 DEGS F

450.8 DEGS $F$

$3.98 \mathrm{ft} / \mathrm{sec}$

7.5

166.1

DEGS $F$

554.1

DEGS $F$

$4.40 \mathrm{ft} / \mathrm{sec}$
2. 7

22.2

49.7

0.50

2.5

24.5

72.6

0.67

2.4

28.5

101.7

0.82

2.3

35.0

137.7

0.95
$2.3 \quad 1438.6$
44.3 DEGS C)
181.5 DEGS C)
$1.09 \mathrm{~m} / \mathrm{sec}$ )

$$
\begin{array}{rl}
2.3 & 1958.0 \\
57.3 & \text { DEGS C) } \\
232.7 & \text { DEGS C) } \\
1.21 & \mathrm{~m} / \mathrm{sec})
\end{array}
$$

$2.3 \quad 2557.4$

74.5 DEGS C)

290.0 DEGS C)

$1.34 \mathrm{~m} / \mathrm{sec}$ )
FIRE

BTU/sec

0.1

37.9

$151 \cdot 6$

341.1

606.4

947.6

1364.5

1857.2

2425.7

D-13 



\section{APPENDIX E}

\section{RESULTS OF COMPUTATIONS RELATED TO SMOKE DETECTORS}

This appendix lists the results of execution of DETACT-QS (See paragraph 2.13) to estimate the potential response of smoke detectors. 
SOUTH BALLROOM SMOKE DETECTOR EVALUATION

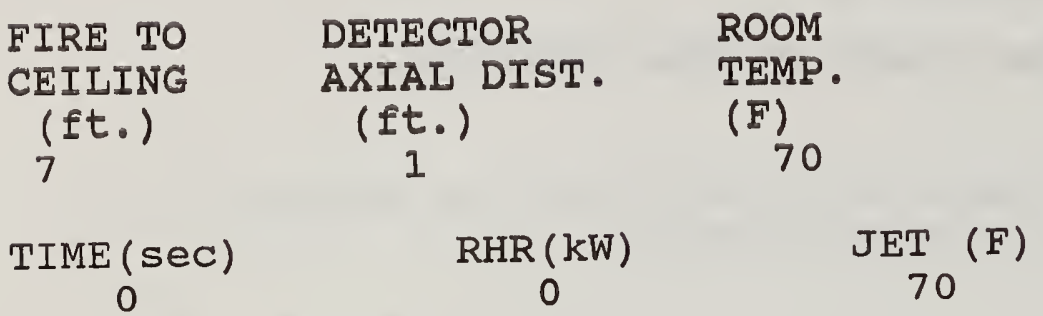

**** DETECTOR ACTIVATION AT

DEVICE RTI

RATING

(F)

93
(English)

.001

NEW RADIUS OF DETECTOR FROM FIRE AXIS

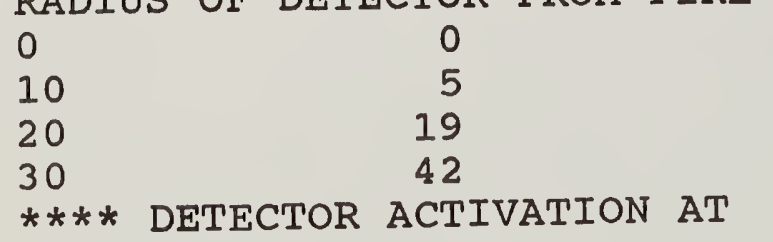

70

74

81

89

NEW RADIUS OF DETECTOR FROM FIRE AXIS

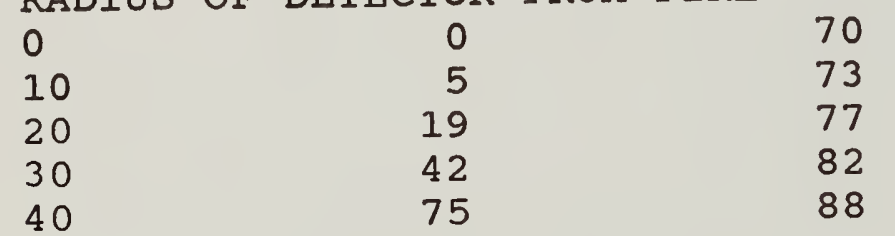

NEW RADIUS OF DETECTOR FROM FIRE AXIS (ft) IS 60

$\begin{array}{lll}0 & 0 & 70 \\ 10 & 5 & 72 \\ 20 & 19 & 74 \\ 30 & 42 & 77 \\ 40 & 75 & 81 \\ 50 & 117 & 85 \\ 60 & 168 & 89 \\ * * * * \text { DETECTOR ACTIVATION AT } & \end{array}$

(ft) IS 15
70
74
81
89
34.5 SECONDS $* * * *$

(ft) IS 30

HEAD/DET • ( F )

70

10.0 SECONDS $* * * *$

**** DETECTOR ACTIVATION AT

82

88

48.6 SECONDS $* * * *$

0

10

30

40

$* * * *$ DETECTOR ACTIVATION AT

72

$\begin{array}{ll}74 & 74 \\ 77 & 79\end{array}$

85

$89 \quad 89$

68.5 SECONDS $* * * *$ 


\section{APPENDIX F \\ RESULTS OF TESTS OF THE FABRIC WAIL COVERING}

Several tests were conducted to obtain information on the burning properties of the fabric wall covering used in both the North and South Ballrooms. The NBS experiential ignition and flame spread apparatus described by Quintiere and Harkleroad [24] and the Cone Calorimeter [3] were used.

In these test the carpet was cemented to the sooth surface of a 2 inch ( $50 \mathrm{~mm}$ ) thick, well cured concrete substrate. The adhesive used to cement the fabric to the concrete is believed to be similar to that used in the ballrooms. The adhesive used was 72 Pressure Sensitive Adhesive manufactured by $3 \mathrm{M}$

Corporation. A thin coat of adhesive was spray applied to cover the entire surface of the concrete face. No adhesive was applied to the fabric. As soon as the adhesive surface became tacky, the fabric was hand pressed in place.

The fabric was conditioned for several days prior to attachment at $70 \mathrm{~F}$ (21C) and 50 \& relative humidity. After cementing the fabric to the concrete the assembled test sample was returned to the conditioning room for about 30 hours before testing. The test facility is housed in an air conditioned laboratory.

The following properties were indicated by these tests:
a. Heat of Gasification - approximately $8 \mathrm{~kJ} / \mathrm{g}$
b. Ignition Temperature - 1160F (670C) to $1270 \mathrm{~F}(688 \mathrm{C})$
c. Thermal Inertia/ phi - 72 to 94
d. Critical Ignition Energy - between 4.6 and $5.4 \mathrm{~kW} / \mathrm{m}^{2}$.

Included in this appendix are:

a. Figure F-1. Wall lining (vertical) rate of heat release and heat of combustion at $50 \mathrm{~kW} / \mathrm{m} 2$ irradiance, Cone Calorimeter

b. Figure F-2. Wall lining (vertical) rate of heat release and heat of combustion at $60 \mathrm{~kW} / \mathrm{m} 2$ irradiance, Cone Calorimeter

c. Figure F-3. Ignition results for wall lining

d. Figure F-4. Correlation of ignition results for wall lining

e. Figure F-5. Correlation of spread velocity for wall lining 


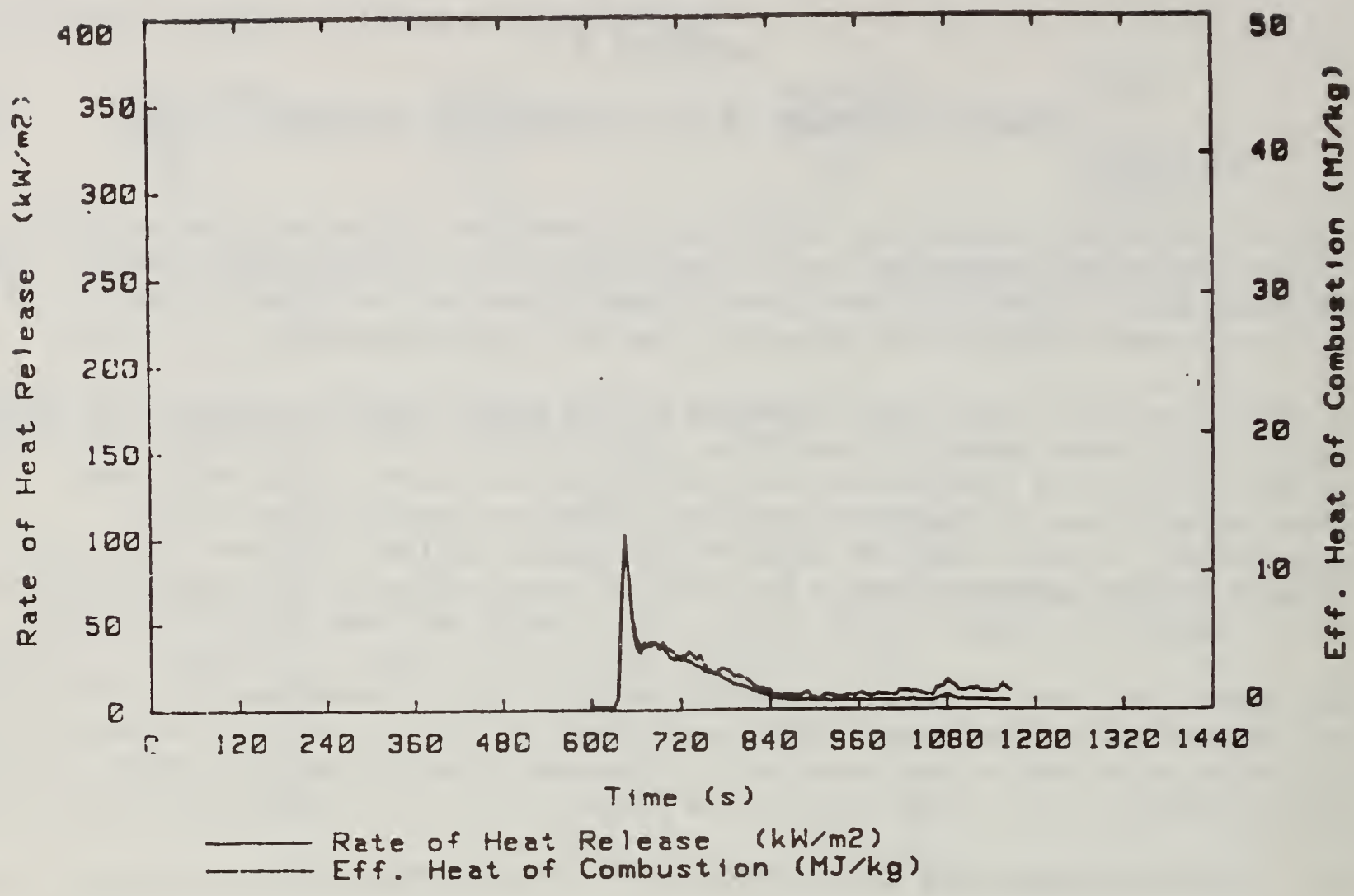

Figure F-1. Wall Lining (vertical) Rate of Heat Release and Heat of Combustion at $50 \mathrm{~kW} / \mathrm{m} 2$ Irradiance, Cone Calorimeter

WRLL COIVERING $60 \mathrm{KW/M2} \mathrm{VERT} \mathrm{TEST} 2464$

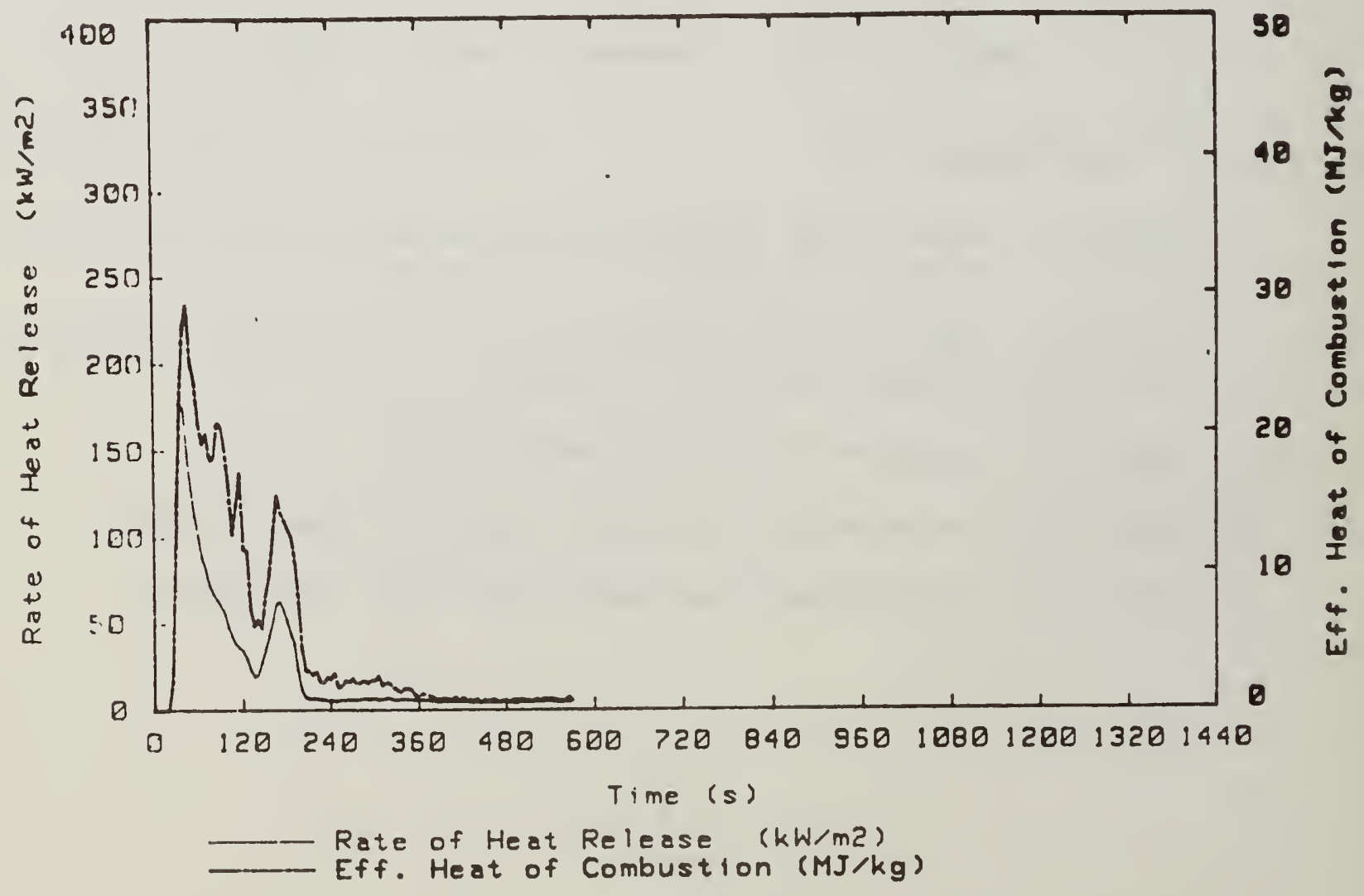

Figure F-2. Wa11-Lining (vertical) Rate of Heat Release and Heat of Combustion at $60 \mathrm{~kW} / \mathrm{m} 2$ Irradiance, Cone Calorimeter F-2 
DUPONT PLAZA WALL LINING

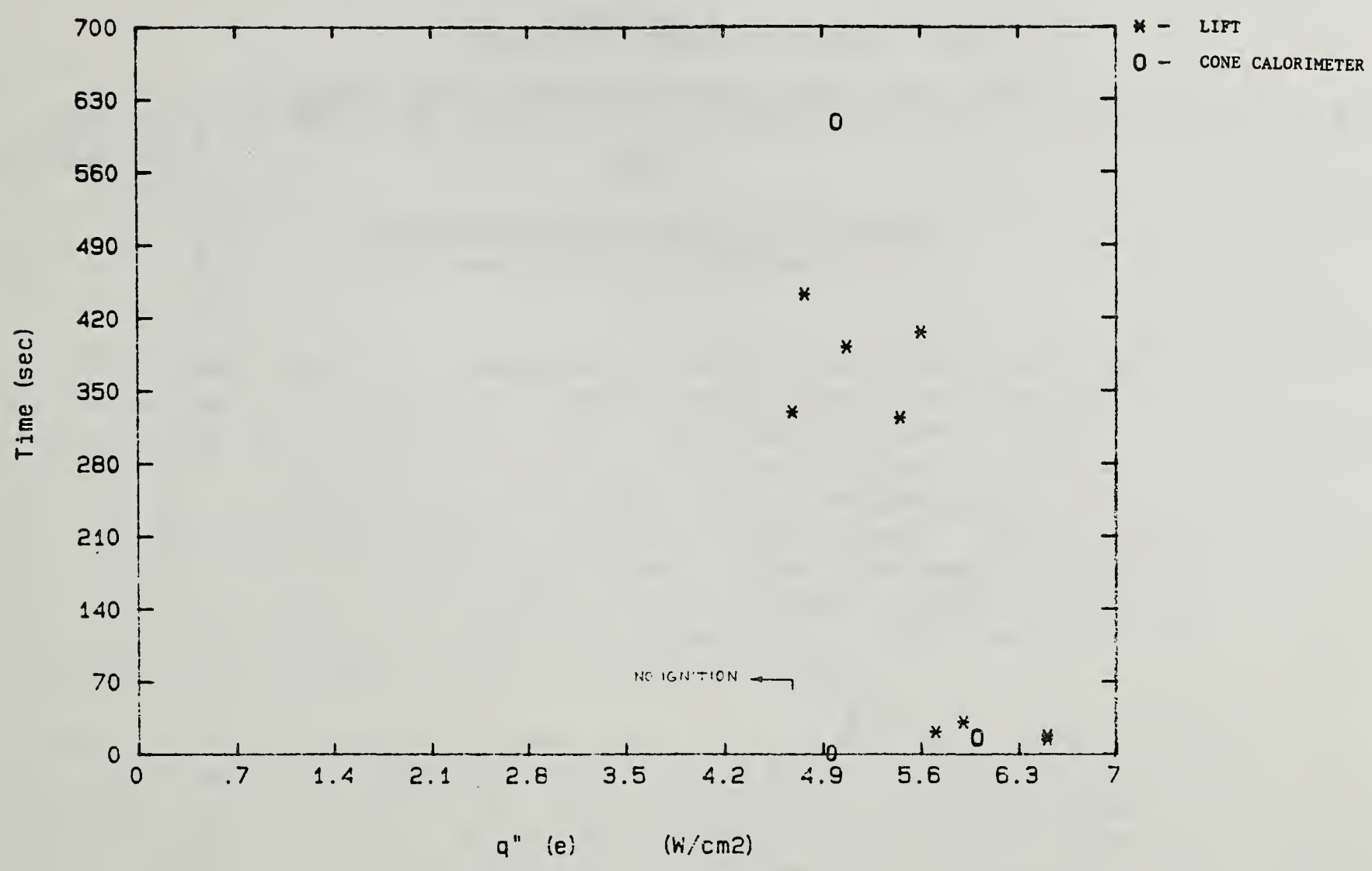

Figure F-3. Ignition Results for Wall Lining

DUPONT PLAZA WALL LINING

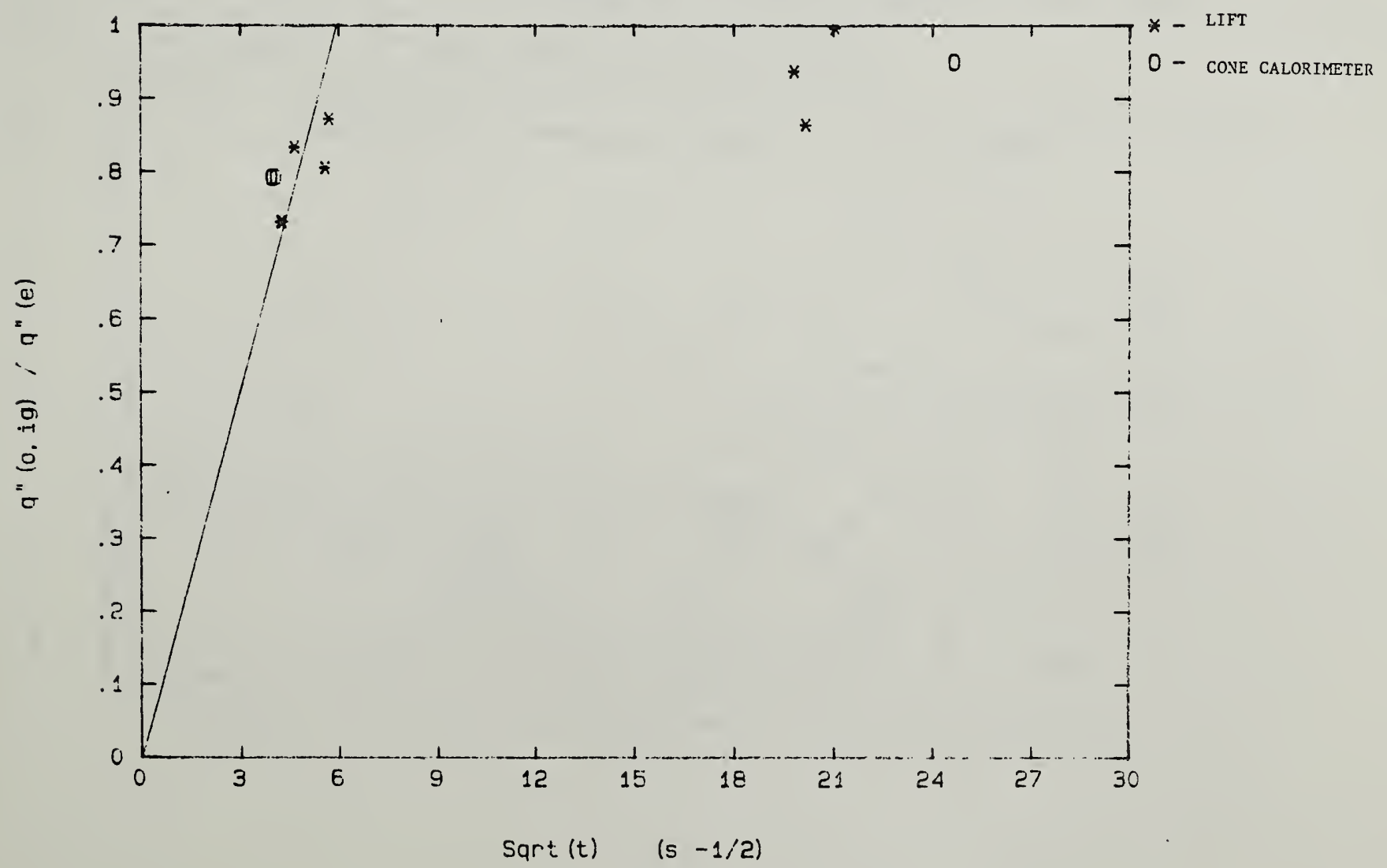

Figure F-4. Correlation of Ignition Results for Wall Lining F-3 
DUPONT PLAZA WALL LINING

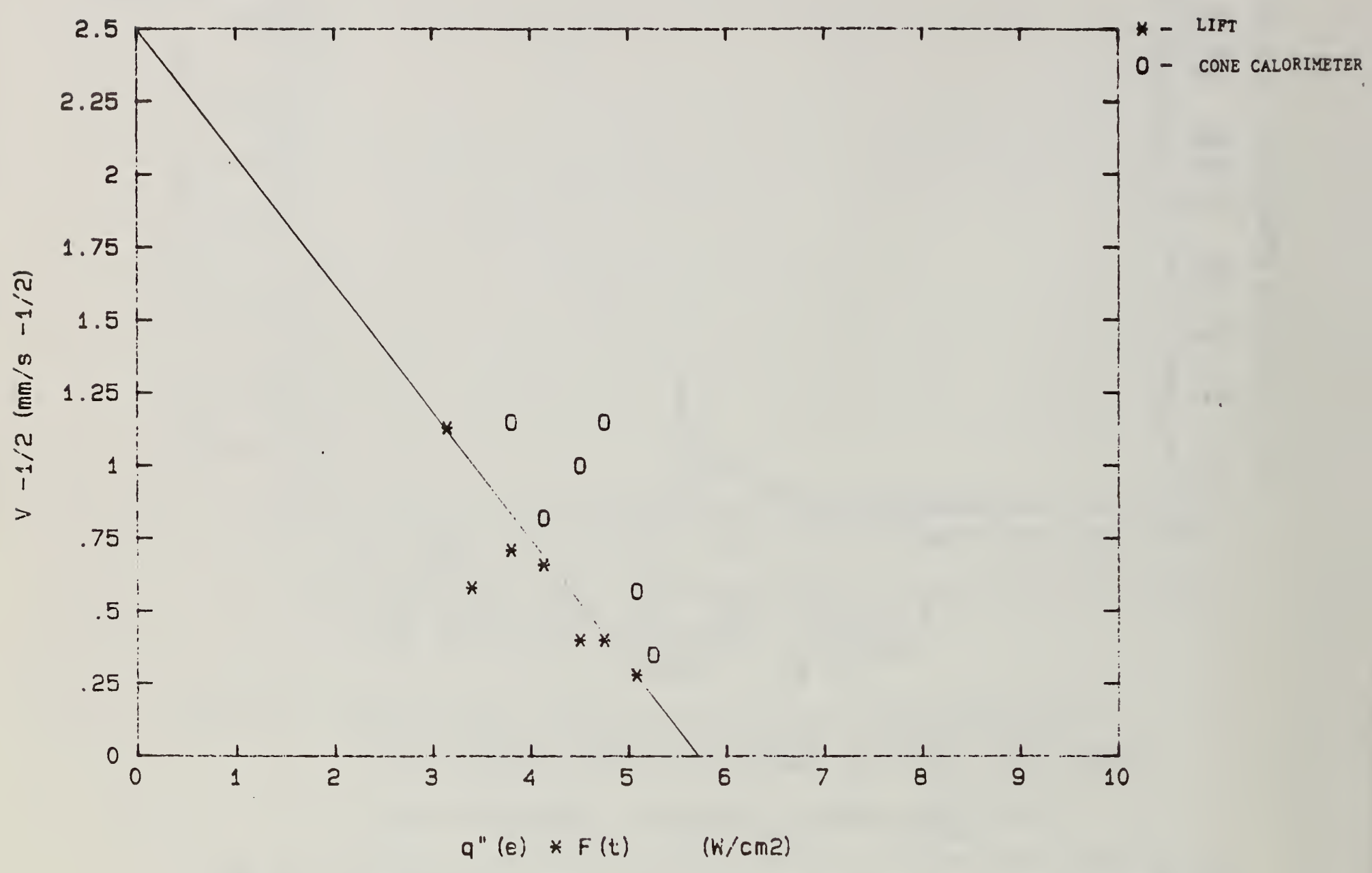

Figure F-5. Correlation of Spread Velocity for Wall Lining 


\section{APPENDIX G}

\section{A METHOD FOR CALCULATING VENTILATION FLOW RATE}

\section{FROM}

\section{SIIde-Rule Estimates of Fire Growth}

J.R. Lawson \& J.G. Quintiere [19]

Now that methods have been presented for estimating burning rates and $\Delta T$ in a fire compartment, it is time to consider ventilation flow rates in the fire. It was pointed out by Steckler, et al. [32] that the flow of air and gases in room fires has a significant influence on the development of a fire. As a fire develops, the air and gas flow rates control compartment temperature and heat transfer which then affects the rate of fire growth. When a compartment fire reaches a fully involved state, the air flow rate usually controls the fire, and the fire is then considered to be ventilation controlled. The mass flow rate of air and gases will be estimated first in this section, and ventilation limit conditions will be examined later.

In order to further understand the terminology of vent flow refer to Figure G-1. Under natural convection conditions and after the hot gases fill the compartment and spill out of the vent, the flow will be countercurrent at the vent. Air will enter at a rate $\dot{\mathrm{m}}_{\mathrm{i}}$ and combustion products will flow out at a rate $\dot{\mathrm{m}}_{\circ}$. These flows result from pressure differences $(\Delta \mathrm{p})$ set up at the vent due to the differences in compartment and ambient gas temperatures. At the flow reversal point in the vent, the $\Delta p$ is zero and this position is termed the neutral plane. The flow rates depend on the fuel mass release rate $\dot{m}_{f}$, the height of the neutral plane $x_{2}$, the height of the hot gas layer $x_{1}$, its temperature $T$, and the vent dimensions $H_{0}$ and $W_{0}$. In general, the vent equations are coupled nonlinear algebraic equations which we will avoid solving, but suggest the approximate procedure below.

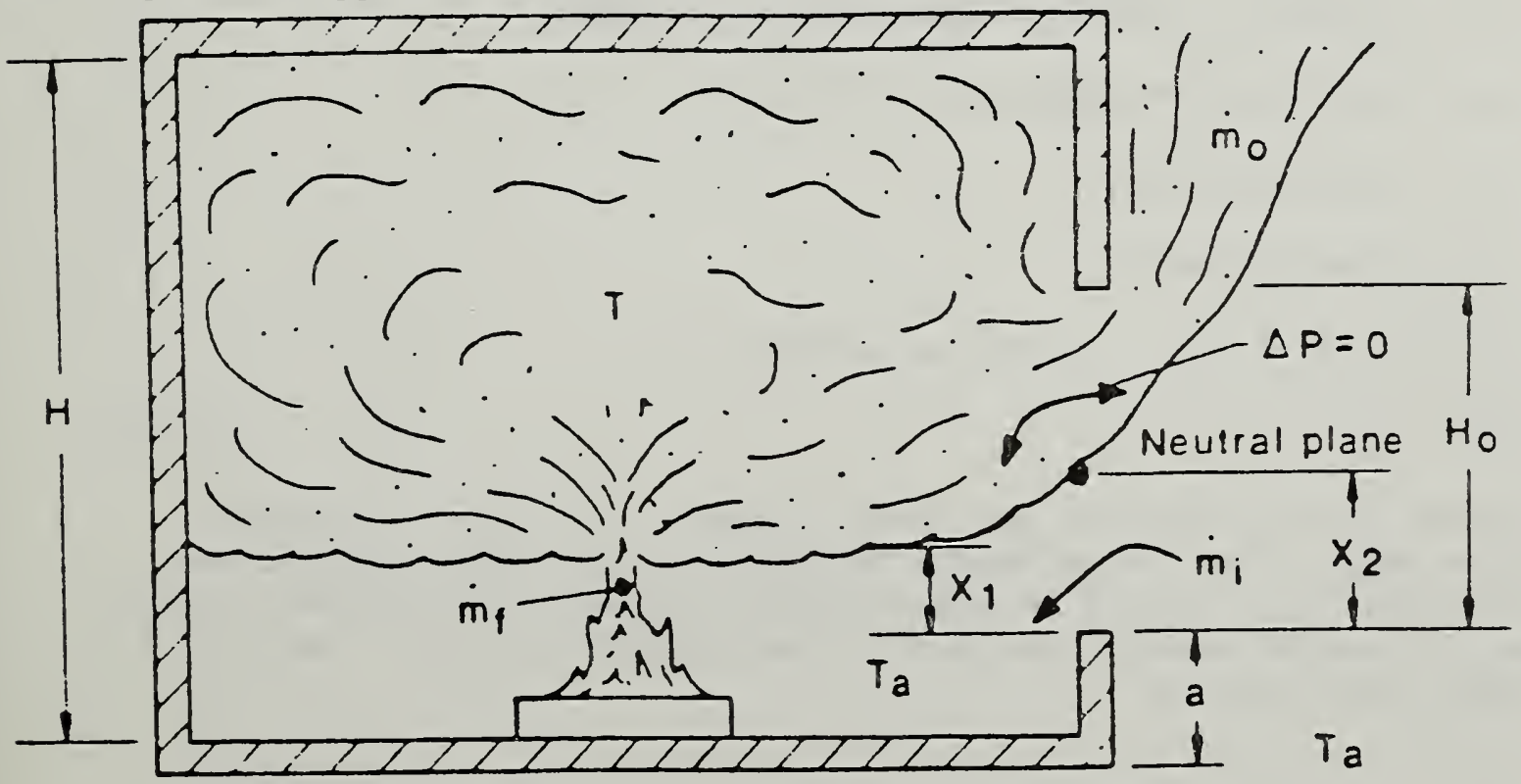

Figure G-1. Sketch of Compartment Ventilation Problem 
To make this ventilation flow rate estimate, it is necessary to assume a free burning condition. The first step in making this estimate is to calculate a fuel mass burning rate, $\dot{m}_{f}$, with one of the methods found in section 2 , and then calculate the compartment gas temperature by the formula presented in section 8. At this point, the dimensionless mass flow rate $M_{0}$ can be calculated [33] using,

$$
M_{0}=\left[\psi^{1 / 2} /(1+\psi)\right]\left(1-y_{2}\right)^{3 / 2}
$$

where $\quad \psi=\frac{\mathrm{T}-\mathrm{T}_{\mathrm{a}}}{\mathrm{T}_{\mathrm{a}}}$

and $y_{2}=x_{2} / H_{0}$ can be estimated as 0.5 to 0.6 for $\psi \leq 1$ and for wellventilated fires where $\dot{\mathrm{m}}_{\mathrm{f}} / \dot{\mathrm{m}}_{\mathrm{i}}$ is small as found in reference [33]. For the case of larger $\psi$ and $\dot{m}_{f} / \dot{m}_{i}$ not small, the neutral plane can be estimated from the work of Kawagoe and Sekine [18] or from reference [33] in which $x_{1}=0$ :

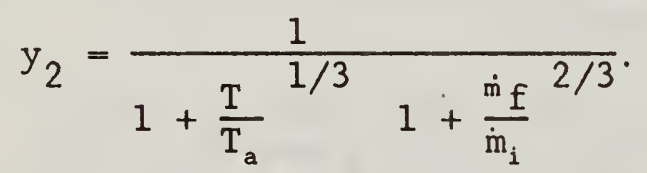

This will yield the lower limit for $y_{2}$ when the hot layer tends to the floor and the enclosure tends toward a uniform gas temperature. Then mass flow rate out, $\dot{\mathrm{m}}_{\mathrm{o}}$, can be calculated using,

$$
\dot{\mathrm{m}}_{\mathrm{o}}=\frac{2}{3} \mathrm{M}_{\mathrm{o}} \mathrm{C} \rho_{\mathrm{a}} \sqrt{2 \mathrm{~g}} \mathrm{~W}_{\mathrm{o}} \mathrm{H}_{\mathrm{o}}^{3 / 2}
$$

where

$$
\begin{aligned}
& \mathrm{C}=\text { opening flow coefficient which is } 0.7 \\
& \rho_{\mathrm{a}}=\text { density of ambient gas surrounding area } \\
& \mathrm{g}=\text { acceleration of gravity }\left(9.8 \mathrm{~m} / \mathrm{s}^{2}\right) \\
& \mathrm{W}_{0}=\text { opening width } \\
& \mathrm{H}_{0}=\text { opening height }
\end{aligned}
$$

The mass inflow rate of air, $\dot{\mathrm{m}}_{\circ}$, can be calculated by,

$$
\dot{\mathrm{m}}_{i}=\dot{\mathrm{m}}_{0}-\dot{\mathrm{m}}_{\mathrm{f}}
$$

for which steady flow conditions have been assumed. Of course, if $\dot{m}_{f} / \dot{m}_{i}$ is found to be large, then iteration is required in the above computations. Moreover the ratio $\dot{\mathrm{m}}_{\mathrm{f}} / \dot{\mathrm{m}}_{\mathrm{i}}$ should be compared with the mass stoichiometric fuel to air ratio to examine whether the fire is ventilation linited. We will return to this point shortly. 


\section{APPENDIX H}

\section{COMPARISON OF RESULTS OBTAINED WITH DIFFERENT PROCEDURES}

For reasons discussed in Chapter 2, a sophisticated mode1, FIRST; a simple model, ROOMFIR; and an engineering correlation UTEMP were all used to evaluate conditions in the preflashover stages in the South Ballroom. All three predict the average temperature in the smoke layer. FIRST and ROOMFIR also predict the elevation of the smoke layer and the oxygen concentration in that layer. Figures $\mathrm{H}-1$. $\mathrm{H}-2$, and $\mathrm{H}-3$ are graphic plots showing the comparisons. 


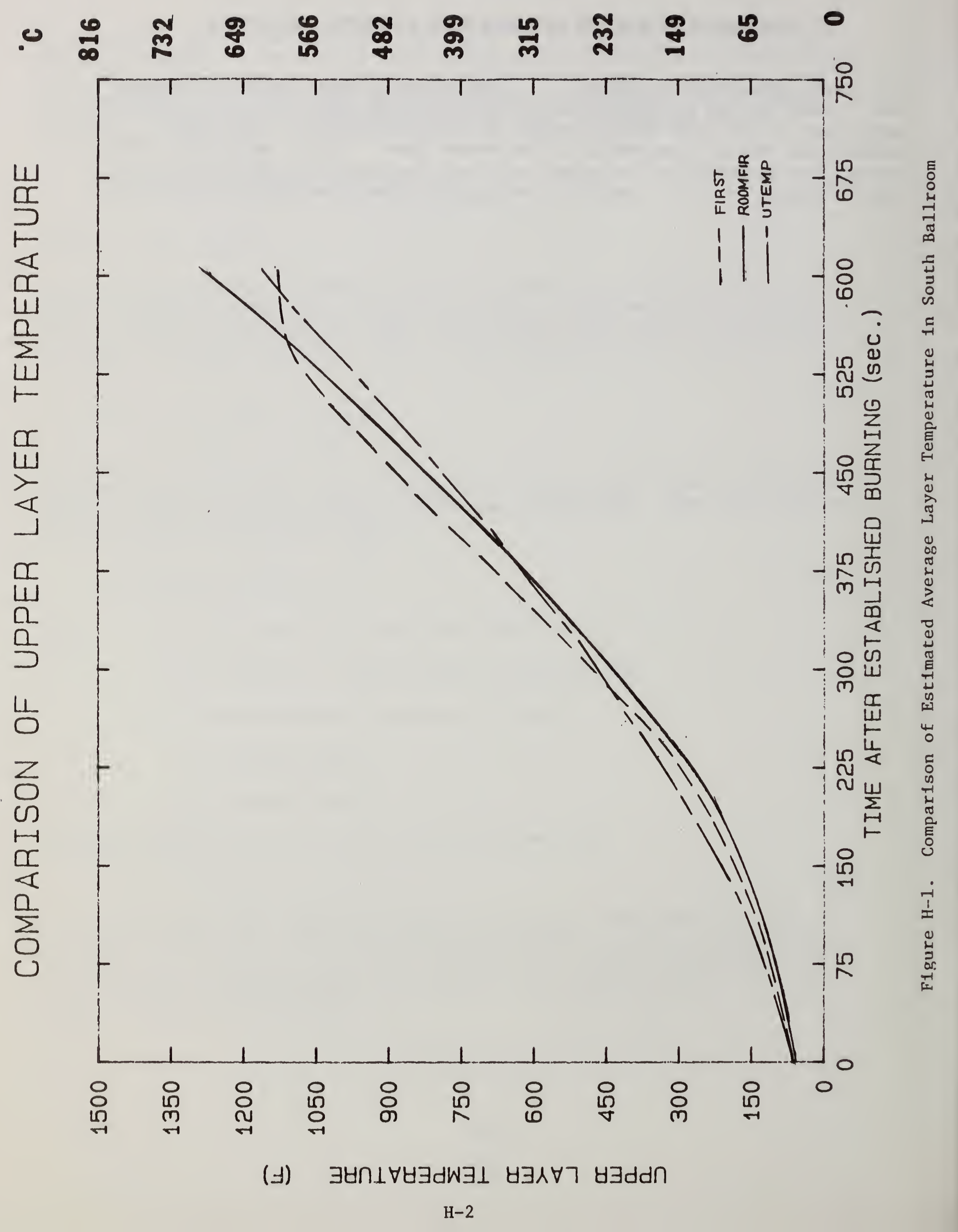




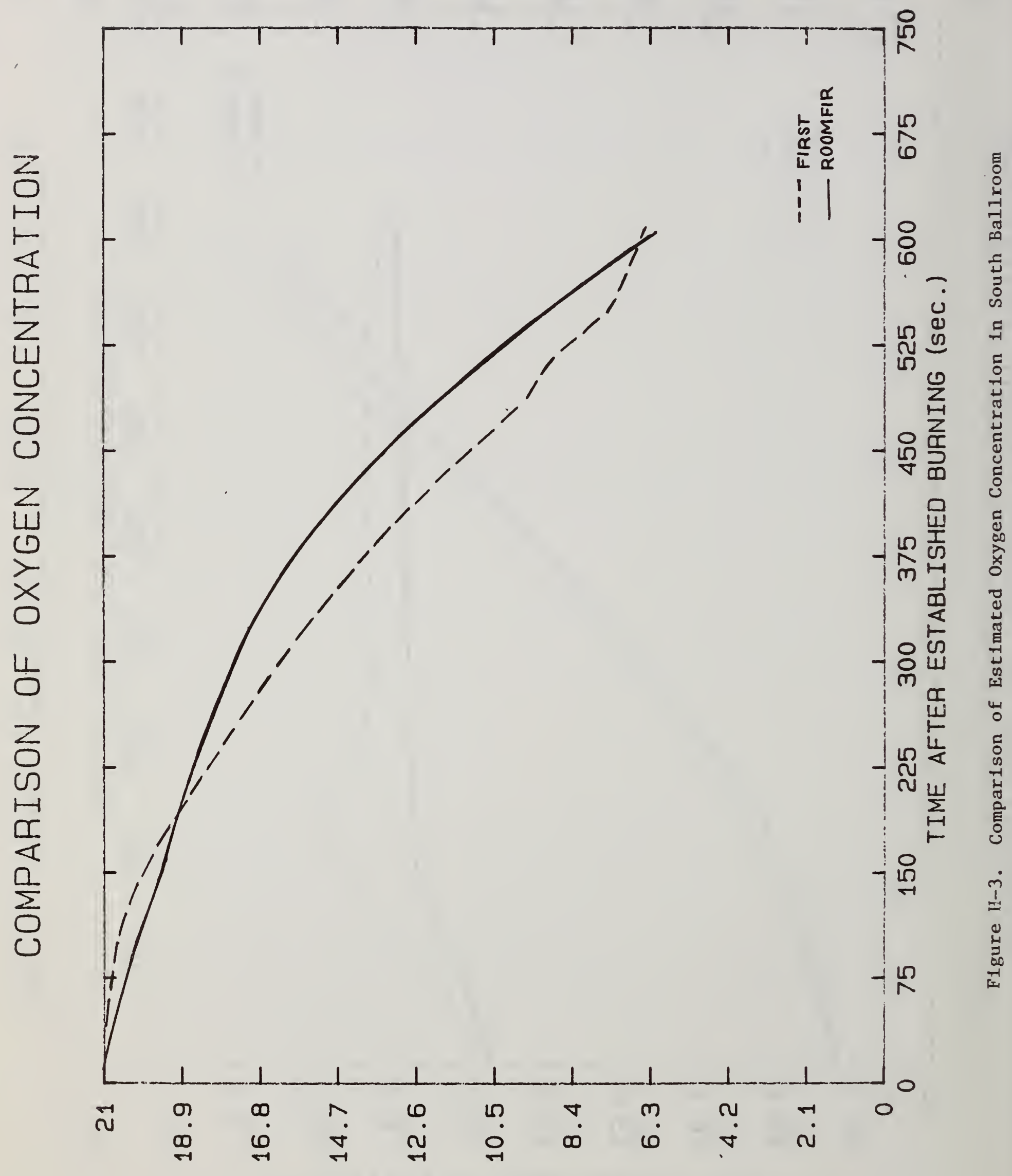

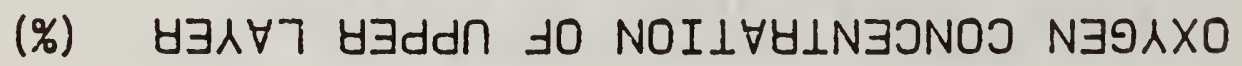


BIBLIOGRAPHIC DATA

SHEET (See instructions)

1. PUBLICATION OR REPORT NO.

NBSIR $87-3560$
2. Performing Organ. Report Nod 3. Publication Date

MAY 1987

4. TITLE AND SUBTITLE

An Engineering Analysis of the Early Stages of Fire Development

- The Fire at the Dupont Plaza Hotel and Casino

- December 31, 1986

5. AUTHOR(S)

Harold E. Nelson

6. PERFORMING ORGANIZATION (If joint or other than NBS, see instructions)

7. ContracU/Grant No.

NATIONAL BUREAU OF STANDARDS

U.S. DEPARTMENT OF COMMERCE

8. Type of Report \& Period Covered

GAITHERSBURG, MD 20899

9. SPONSORING ORGANIZATION NAME AND COMPLETE ADDRESS (Street, City. State, ZIP)

NBS

10. SUPPLEMENTARY NOTES

Document describes a computer program; SF-185, FIPS Software Summary, is attached.

11. ABSTRACT (A 200-word or less factual summary of most significant information. If document includes a significant
bibliography or literature survey. mention it here)

This report presents the methods and results of an analytical analysis of the fire development through the first and second floors during the December 31, 1986 fire in the Dupont Plaza Hotel and Casino, San Juan, Puerto Rico. The analysis involved the use of fire growth models, engineering formulae, and technical data. The repor details the procedures and data used, the reason for those selected, and the results obtained. The analysis addressed mass burning rate, rate of heat release, smoke temperature, smoke layer depth, velocity of smoke/flame front, mass products in smoke layer, oxygen concentration in smoke layer, visibility in smoke layer, flame length/extension, flame spread, sprinkler response, smoke detector response, and fire duration. The areas of the building analyzed include the ballroom complex to the areas where the fatalities occurred, and the lobby and casino areas where most of the deaths occurred. This report does not address smoke movement above the first floor, the conditions that caused the deaths of three persons caught in an elevator, or the conditions that caused the death of one victim in a guest room on the fourth floor.

12. KEY WORDS (Six to twelve entries; alphabetical order; capitalize only proper names; and separate key words by semicolons)

Fire engineering analysis; fire growth models; flashover; Fire investigation; Dupont Plaza Hotel

[X] Unlimited

14. NO. OF

$\square$ For Official Distribution. Do Not Release to NTIS Order From Superintendent of Documents, U.S. Government Printing Office, Washington, D.C.
20402 .

PRINTED PAGES

113

[X] Order From National Technical Information Service (NTIS), Springfield, VA. 2216I

15. Price 


